\title{
LA PRODUCCIÓN DE BIOETANOL
}

Ing. Julia KRUYENISKI

Tesis presentada a la Facultad de Ciencias Exactas, Químicas y Naturales de la Universidad Nacional de Misiones para optar al grado académico de DOCTOR EN CIENCIAS APLICADAS

Posadas, República Argentina 
Directora

Dra. María Cristina AREA

TRIBUNAL EXAMINADOR (Resolución Consejo Directivo No 588/17)

$\begin{array}{ll}\text { Dra. Silvia Daniela ROMANO } & \text { Universidad de Buenos Aires } \\ \text { Dr. Oscar Alfredo ALBANI } & \text { Universidad Nacional de Misiones } \\ \text { Dra. Claudia Marcela MÉNDEZ } & \text { Universidad Nacional de Misiones }\end{array}$

DEFENSA ORAL Y PÚBLICA (Disposición Nº 295/18)

Posadas, lunes 23 de abril de 2018 


\title{
INFLUENCIA DEL PRETRATAMIENTO DE RESIDUOS FORESTOINDUSTRIALES SOBRE LA PRODUCCIÓN DE BIOETANOL
}

\author{
Ing. Julia KRUYENISKI
}

\author{
Lugar de desarrollo del trabajo de tesis \\ Instituto de Materiales de Misiones (IMAM) UNaM-CONICET \\ Programa de Celulosa y Papel (PROCYP) \\ Facultad de Ciencias Exactas, Químicas y Naturales (UNaM) \\ Félix de azara 1552 - Posadas - Misiones - Argentina \\ procyp@ fceqyn.unam.edu.ar
}

COMISIÓN DE SUPERVISIÓN (Resolución Consejo Directivo Nº 068/14)
Dra. Silvia Daniela ROMANO
Universidad de Buenos Aires
Dra. Laura Lidia VILLALBA
Universidad Nacional de Misiones
Dra. María Alicia MARTOS
Universidad Nacional de Misiones

\section{CARRERA DE DOCTORADO EN CIENCIAS APLICADAS}

Proyecto de Carrera No 10933/11

Con reconocimiento de la Comisión Nacional de Evaluación y Acreditación

Universitaria (CONEAU) No 344/11 


\section{AGRADECIMIENTOS}

Por suerte no son los "Oscars" así que puedo explayarme sin que comience a sonar la música...

Al CONICET por la beca doctoral y a la UNaM por el espacio de trabajo brindado.

A mi directora Dra. María Cristina Area por ser mi guía estos años, por el acompañamiento y compromiso permanente.

Al Dr. Fernando Felissia por la paciencia y ayuda en el trabajo de laboratorio, estaré siempre agradecida.

Al profesor Carlos Nuñez, por hacernos sentir "en casa" en el ambiente laboral, su carisma es irremplazable. Por tantos consejos para el trabajo y para la vida.

A la Dra. María Vallejos, por su colaboración y ayuda.

A la Dra. Alicia Ares por su predisposición como directora del doctorado.

A los integrantes del departamento de fisicoquímica, por su apoyo a lo largo de estos años.

Al Dr. Sarita Candida Rabelo y a todo el grupo de trabajo del CTBE de Campinas, por su disponibilidad y colaboración.

Al Dr. Paulo Ferreira y Maria da Graça Videira Sousa Carvalho por la posibilidad ofrecida y su colaboración en trabajos.

A la comisión de supervisión, Dra. Laura Villalba, Dra. Alicia Martos y Dra. Daniela Romano por el tiempo brindado para poder avanzar con el doctorado.

Al Lic. Victor Bundrea, por darme el empujón que necesitaba.

A mis queridos compañeros del PROCyP: Cami, Nanci, Romi, Javi, Juancito, Laura, Nico, Yani, Shoshy y Julieta por ayudarme siempre. Gracias a Cami por la ayuda desinteresada (cualquier día y horario). Gracias a Romi y a Cami por proveer materiales necesarios para llevar a cabo las experiencias. Gracias a sala Stark por las reuniones de got, catarsis y comida, me llevo amigos invaluables. Y son solo algunos, también están Pauli, Cris, Sil, Anita, Gustavo, Dany, Ale, Juan y Hernán, hermosa gente que sigue presente.

Como no mencionar a mis amistades de la secundaria y la vida, Paula G., Belén, Melody, Naty, Yeni, Paula W., Selva, Cami, Nadia, Mara y Ceci.

A mi familia, todo lo que este gran concepto involucra. A mis padres, mis hermanas, Ricardo y Mabel por el apoyo. Y a la familia de Lisandro, que por protocolo los menciono así pero ya son mía también.

A Lisandro por su compañía y apoyo incondicional, hoy y siempre.

Y a Dios por todo esto y más. 
A mi familia extendida (la de antes, la de ahora, la futura y los amigos) 


\section{LISTA DE ABREVIATURAS}

1G: primera generación

2G: segunda generación

3G: tercera generación

AQ: antraquinona

BGL: $\beta$ - glucosidasas

$\mathrm{CBH}$ : celobiohidrolasas

CLC: complejo lignina carbohidratos

DMA: Dynamic Mechanical Analizer (análisis mecánico diferencial)

DMC: direct microbial conversion (conversion directa microbiana)

DTPMPA: sal del ácido dietilentriamina penta metilen fosfónico

EC: Enzyme Commission numbers (número de identificación de las enzimas)

EG: endoglucanasas

EV: explosión de vapor

Factor $\mathrm{H}$ : factor que combina el tiempo y la temperatura en una única variable

FPU: filter paper units (unidades de papel de filtro)

GEI: gases de efecto invernadero

GP: grado de polimerización

HAD: hidrólisis con ácido diluido

HE: hidrólisis enzimática

HMF: 5-hidroximetilfurfural

HPLC: High Pressure Liquid Chromatography (cromatografía líquida de alta presión)

IC: Índice de Cristalinidad

IR: Índice de Refracción

IU: International Units (unidades internacionales)

m: masa

MM: masa molar 
NREL: American National Renewable Energy Laboratory

p-NP: 4-nitrofenol

p-PNG: p-nitrofenol- $\beta$-D-glucopiranósido

RHE: rendimiento de hidrólisis enzimática

RLM: relación licor/madera

smi: sobre material inicial (aserrín)

smp: sobre material pretratado

t: tiempo

$\mathrm{T}$ : temperatura

u.a.: unidades arbitrarias

$\mathrm{v}$ : volumen

SHF: separated hydrolysis and fermentation (hidrólisis y fermentación separadas)

SSF: simultaneously hydrolysis and fermentation (hidrólisis y fermentación simultánea)

YDP: Yeast Extract Peptone Dextrose (extracto de levadura peptona dextrosa) 


\section{RESUMEN}

El interés global por el uso y la producción de biocombustibles ha crecido significativamente en la última década enfocado en la reducción de gases de efecto invernadero. Existen políticas nacionales e internacionales que contemplan subsidios y exención de impuestos, así como directivas respecto a las mezclas que influyen en la producción de biocombustibles. Una biorrefinería forestal puede procesar residuos lignocelulósicos (aserrín, corteza, trozos de madera) para producir energía, productos químicos y biomateriales, análogamente a las refinerías de petróleo. En la región Noreste de Argentina (NEA) la industria de la madera es muy importante y el aserrín (de pino y eucaliptus) es uno de los principales desechos de su industrialización primaria. Se estima que hay 1,5 millones de toneladas secas al año de residuos que no son debidamente aprovechados. La producción de bioetanol de segunda generación a partir de la celulosa (presente en el residuo lignocelulósico) involucra tres etapas básicas: fraccionamiento o pretratamiento, hidrólisis enzimática y fermentación. La primera etapa tiene como objetivo extraer hemicelulosas y lignina, evitando la formación de subproductos inhibidores para la hidrólisis y/o fermentación y abrir la estructura del material para mejorar la accesibilidad a los componentes restantes (principalmente celulosa) en las posteriores etapas de procesamiento. Las enzimas (empleadas en la hidrólisis) y el substrato (material pretratado) son los principales factores que influyen en la hidrólisis enzimática, directamente relacionada con el pretratamiento al cual es sometido el material.

La hipótesis de este trabajo es que la calidad del material fibroso (específicamente, celulosa de diferente calidad y pureza proveniente de aserrines pretratados) tiene influencia sobre su conversión a bioetanol.

El objetivo general de este trabajo es encontrar los requisitos de calidad que debe poseer el material lignocelulósico pretratado para maximizar la conversión a bioetanol mediante procesos técnicamente viables y económicamente y ambientalmente sostenibles. 
Para esto se empleó aserrín de pino sometido a diferentes pretratamientos, como ser: desresinación alcalina, hidrólisis ácida diluida, soda-AQ (antraquinona), soda-AQ-oxígeno, Kraft-AQ, explosión de vapor (EV, con o sin lavado alcalino posterior), soda-etanol, soda, etanol y combinaciones de algunos de los tratamientos mencionados. El aserrín sin pretratar también fue sometido a hidrólisis enzimática. Luego de determinar la digestibilidad de los materiales, se seleccionaron ocho muestras (en base a su composición química y rendimiento de la hidrólisis enzimática) y se evaluó su cristalinidad y porosidad, por medio de rayos X y termoporosimetría, respectivamente.

Todos los pretratamientos aplicados aumentaron el rendimiento de la hidrólisis enzimática (digestibilidad) frente a la hidrólisis del aserrín sin pretratamiento. Los pretratamientos realizados para extraer hemicelulosas o extractivos, como hidrólisis ácida diluida, explosión de vapor y desresinación alcalina, no mejoraron significativamente la digestibilidad. El máximo rendimiento alcanzado fue del $25 \%$ a las 72 h con EV, demostrando que la extracción de hemicelulosas participa con un rol menor en la digestibilidad.

Por el contrario, los tratamientos fuertemente alcalinos que promovieron mayor remoción de lignina, mejoraron la accesibilidad del material a la acción enzimática. En concordancia, se obtuvieron altos valores de cristalinidad de la celulosa (IC alrededor de 75-76\%). Los ensayos de termoporosimetría mostraron que los pretratamientos aumentaron el número de poros pero no su diámetro. El orden de porosidades fue: aserrín sin pretratamiento $<$ Kraft-AQ $<\mathrm{EV}<\mathrm{NaOH}-\mathrm{AQ}<<\mathrm{NaOH}-\mathrm{EtOH}<<\mathrm{NaOH}-$ AQ- $\mathrm{O}_{2}$. La porosidad, que aumentó tanto con la extracción de hemicelulosas como de lignina, no mostró una clara influencia en la digestibilidad.

Se pueden encontrar dos tendencias de la digestibilidad en función del contenido de lignina del material pretratado I) lineal negativa, basada en la remoción de lignina $\left(\mathrm{R}^{2} \approx 0,95\right)$ y II) lineal positiva, basada en la extracción de hemicelulosas $\left(\mathrm{R}^{2} \approx 0,94\right)$. Además se encuentra una tendencia lineal positiva de la digestibilidad en función del contenido de glucanos del material $\left(\mathrm{R}^{2} \approx 0,86\right)$. 
Considerando una regresión múltiple, el modelo resultante incluye tanto el contenido de lignina como el producto entre lignina y hemicelulosas, ambos con influencia negativa sobre la digestibilidad $\left(\mathrm{R}^{2} \approx 0,95\right)$.

La fermentación (con Saccharomyces cerevisiae) de los hidrolizados seleccionados, indicó ausenciade inhibidores del proceso fermentativo. El rendimiento al final de la fermentación varió entre 88 y 93\%. En la mayoría de los casos estos valores se alcanzaron las 30h, mostrando que los hidrolizados son viables para el proceso de fermentación empleado.

El requisito de calidad que debe poseer un material lignocelulósico pretratado es fundamentalmente un bajo contenido de lignina, mientras que el contenido de hemicelulosas influye significativamente solo por interacción con la lignina. Considerando los resultados observados, la mejor opción es aplicar directamente un tratamiento alcalino deslignificante sobre el aserrín para luego sacarificarlo. 


\begin{abstract}
The global interest for the use and production of biofuels has significantly increased in the last decade, with special focus on the reduction of greenhouse gases emission. There are national and international policies which include subsidies and taxes exemption as well as directives regarding the mixtures that influence the production of biofuels. A forest biorefinery can process lignocellulosic waste (sawdust, bark, wood chip) to produce energy, chemical products and biomaterials, similar to petroleum refineries. In the Northeast region of Argentina (NEA), the wood industry is very important and sawdust (mainly from pine and eucalyptus) is one of the main wastes of its primary industrialization. It is estimated that there are 1.5 million dry tons per year of waste that are not properly used.
\end{abstract}

The production of second generation bioethanol from cellulose (present in the lignocellulosic waste) involves three basic stages: fractionation or pretreatment, enzymatic hydrolysis and fermentation. The aim of the first stage is to extract hemicelluloses and lignin, avoiding the formation of inhibitory by-products for hydrolysis and / or fermentation and to open the structure of the material to improve the accessibility to the remaining components (mainly cellulose) during the downstream processes.The enzymes (used in hydrolysis) and the substrate (pretreated material) are the main factors that influence the enzymatic hydrolysis, being the last one closely relatedto the pretreatment to which the material is subjected.

The hypothesis of this work is that the quality of the fibrous material (specifically, cellulose of different quality and purity from pre-treated sawdust) has an influence on its conversion to bioethanol.

The general objective of this work is to find the quality requirements that the lignocellulosic pretreated material must have to maximize their conversion to bioethanol, using processes technically viable and economically and environmentally sustainable. 
For this purpose pine sawdust was used and subjected to different pretreatments, such as alkaline deresination, diluted acid hydrolysis, soda-AQ (anthraquinone), soda-AQ-oxygen, Kraft-AQ, steam explosion (SE, with and without a posterior alkaline wash), soda-ethanol, soda, ethanol and a combination of some treatments. The untreated sawdust was also subjected to enzymatic hydrolysis. After determining the digestibility of the materials, eight samples were selected (based on their chemical composition and enzymatic hydrolysis yield) and their crystallinity and porosity were evaluated by means of X-rays and thermoporosimetry respectively.

All studied pretreatments increased the enzymatic hydrolysisyield (digestibility) when compared to the hydrolysis of sawdust without pretreatment. The pretreatments accomplished to extract hemicelluloses or extractives as diluted acid hydrolysis, steam explosion, and alkaline deresination did not significantly improve the digestibility. The maximum yield reached was $25 \%$ at $72 \mathrm{~h}$ with $\mathrm{EV}$, demonstrating that the extraction of hemicelluloses plays a minor role in digestibility.

On the contrary, strongly alkaline treatments, which promoted greater lignin removal, improved the accessibility of the material to the enzymatic action. In agreement, high values of crystallinity index (CrI of around $75-76 \%$ ) were obtained. The thermoporosity studies showed that all pretreatments increased the number of pores but not their diameter. The order found was: sawdust without pretreatment $<$ Kraft-AQ $<\mathrm{EV}<\mathrm{NaOH}-\mathrm{AQ}<<\mathrm{NaOH}-\mathrm{EtOH}<<\mathrm{NaOH}-\mathrm{AQ}-\mathrm{O}_{2}$. The porosity, which increased with the extraction of both hemicelluloses and lignin, did not show a clear influence on the digestibility.

Two tendencies were found with respect to the digestibility of the pretreated material: I) negative linear, based on the removal of lignin $\left(\mathrm{R}^{2} \approx 0.95\right)$ and II) positive linear, based on the extraction of hemicelluloses $\left(\mathrm{R}^{2} \approx 0.94\right)$. There is also a positive lineal tendency between digestibility and glucans content in the material $\left(\mathrm{R}^{2} \approx 0.86\right)$. Using multiple regression, the resultant model considers both 
lignin content and the product between lignin content and hemicelluloses, with negative influence on the digestibility $(\mathrm{R} \approx 0.95)$.

The fermentation (with Saccharomyces cerevisiae) of the selected hydrolysates indicated that inhibitors of the fermentationwere not presentin any case. The yield at the end of the fermentation varied between 88 and 93\%. In most cases, these values were reached at 30h, showing that the hydrolysates are viable for the fermentation process used.

The quality requirement that a pretreated lignocellulosic material must have is basically a low lignin content, whereas the content of hemicelluloses is significant only by its interaction with lignin. Considering the observed results, the best choice is to directly apply an alkaline delignifying treatment on the sawdust and then proceed to saccharify it. 


\section{CONTENIDO}

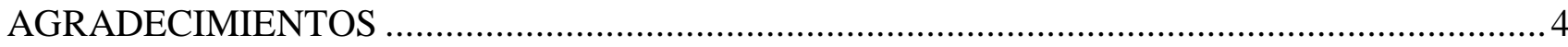

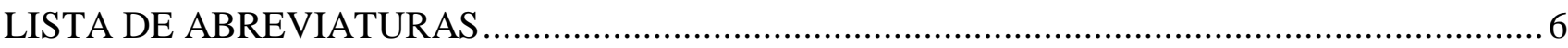

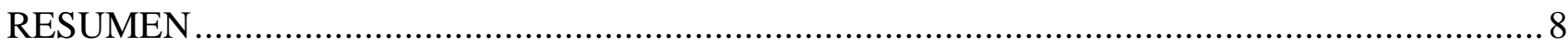

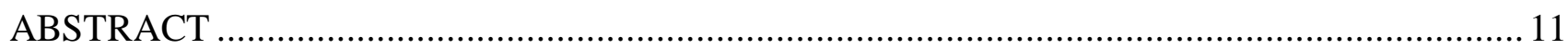

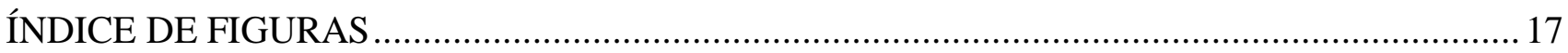

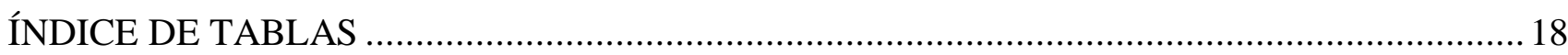

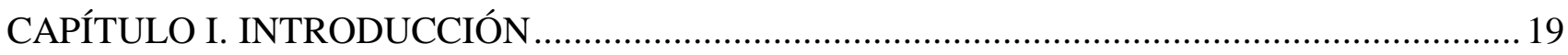

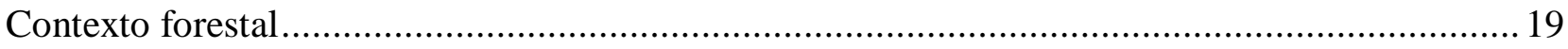

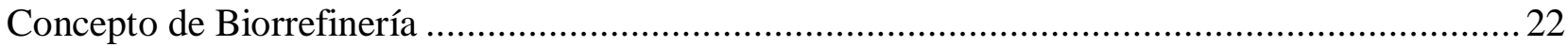

Composición de losmateriales lignocelulósicos ............................................................ 23

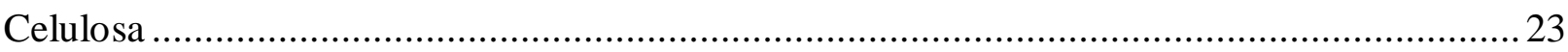

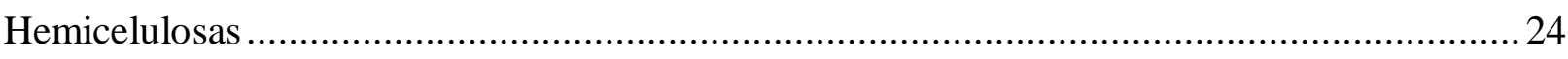

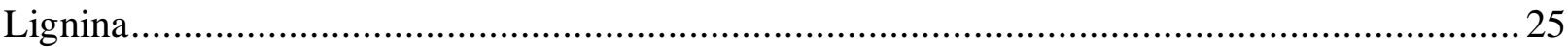

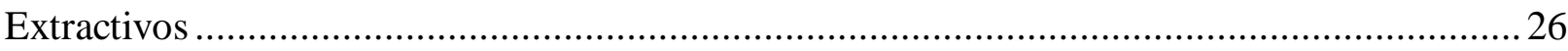

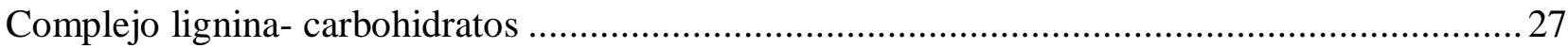

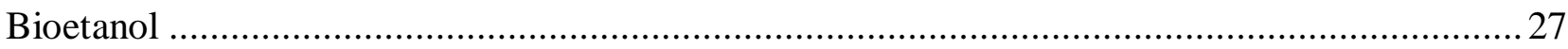

Proceso de producción de bioetanol ............................................................................... 29

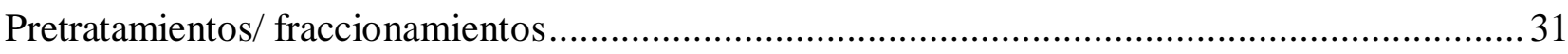

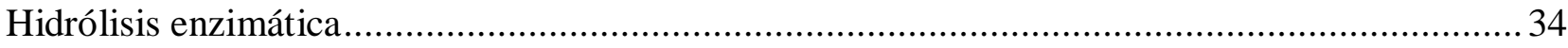

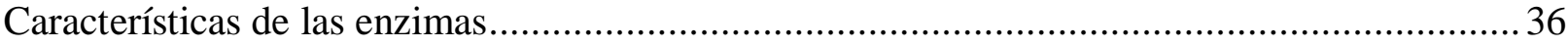

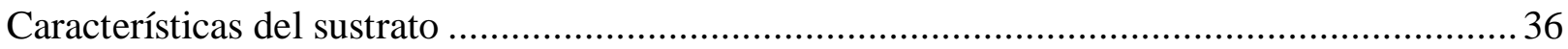

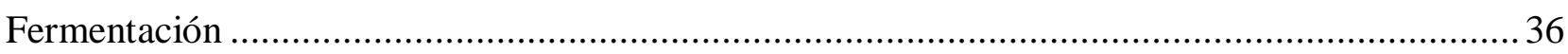

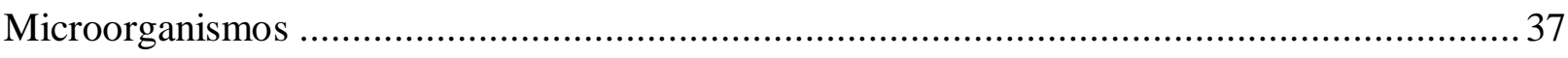

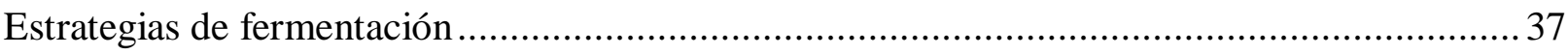

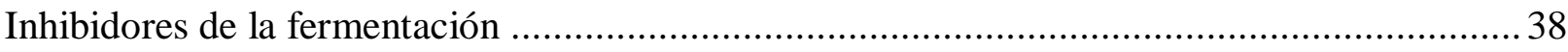

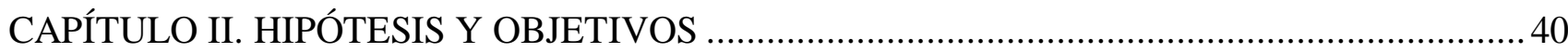

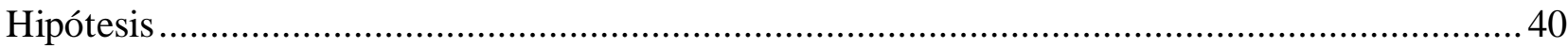

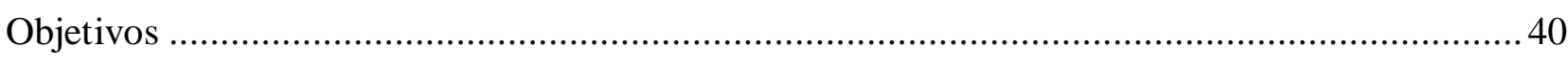

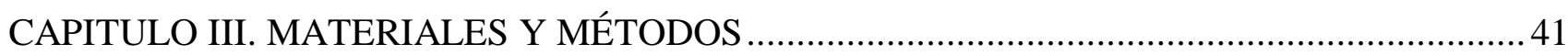

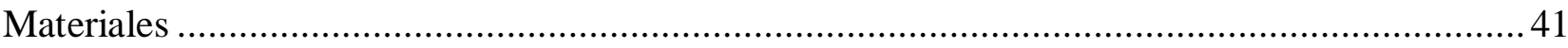

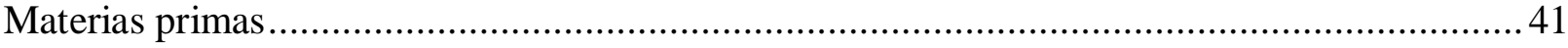

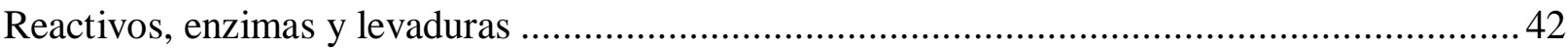


Métodos

Caracterización química de muestras sólidas (materias primas y sólidos pretratados) 42

Pretratamientos 44

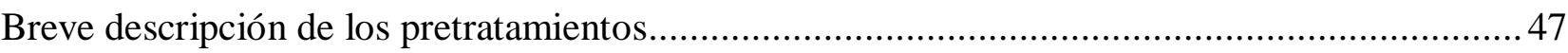

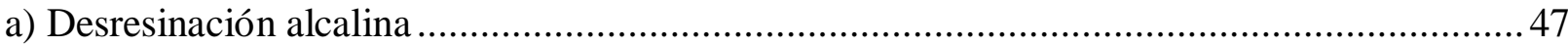

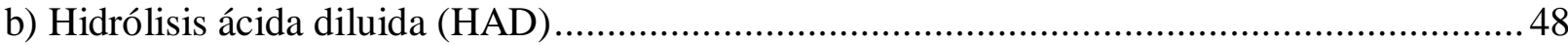

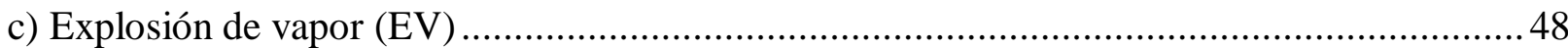

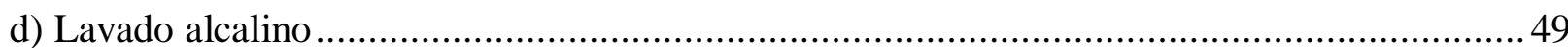

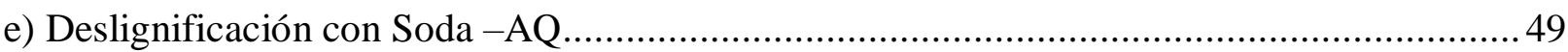

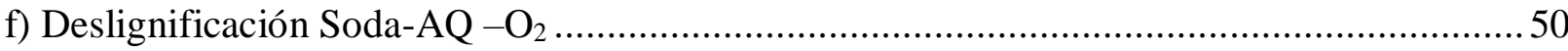

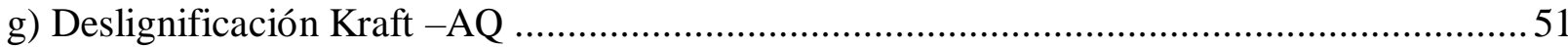

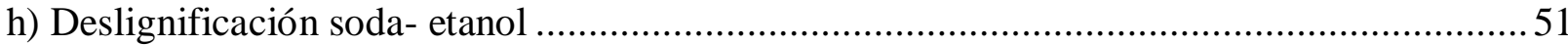

i) Deslignificación con peróxido de hidrógeno en medio alcalino de materiales pretratados con ácido 52

j) Deslignificación con oxígeno alcalino de materiales pretratados con ácido..........................53

k) Deslignificación $\mathrm{NaOH}$ - etanol de materiales pretratados con ácido ................................. 53

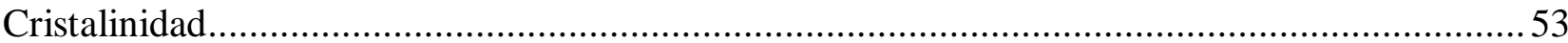

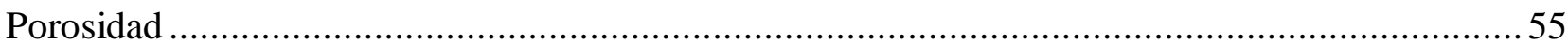

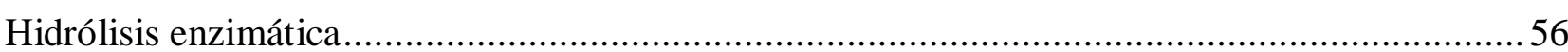

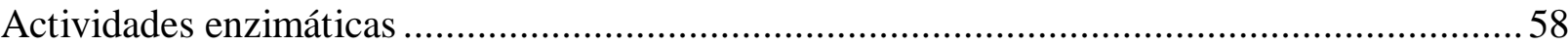

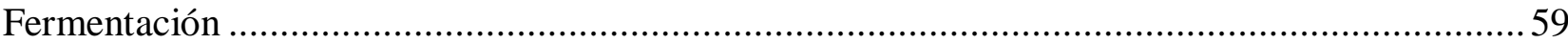

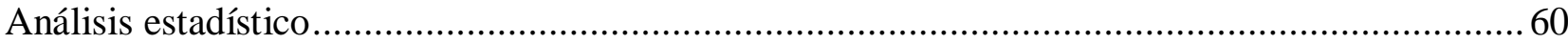

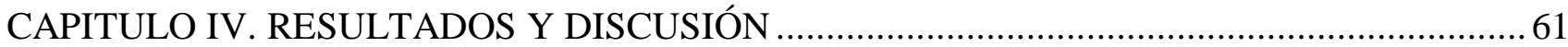

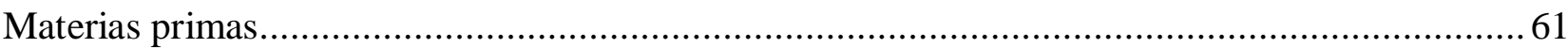

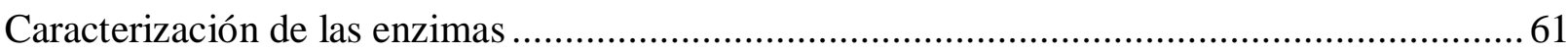

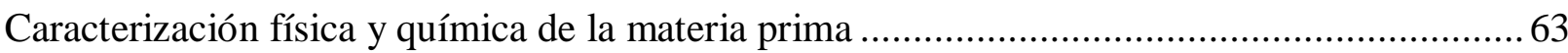

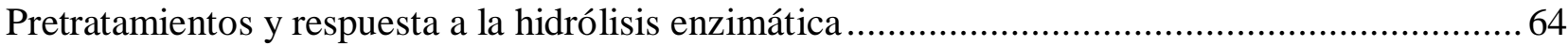

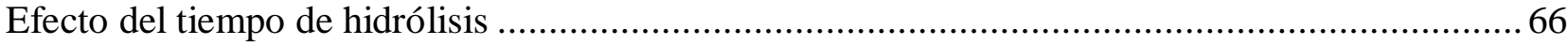

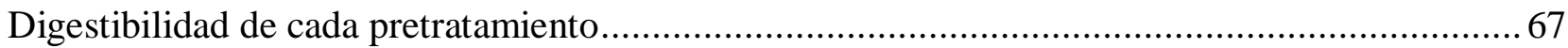

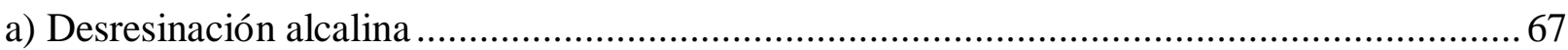

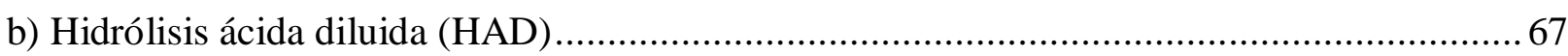

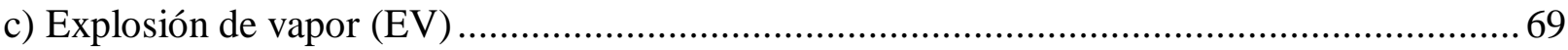

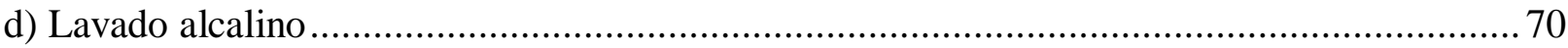

e) Deslignificaciones con Soda -AQ (e) y Kraft -AQ (g) ............................................. 71 


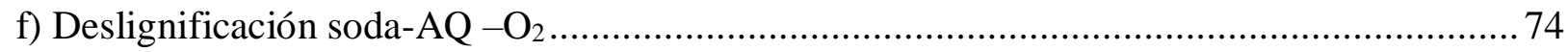

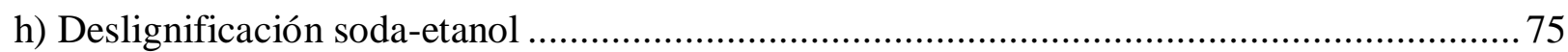

i) Deslignificación con peróxido de hidrógeno en medio alcalino de materiales pretratados con ácido 78

j) Deslignificación con oxígeno alcalino de materiales pretratados con ácido......................... 79

k) Deslignificación con $\mathrm{NaOH}-$ etanol de los materiales pretratados con ácido ........................80

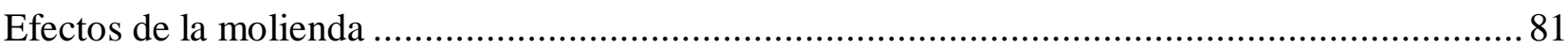

Análisis del efecto de la composición química del material sobre la hidrólisis enzimática ...........82

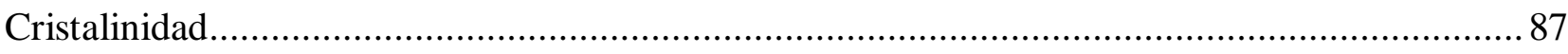

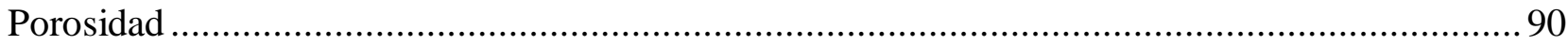

Resumen del análisis de las muestras seleccionadas ............................................................. 92

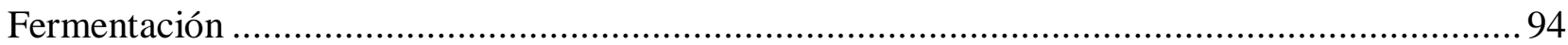

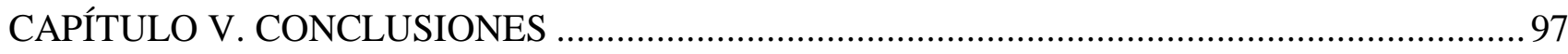

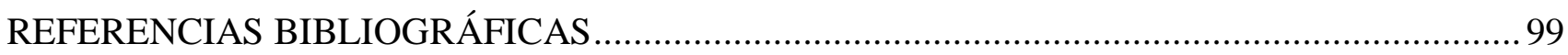

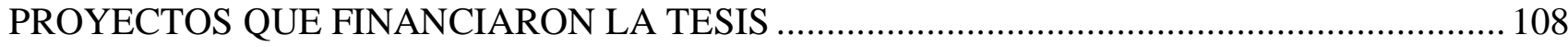

PUBLICACIONES DERIVADAS DE ESTE TRABAJO DE TESIS ....................................... 110 


\section{ÍNDICE DE FIGURAS}

Figura 1. Mapa de la distribución forestal por especie, 2009 ..................................................... 19

Figura 2. Residuos forestoindustriales según tipo y destino .................................................... 21

Figura 3. Reducción de gases de efecto invernadero (GEI) por bioetanol producido de diferentes materias primas (sobre una base de ciclo de vida), comparado con nafta ....................................223

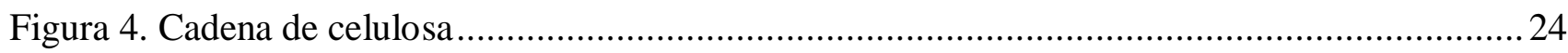

Figura 5. Unidades fenil propano presentes en la lignina. ................................................. 26

Figura 6. Modelo propuesto del arreglo ultraestructural de los polímeros de la madera en la pared

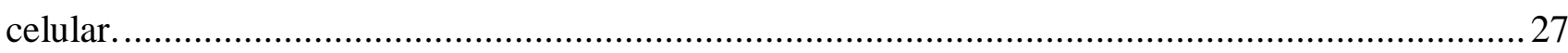

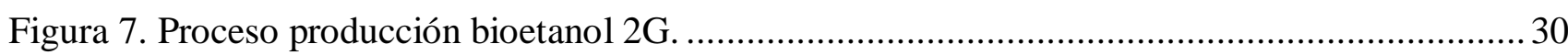

Figura 8. Esquema del mecanismo de hidrólisis enzimática de celulosa por celulasas ...................... 35

Figura 9. Productos de degradación.................................................................................... 38

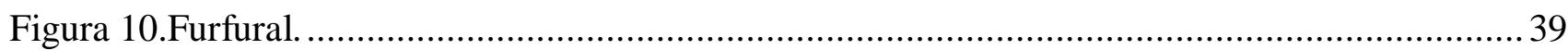

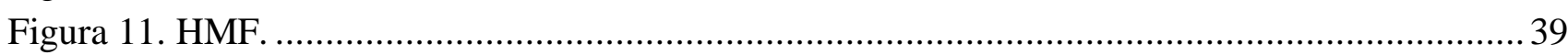

Figura 12. Esquema de caracterización del aserrín, antes y después de los tratamientos..................43

Figura 13. Esquema del origen de los diferentes materiales sometidos a hidrólisis enzimática ......... 45

Figura 14. Reactores empleados en los tratamientos soda- etanol. .............................................52

Figura 15. Molino utilizado para acondicionar el material. ...................................................5

Figura 16. Ejemplo de difractograma. ................................................................................. 55

Figura 17. a) Termograma obtenido durante el análisis TP-DSC. b) Luego del análisis de los resultados. c) Ejemplo distribución tamaño de poros. ....................................................... 56

Figura 18. Hidrólisis enzimática en proceso. ....................................................................... 57

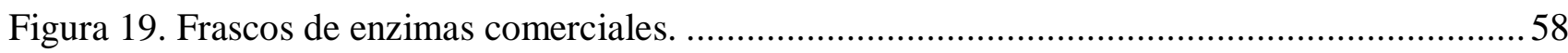

Figura 20. Gráfico para la determinación de la actividad de las celulasas. ................................... 61

Figura 21. Digestibilidad en función del tiempo de hidrólisis enzimática....................................67

Figura 22. Digestibilidad (72 h) y contenido de lignina, todas las experiencias a los 90 minutos. .... 76

Figura 23. Digestibilidades enzimáticas (72 h) en función del contenido de hemicelulosas o glucanos,

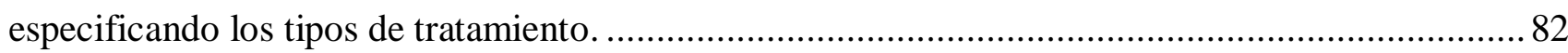

Figura 24. Digestibilidades enzimáticas (72h) en función del contenido de lignina, especificando los

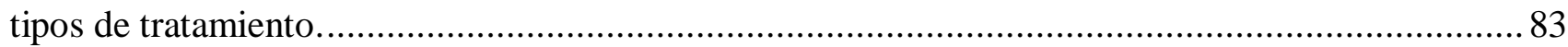

Figura 25. Diagrama rayos X de las muestras seleccionadas.................................................. 88

Figura 26. Gráfico de correlaciones significativas entre las variables estudiadas...........................89

Figura 27. Gráfico de porosidad acumulada de las muestras seleccionadas. ................................90

Figura 28. Gráfico de la distribución de poros de las muestras seleccionadas. ...............................91

Figura 29. Resumen de la composición química, digestibilidad (72 h), cristalinidad y porosidad de las ocho muestras seleccionadas................................................................................... 93

Figura 30. Concentración (g/L) de glucosa (azul) y de etanol (naranja) en función del tiempo (horas).

Figura 31. Rendimiento de etanol (\% sobre el máximo) en función del tiempo.............................96 


\section{ÍNDICE DE TABLAS}

Tabla 1. Fracción empleada para los pretratamientos. P: pasa, R: retenido................................ 41

Tabla 2. Procedimiento y norma NREL/TP correspondiente................................................. 43

Tabla 3.Condiciones de los pretratamientos de las diferentes muestras. ...................................... 45

Tabla 4. Diluciones empleadas para determinar actividad celulasas...........................................6 61

Tabla 5. Diluciones realizadas con la solución madre de las celobiasas para determinar actividad...62

Tabla 6. Resultados caracterización física según tamaño tamices (R: retenido, P: pasa) para cada

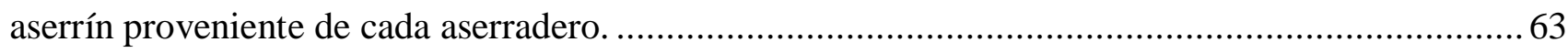

Tabla 7. Análisis químico de los aserrines según el origen. ...................................................64

Tabla 8. Caracterización química de las muestras sometidas a diferentes pretratamientos determinada

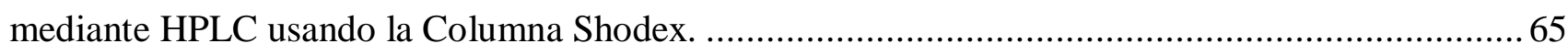

Tabla 9. Caracterización química de los las muestras sometidas a diferentes pretratamientos de las diferentes muestras, determinada mediante HPLC usando la columna AMINEX..........................66

Tabla 10. Comparación entre coníferas pretratados con etapa ácida............................................6 68

Tabla 11. Comparación entre coníferas pretratados con explosión de vapor..................................69

Tabla 12. Comparación del RHE del material pretratado con EVconsiderando el tipo de lavado

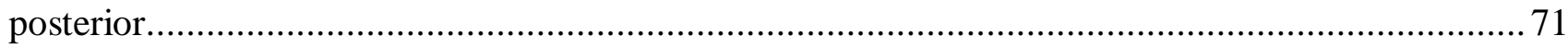

Tabla 13. Comparación entre materiales sometidos a pretratamiento alcalino.............................. 73

Tabla 14. Comparación entre coníferas sometidas a deslignificación con oxígeno......................... 75

Tabla 15. Comparación de coníferas sometidas a un pretratamiento organosolv ........................... 77

Tabla 16. Comparación de coníferas sometidas a explosión de vapor y deslignificación con peróxido

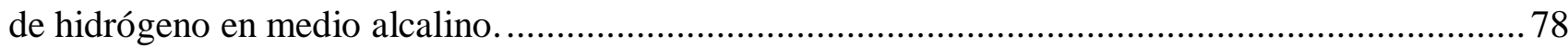

Tabla 17. Comparación de los RHE de coníferas pretratadas con ácido y luego deslignificadas con

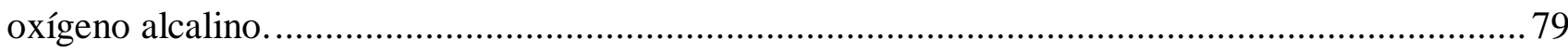

Tabla 18. Digestibilidad de los materiales con y sin molienda. ............................................... 81

Tabla 19. Compendio de la caracterización de los pretratamientos seleccionados........................8 87

Tabla 20. Materiales sobre los cuales se realizó la fermentación empleando el hidrolizado de la HE. 


\section{CAPÍTULO I. INTRODUCCIÓN}

\section{Contexto forestal}

Argentina posee 50 millones de hectáreas de bosques nativos y más de 1,2 millones de hectáreas de plantaciones forestales. Casi el $80 \%$ de la superficie implantada se encuentra localizada en la región mesopotámica y en el delta del rio Paraná (Figura 1).

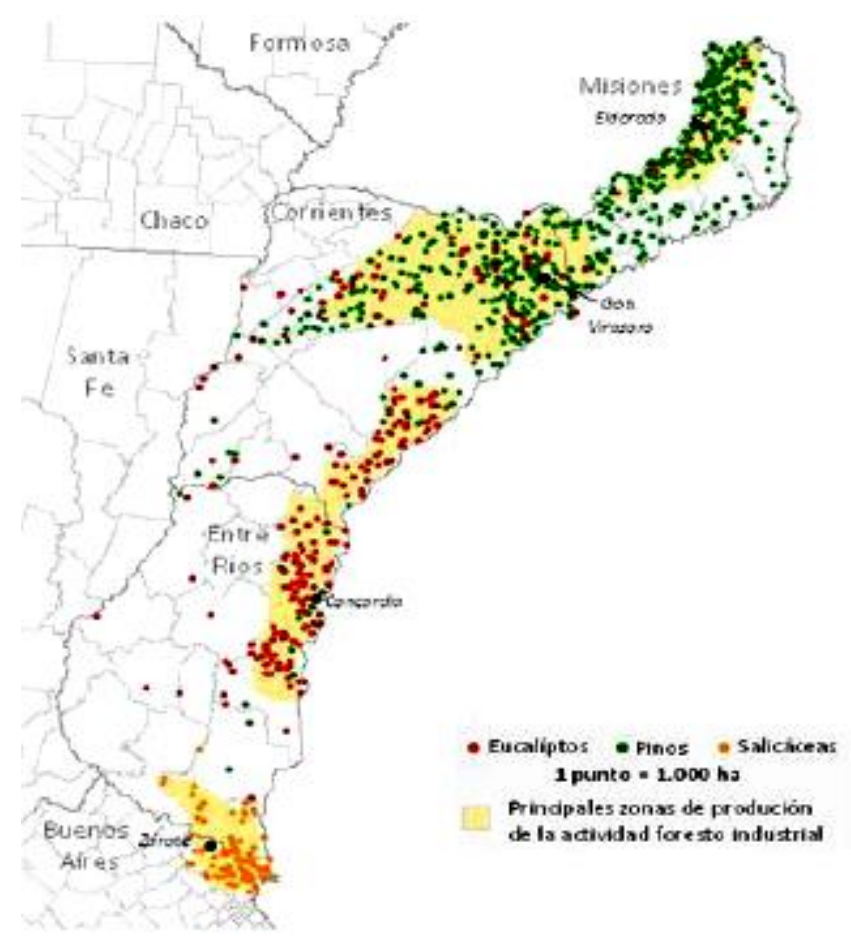

Figura 1. Mapa de la distribución forestal por especie, 2009 (Rosa María Gorzycki, 2014).

Según el inventario nacional de plantaciones forestales por superficie (Ministerio de Modernización, 2017) en 2015 había aproximadamente 406 mil hectáreas de bosque cultivado en Misiones, de las cuales $86 \%$ corresponde a pino, $10 \%$ a eucalipto y el restante $4 \%$ a otras especies. Las especies principales de pinos implantados en Misiones son Pinus elliottii y Pinus taeda, originariosde los Estados Unidos y denominados en forma corriente "southern pines". 
La principal actividad industrial de la producción primaria de la madera es el aserrado (transformación mecánica, empleando el 46\% del tronco). El resto es utilizado para pulpa celulósica, papel, tableros y generación energética (trasformación química).

En la provincia de Misiones operan más de 900 establecimientos que procesan la madera de diversas maneras (actividades celulósico-papeleras, aserraderos, laminadoras, fábricas de tableros, carpinterías de obra, remanufactura, producción de envases, fábrica de muebles y partes, impregnadoras de maderas, productores de leña y carbón y diversos establecimientos artesanales). Exceptuando algunas industrias de gran escala, la mayoría es pequeña y presenta deficiencias en aspectos tecnológicos, organizativos y de información. El sector foresto-industrial en el año 2011 generaba actividades directas (silvicultura, aserrado, fabricación de pulpa para papeles, laminados y terciados) correspondientes a un 9,62\% del valor bruto de producción total, marcando una tendencia decreciente, ya que en el año 2005 su participación era del 20\%. Claramente esto se refleja en la capacidad del sector para generar trabajo, en 2003 el empleo directo e indirecto fue de 69.646 personas, mientras que en 2013 bajó a 40.010 personas (Informe sobre la situación actual del sector foresto industrial de la provincia de Misiones. Diagnóstico y perspectivas para el año 2016., 2015). Según el censo foresto industrial de 2009 de la provincia de Misiones, se disponen teóricamente de 2,1 millones de toneladas anuales de subproductos de la industria de la madera, incluyendo viruta, costaneros, corteza, aserrín, despuntes y chips (Figura 2). De ese total de residuos generados, se dispone estimativamente del 19,8\% (es decir, 10,3\% que se quema bajo combustión no controlada más 9,5\% que se desecha), equivalente a más de 400 mil toneladas al año de biomasa forestal. Si consideramos además a la provincia de Corrientes, se dispone adicionalmente de 483.000 toneladas al año según el informe técnico de bioenergía 2012 (Uasuf \& Hilbert, 2012). 


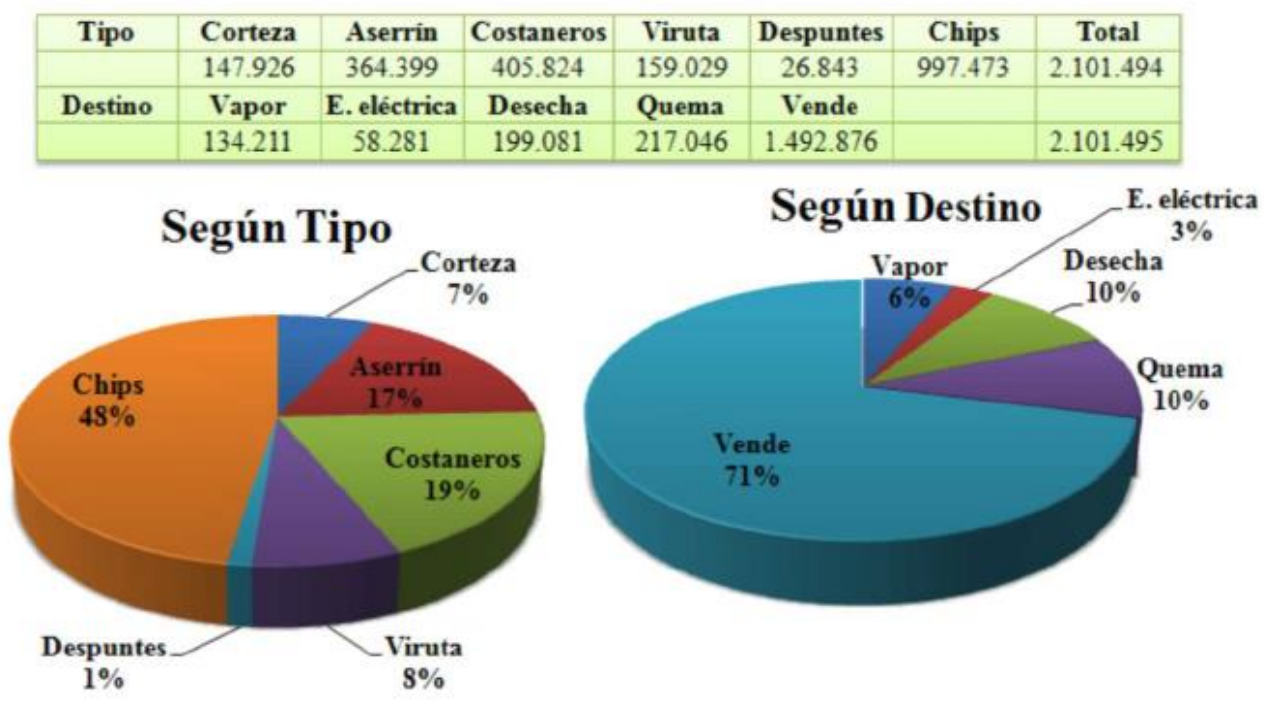

Figura 2. Residuos forestoindustriales según tipo y destino (Uasuf \& Hilbert, 2012).

Estos residuos forestoindustriales constituyen recursos naturales renovables disponibles en grandes cantidades y a bajo costo ( $\$ 120$ o 6,7 USD por tonelada aserrín en el mes de octubre $2017^{1}$, sin flete). Como se ve en la Figura 2 el aserrín de pino se encuentra entre los desechos más importantes de la elaboración primaria de la madera en la Mesopotamia Argentina. La quema incontrolada de los residuos es una problemática ambiental y social, además de ser un acto ilícito de conformidad a la prohibición estipulada en el inciso b del artículo 3 de la Ley provincial XVI Nro 106 de la Provincia de Misiones (que prohíbe a partir delprimero de enero de 2012 la quema incontrolada de residuos biomásicos de la forestoindustria) (Cámara de representantes. Provincia de Misiones. República Argentina., 2017). Por lo anteriormente mencionado, es necesario buscar una solución para el adecuado tratamiento de estos residuos. En este punto es importante destacar el concepto de biorrefinería.

\footnotetext{
${ }^{1}$ Cotización: 17,9\$/USD.
} 


\section{Concepto de Biorrefinería}

La biomasa, a semejanza del petróleo, posee una composición química compleja basada en cadenas carbonadas, que pueden separarse en moléculas intermediarias y procesarse para obtener subproductos, es decir que el concepto biorrefinería es análogo al de una refinería de petróleo. El American National Renewable Energy Laboratory (NREL) definió a la biorrefinería como una instalación que integra procesos de conversión y equipos para producir combustibles, energía y productos químicos a partir de biomasa (Luo et al, 2010). La biomasa forestal, que también denominaremos material lignocelulósico (la razón de esto se explicitará más adelante) es una materia prima renovable apta para la instalación de una biorrefinería industrial, concepto que surgió inicialmente con el objetivo de diversificar a las industrias de pulpa y papel.

Las biorrefinerías se clasifican en "plataforma de azúcares" (procesos de conversión bioquímica que se centran en la fermentación de los azúcares extraídos de la biomasa) y la "plataforma syngas o termoquímica" (procesos de conversión que se centran en la gasificación de la biomasa) (Kamm, 2006). Otra alternativa de clasificación es en biorrefinerías de primera, segunda o tercera generación. Las de primera generación implican la producción de biocombustibles (etanol y biodiesel) empleando materias primas como aceite de soja, almidón de maíz o caña de azúcar, queson renovables pero son alimentos. Las de segunda generación emplean biomasa lignocelulósica (diferentes variedades de madera, bagazo o paja de caña de azúcar entre otros). Este tipo de materias primas tiene, en principio, tres componentes que aprovechar: celulosa, hemicelulosas y lignina, lo que genera la complejidad del fraccionamiento a costos razonables. La ventaja primordial de las biorrefinerías de segunda generación es la recuperación de la fuente más abundante de carbono renovable en el planeta. Las de tercera generación emplean un abanico más amplio de residuos, como ser procedentes de: la agricultura, ganadería, residuos sólidos urbanos, petroquímicas, y papeleras; ampliando a su vez la gama de productos a obtener (Energías renovables. El periodismo de las energías limpias, 2017). 
Nos abocaremos a las biorrefinerías de segunda generación y de "plataforma de azúcares". En este ámbito las estrategias abarcan el empleo de cultivos energéticos (materias primas agrícolas o forestales cultivadas con el propósito de producir fibras para la obtención de energía), el empleo de los residuos de actividades agrícolas y forestales (primarias e industriales), o una combinación de ambas.

Dentro de los posibles productos de una biorrefinería se encuentra el bioetanol, atendiendo al interés global para reemplazar combustibles fósiles con fuentes renovables de energía. A escala comercial, el etanol se mezcla con la nafta. El interés en la producción de biocombustibles también se basa en la reducción de gases de efecto invernadero producidos por los combustibles fósiles (Figura 3). Actualmente el $60 \%$ del bioetanol se produce a partir de caña de azúcar, maíz y otros cultivos.

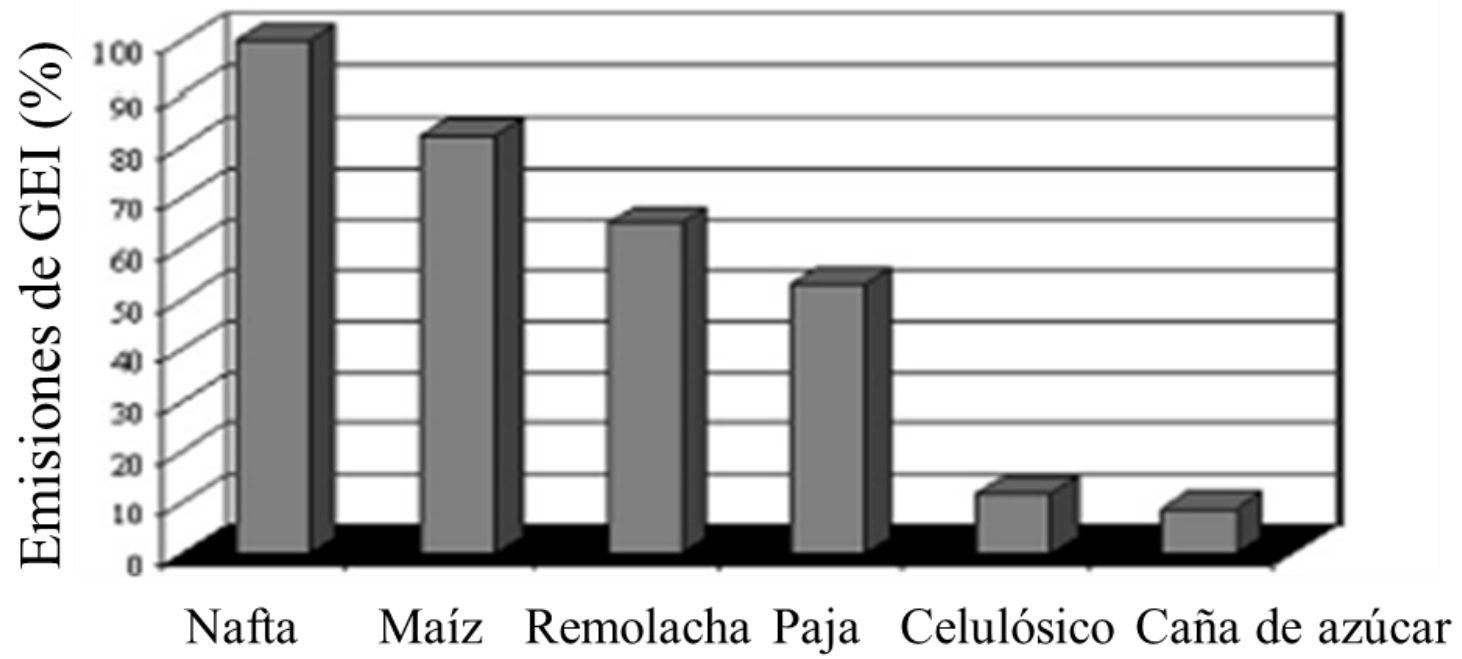

Figura 3. Reducción de gases de efecto invernadero (GEI) por bioetanol producido de diferentes materias primas ( sobre una base de ciclo de vida), comparado con nafta (Balat, 2011).

\section{Composición de losmateriales lignocelulósicos}

\section{Celulosa}

La celulosa es el principal componente de la pared de las fibras de la madera, totalizando un $40-45 \%$ de la misma. Es una larga cadena polimérica compuesta de $\beta$-D-glucosa en forma piranósica, unida 
por enlaces (1-4') glucosídicos (Figura 4). Al par de unidades monoméricas de D-glucosa se lo denomina celobiosa. La configuración $\beta$ impone una rotación de $180^{\circ}$ en las unidades alternas de glucosa (Lewin \& Goldstein, 1991).

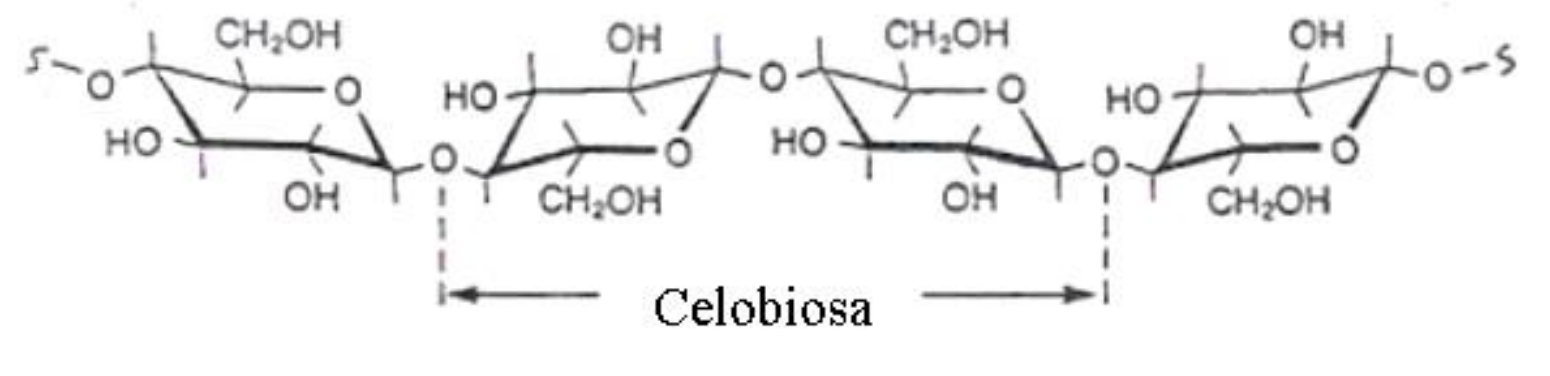

Figura 4. Cadena de celulosa (Walker J., 1993).

La estructura de la celulosa favorece que las cadenas se organicen en conjuntos/paquetes con un orden cristalino, que se mantienen juntos por fuertes puentes de hidrógeno, produciendo una configuración fibrosa. La celulosa también tiene regiones amorfas. El grado de cristalinidad y el grado de polimerización (1.000 a 15.000) dependen de la historia y el origen de la celulosa.

La celulosa es insoluble en agua, mientras que la disuelven algunas soluciones concentradas de sales y complejos de metal y ácidos o bases fuertes (con degradación).

\section{Hemicelulosas}

Las hemicelulosas son heteropolímeros constituidos por un pequeño número de azúcares y algunos de sus derivados, como azúcares acetilados y ácidos urónicos. Las hemicelulosas están constituidas principalmente por tres hexosas (glucosa, galactosa y manosa) y dos pentosas (xilosa y arabinosa).

Otras diferencias que presentan las hemicelulosas con respecto a la celulosa son: el grado de polimerización (entre 200-300 en las hemicelulosas frente a 1000-15.000 de la celulosa); la presencia de ramificaciones (la celulosa es un polímero lineal); la heterogeneidad (las hemicelulosas son heteropolímeros formados por distintos azúcares que pueden presentar sustituyentes, mientras que la 
celulosa es un homopolímero que está compuesto únicamente por glucosa); y la falta de cristalinidad (presentan una estructura amorfa, a diferencia de la celulosa que posee una acusada cristalinidad).

La cadena principal de hemicelulosas puede consistir de una sola unidad (homopolímero), por ejemplo los xilanos, o de dos unidades (heterompolímeros), por ejemplo glucomananos. La cadena principal suele tener grupos laterales de galactosa y/o ácido 4-O-metilglucrónico (Fengel \& Wegener D., 1984).

La cantidad de hemicelulosas en la madera varía entre 20 y $30 \%$ sobre madera seca. La composición y la estructura de las hemicelulosas son diferentes en las coníferas (pinos, abetos) y en las latifoliadas (por ejemplo: eucalipto, álamo, sauce). Las hemicelulosas de las coníferas tienen mayor contenido de hexosas que las hemicelulosas de las latifoliadas.

\section{Lignina}

La lignina es el segundo polímero más abundante en la naturaleza después de la celulosa, tiene una estructura tridimensional compuesta por unidades fenilpropano o unidades C9. Hay tres diferentes tipos de unidades C9: p-hidroxifenil propano, guayacil propano y siringil propano, las cuales se presentan en diferentes proporciones dependiendo de su origen. En general, las ligninas de coníferas están compuestas principalmente de unidades guayacil propano, las latifoliadas presentan unidades guayacil y siringil propano en proporciones variables dependiendo de la especie y las gramíneas pueden presentar los 3 tipos. En la Figura 5 se muestra la estructura de las 3 unidades (Sarkanen, 1971; Glasser W.G., 2000). 
<smiles>CCCc1ccc(OC)c(OC)c1</smiles>

(G)

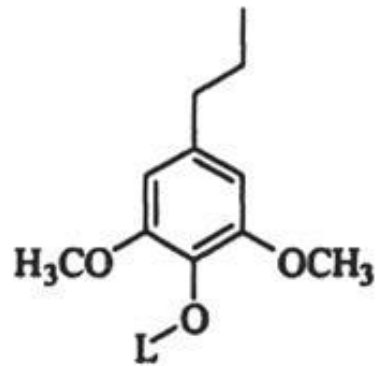

(S)

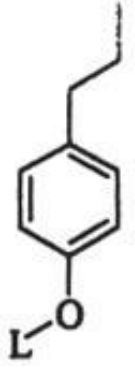

(H)

\section{Unidad guayacilpropano Unidad siringilpropano Unidad p-hidroxifenilpropano $\mathrm{L}=\mathrm{H}$ o fracción de lignina}

Figura 5. Unidades fenil propano presentes en la lignina (Glasser W.G., 2000).

Las unidades fenilpropano se unen entre sí mediante enlaces éter (C-O-C) y carbono-carbono (C-C).

\section{Extractivos}

Además de los carbohidratos estructurales; lignina, celulosa y hemicelulosa; existen en menor proporción (entre 2-8\%) otras sustancias que se denominan extractivos. Los mismos son de baja masa molecular, por lo cual es posible extraerlos con diversos solventes. Ademas son responsables de algunas características como ser: la resistencia natural a la pudrición, el sabor y las propiedades abrasivas (Álvarez Godoy, 2017). Los extractivos de las coníferas son principalmente los ácidos resínicos, pero además contienen ácidos grasos, ésteres grasos, esteroles, azúcares, almidón, taninos condensados, sales (orgánicas e inorgánicas) y lignanos.

Los extractivos pueden ocasionar problemas en el procesamiento químico de la biomasa, tales comola disminución del rendimiento, el aumento del consumo de reactivos en los tratamientos alcalinos para neutralizar los ácidos, y problemas de pitch en medio ácido (sustancia pegajosa que se adhiere a los equipos, filtros, etc.).

Otros componentes minoritarios son los inorgánicos (no extraíbles). 


\section{Complejo lignina- carbohidratos}

En la pared celular, las hemicelulosas no están unidas químicamente a la celulosa, pero se encuentran íntimamente asociadas, físicamente y por uniones hidrógeno. Por otro lado, existe una fuerte evidencia de que las hemicelulosas están unidas químicamente a la lignina.

Se propusieron muchos modelos a lo largo de los años, entre ellos Björkman (1957), Fengel (1970), Kerr y Goring (1975) entre otros, el último y más refinado es el de la Figura 6, de Salmen y Olsson (1998). El mismo fue obtenido a partir de mediciones del ablandamiento de maderas extraídas a distintos contenidos de humedad mediante análisis mecánico diferencial (DMA, Dynamic Mechanical Analizer). Este modelo sugiere que los glucomananos están más estrechamente unidos a la celulosa formando una capa de moléculas asociadas estrechamente a la misma. Los xilanos están dispuestos en una mezcla con la lignina, rodeada por la capa de glucomananos.

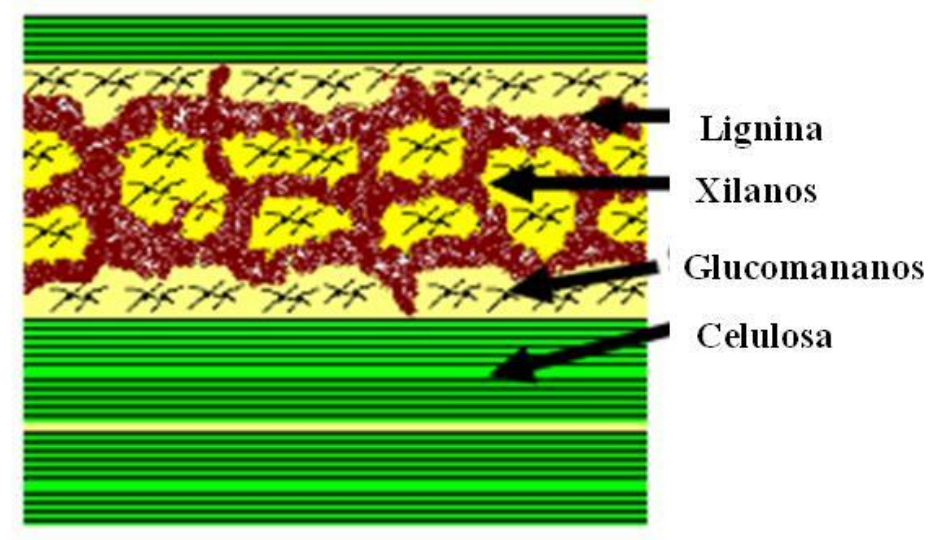

Figura 6. Modelo propuesto del arreglo ultraestructural de los polímeros de la madera en la pared celular (Salmén \& Olsson, 1998).

\section{Bioetanol}

Análogamente a la clasificación de las biorrefinerías, este producto se puede dividir en: bioetanol de primera generación $(1 \mathrm{G})$, de segunda generación $(2 \mathrm{G})$ y de tercera generación (3G). El de $1 \mathrm{G}$ utiliza como materia prima cultivos empleados generalmente con fines alimenticios, el de $2 \mathrm{G}$ aprovecha 
biomasa lignocelulósica y el de 3G usa métodos de producción similares a los de segunda, pero empleando como materia prima cultivos bioenergéticos específicamente diseñados o adaptados para mejorar la conversión de biomasa a biocombustible.

La producción global de bioetanol en 2015 fue de 90 mil millones de litros (Araújo, 2016), de los cuales Estados Unidos y Brasil produjeron más del 70\% (Achinas \& Euverink, 2016). El mercado de bioetanol de $1 \mathrm{G}$ ya está establecido en Brasil, Colombia y Argentina, e iniciándose en Paraguay y Bolivia (Janssen \& Rutz, 2011). En la República Argentina, está vigente la ley de biocombustibles 26.093/06 (InfoLEG. Información Legislativa., 2017a) y su decreto reglamentario 109/07 (InfoLEG. Información legislativa., 2017b). En consecuencia, desde del año 2010, es obligatorio el uso de 5\% de bioetanol "cortando" las naftas que se consuman en territorio nacional, este mandato fue cumplido en tiempo y forma (Huergo, 2011). Las regulaciones recientes aumentaron la fracción de corte a 12\% (Diario ámbito financiero, 2016). El desarrollo de biocombustibles tuvo su primer impulso durante parte de las décadas de 1970 y 1980, tiempo en el que funcionó el Programa Alconafta, que promovía la utilización de alcohol etílico anhidro como combustible (Di Paola, 2013). En 2016 la producción de bioetanol de $1 \mathrm{G}$ en el país fue del orden de $900.000 \mathrm{~m}^{3}$, con aportes del 55\% y 45\%, del maíz y de la caña de azúcar respectivamente (Molina, 2017). Esto implica la necesidad de incrementar fuertemente la producción de bioetanolpara satisfacer la demanda.

En este contexto, la biomasa lignocelulósica se revela como una fuente importante de materias primas dado su carácter poco contaminante, permitiendo la obtención de combustibles y de otros productos. El bioetanol de $2 \mathrm{G}$ presenta ciertas complicaciones tecnológicas que dificultan el proceso. El material contiene importantes cantidades de hemicelulosas (principalmente pentosas), que son refractarias a los procesos tradicionales de fermentación, la presencia de lignina obstaculiza el tratamiento debido a que compacta la estructura del material, y la celulosa se encuentra principalmente en forma cristalina y debe ser depolimerizada para poder ser fermentada. 
La biomasa lignocelulósica es considerada una fuente sustentable de sustitución de combustibles fósiles. Los estudios del ciclo de vida que evalúan las implicaciones ambientales de la producción de etanol a partir de plantaciones de madera (de rápido crecimiento) comparando con nafta convencional, mostraron reducciones en casi todas las categorías cuando se cambiaba a combustibles con base de etanol (González \& García, 2015). Otra ventaja del bioetanol de 2G sobre la madurez de la tecnología de producción del bioetanol de $1 \mathrm{G}$ es la habilidad para usar diferentes materialeslignocelulósicos como fuente de glucosa. En este contexto, los materiales lignocelulósicos están siendo intensamente estudiados como materia prima para la producción de bioetanol, con foco en los costos de los procesos de la producción de azúcares fermentables y su fermentación a etanol (Achinas \& Euverink, 2016; Alvira et al, 2010; Gonzalez et al, 2011; Zhu et al, 2010; Zhu \& Pan, 2010) y en la mejora de los esquemas tecnológicos (Araújo, 2016; Zabed et al, 2017). Sin embargo, de los 16 proyectos de etanol celulósico que usan plataforma de azucares a escala comercial en el mundo en 2012, solo uno considera a la madera como materia prima (Araújo, 2016). En Finlandia está St1, SOK (NEB), biorrefinerías cuyo principal producto es el bioetanol a partir de residuos forestoindustriales (aserrín), la misma empezó en el 2017 con una capacidad de 10 Ml/y (BioRefineries Blog, 2018).

Las ventajas de los residuos de madera comparados con los residuos agroindustriales están relacionadas con el almacenamiento y el transporte (gracias a su mayor densidad) y con su bajo contenido en ceniza (Zabed et al, 2017). En general los residuos de madera son recursos sin explotar con un gran potencial de producción de etanol (220-285 litros/ tonelada de madera).

\section{Proceso de producción de bioetanol}

El proceso de producción de bioetanol de 2G puede ser esquematizado como se ve en la Figura 7. 


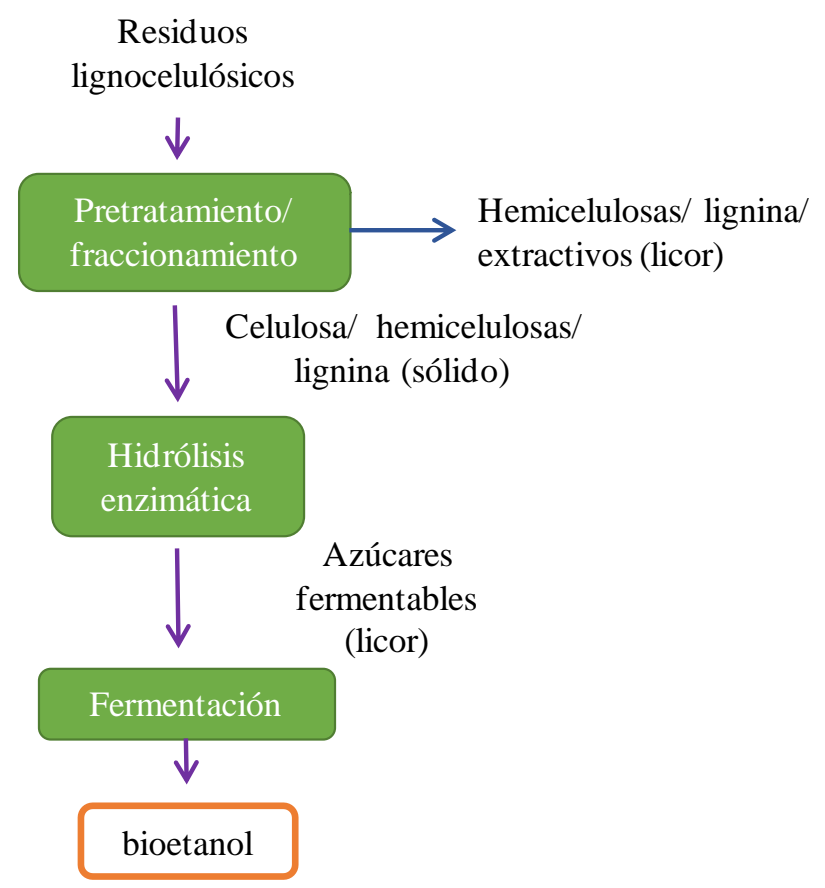

Figura 7. Proceso producción bioetanol 2G.

El bioetanol de $2 \mathrm{G}$ está en etapa de desarrollo a escala piloto y escala pre-comercial. Su viabilidad económica a gran escala no ha sido alcanzada debido a sus altos costos, que son dos a tres veces más elevados que los de combustibles de petróleo si consideramos una base de energía equivalente (Achinas \& Euverink, 2016; Carriquiry et al, 2011; Lynd et al, 2005; Van Eijck et al, 2014). Los costos de producción pueden disminuir por: (i) mejoras en producción y logística, (ii) mejoras en la eficiencia energética del proceso (pretratamiento, sacarificación y fermentación) y (iii) producción de subproductos (Carriquiry et al, 2011; Melin \& Hurme, 2011). En la mayoría de los casos, los costos energéticos determinan el costo global del proceso. Los ahorros de energía por optimización de las diferentes condiciones de los sistemas de operación son esenciales para aumentar la ganancia y reducir emisiones (Kemp, 2007).

El desarrollo de pretratamientos adecuados para minimizar el consumo de energía y mejorar la sacarificación enzimática y fermentación son claves para alcanzar altos rendimientos de azúcares y etanol. Los pretratamientos pueden ser evaluados a través de su eficiencia energética y el 
rendimiento de azúcares que se puede obtener (Kang et al, 2014; Walker G., 2011; Zhu \& Pan, 2010). En las biorrefinerías, los pretratamientos afectan a los procesos posteriores, el escalado y el esquema tecnológico. El tipo de pretratamiento también determina el proceso de recuperación de los químicos y el agua residual del tratamiento. El escalado es un desafío tecnológico que involucra inversión de capital, de investigación y de desarrollo (Aditiya et al, 2016; Muktham et al, 2016; Naik et al, 2010).

\section{Pretratamientos/ fraccionamientos}

Un pretratamiento es esencial para hacer a la celulosa más accesible al ataque enzimático para la producción de bioetanol de $2 \mathrm{G}$. Los requerimientos que debe cumplir un pretratamiento para ser efectivo son (Bengoechea et al, 2012):

- Reducción de la cristalinidad de la celulosa.

- Eliminación de los grupos acetilo de las hemicelulosas.

- Eliminación de enlaces entre hemicelulosas y lignina, con la consecuente separación de la lignina.

- Aumento del área superficial del material.

- Obtención de alto rendimiento azúcares (hexosas y/o pentosas).

- Mínima formación de productos de degradación tóxicos para evitar o simplificar la etapa de detoxificación (proceso realizado en previo a la fermentación generalmente).

- Bajos costos de inversión y bajo consumo energético.

- Uso de reactivos baratos y fácilmente recuperables.

- Mínima degradación de los azucares provenientes de las hemicelulosas.

El bioetanol es un producto de bajo valor agregado, es decir, un commodity. En noviembre de 2017 los precios de bioetanol según la resolución del Ministerio de Minería y Energía 415-E2017 son 
$14,342 \$ / \mathrm{L}$ para el producido a base de caña y 10,742 \$/L para el producido a partir de maíz. Estos precios, sin embargo han sufrido una baja reciente, ya que en el mes de octubre de 2017 según resolución SE 44/2014 eran 16,873 \$/L y 13,623\$/L respectivamente (Ministerio de Energía y Minería, 2017). Por este motivo, la estrategia más promisoria es integrar la producción de etanol a un esquema de biorrefinería en el cual se obtengan productos y/o coproductos de alto valor agregado a partir de la lignina, hemicelulosas y extractivos de la biomasa lignocelulósica. Esta es una manera de compensar los costos del pretratamiento y las enzimas para la hidrólisis de la celulosa. De esta forma, la biorrefinería extiende el concepto de pretratamiento a fraccionamiento del material, obteniendo fracciones tan puras como sea posible para su uso y transformación posterior.

Los pretratamientos más estudiados y sus efectos son:

- Tratamientos mecánicos (molienda mecánica o termomecánica, extrusión, refinación): disminuye el tamaño de las partículas para aumentar la superficie y entonces hacer que el material sea más accesible a las enzimas.

- Agua caliente (auto-hidrólisis): el tratamiento con agua caliente produce la desacetilación de los xilanos acidificando la solución con ácido acético, el cual cataliza la hidrólisis de las hemicelulosas (mayormente usado en latifoliadas y gramíneas).

- Hidrólisis ácida diluida (HAD): hidroliza las hemicelulosas y la celulosa menos cristalina a azúcares, generando a su vez productos de degradación.

- Explosión de vapor (EV): la inyección de vapor saturado de alta presiónseguido de una súbita descompresión a presión atmosférica produce la separación de las fibras y la despolimerización y ruptura de los enlaces entre carbohidratos y lignina, promoviendo la extracción de hemicelulosas. 
- Dióxido de carbono supercrítico: favorece la impregnación y la efectividad para extraer sustancias de baja polaridad. También actúa como una suave extracción ácida y como sistema de sacarificación para las hemicelulosas.

- Tratamientos organosolv (solventes orgánicos catalizados con ácidos o álcalis): la catálisis rompe los enlaces internos entre la lignina y las hemicelulosas, mientras que el solvente promueve la extracción de la lignina.

- Deslignificación con sulfito en medio ácido (proceso al sulfito): extrae la lignina de la madera en forma de lignosulfonatos y también las hemicelulosas, dependiendo de la concentración del licor y de la severidad de las condiciones empleadas.

- Deslignificación alcalina (proceso kraft, deslignificación con oxígeno): produce el hinchamiento de las fibras y extrae la mayor parte de la lignina separando los enlaces de la lignina y carbohidratos e hidrolizando la lignina.

- Irradiación ultrasónica: mejora los tratamientos químicos.

- Tratamiento biológico (por microorganismos o enzimas): produce la degradación de los componentes de la madera y aumenta la porosidad.

- Tratamientos con líquidos iónicos: produce la disolución de la biomasa y promueve cambios estructurales en la biomasa regenerada por reducción de la cristalinidad de la celulosa y el contenido de lignina.

Los diferentes materiales lignocelulósicos tienen distintas características fisicoquímicas por lo cual es necesario adoptar pretratamientos adecuados para cada uno (Alvira et al 2010).

Las coníferas han sido reconocidas como materias primas altamente recalcitrantes a la hidrólisis enzimática (Morales et al, 2017). El carácter recalcitrante de los materiales lignocelulósicos es debido a la resistencia de la pared celular, que evolucionó como barrera a agentes externos y de degradación. 
Varios estudios y revisiones publicadas en los últimos años incluyen coníferas genéricas, mezcla de coníferas, empleando principalmente abetos (géneros Picea y Abies) como fuente de de producción de bioetanol (Alvarez-Vasco \& Zhang, 2017; Inoue et al, 2016; Pan et al, 2005; Wingren et al, 2008).

\section{Hidrólisis enzimática}

Las celulasas, pertenecientes al grupo de las glicosidasas o glucosidasas, también llamadas glicosil hidrolasas, son un amplio grupo de enzimas responsables de la ruptura de enlaces glicosídicos (Weijers et al, 2008).

Específicamente, las celulasasconstituyenun conjunto de enzimas que actúan sinérgicamente hidrolizando la celulosa (Figura 8). El mecanismo del complejo enzimático ampliamente aceptado para la hidrólisis de la celulosa involucra acciones sinérgicas de las endoglucanasas (EG, 1,4- $\beta$-dglucan-4-glucanohidrolasas o EC 3.2.1.4), exoglucanasas o celobiohidrolasas (CBH, 1,4- $\beta$-Dglucanglucanohidrolasas y 1,4- $\beta$-D-glucáncelobiohidrolasas o EC 3.2.1.91), y las $\beta$-glucosidasas (BGL, celobiasas o EC 3.2.1.21). Las EG hidrolizan los enlaces intramoleculares accesibles $\beta$-1,4glucosídicos de la cadena de celulosa al azar para producir nuevos terminales de cadena, las CBH producen la ruptura de los terminales de la cadena de celulosa liberando celobiosa soluble o glucosa; y las BGL hidrolizan la celobiosa a glucosa para eliminar la inhibición debido a la celobiosa. Es necesario suplementar el complejo de celulasas original con $\beta$-glucosidasas cuando el mismo proviene de Trichoderma reesei, debido a la insuficiente cantidad de $\beta$-glucosidasas para prevenir la inhibición por acumulación de celobiosa. 


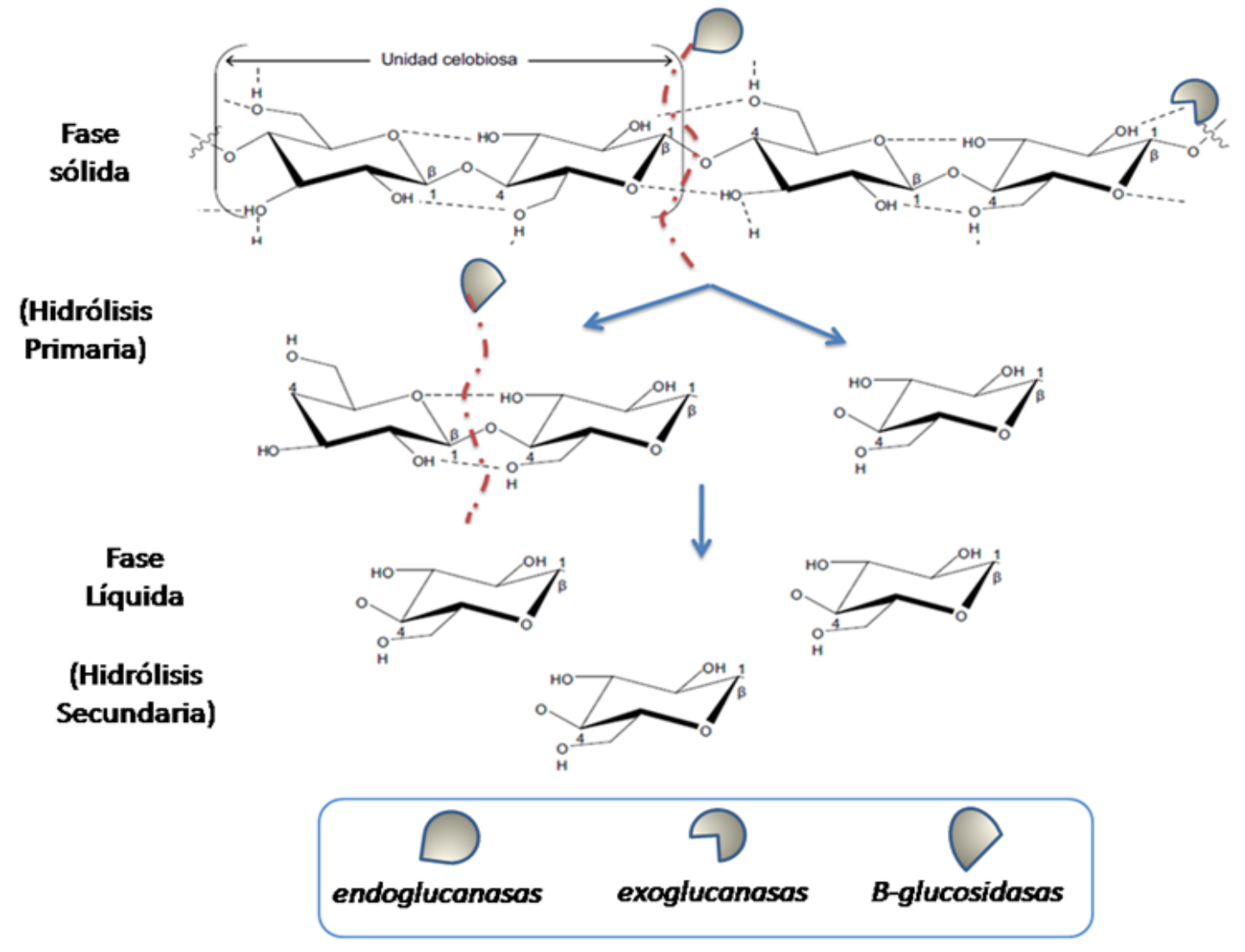

Figura 8. Esquema del mecanismo de hidrólisis enzimática de celulosa por celulasas (Dagnino, 2012).

La hidrólisis primaria se produce en la superficie de sólidos y libera azúcares solubles con un grado de polimerización de hasta 6 en la fase líquida. La hidrólisis secundaria, que se produce en la fase líquida, implica principalmente la hidrólisis de celobiosa a glucosa por $\beta$-glucosidasas (Dagnino, 2012).

La hidrólisis enzimática se lleva a cabo bajo condiciones suaves ( $\mathrm{pH}$ 4,5-5,0 y temperaturas entre 40 y $50^{\circ} \mathrm{C}$ ). Se ve influenciada por las características del sustrato (celulosa) y de la enzima y su modo de acción. 


\section{Características de las enzimas}

En lo que respecta a las enzimas influyen su origen, concentración, absorción, inhibición por productos finales, inactivación térmica $\left(\mathrm{T}>60^{\circ} \mathrm{C}\right.$ posible desnaturalización), sinergismo y actividad específica. Todos estos factores afectan colectivamente a la eficiencia enzimática (Yang et al, 2011).

\section{Características del sustrato}

Las características estructurales de la celulosa incluyen su cristalinidad, grado de polimerización (GP), superficie accesible, porosidad, organización estructural (macroestructura y microestructura), tamaño de partícula y presencia de materiales asociados como lignina y hemicelulosas (Sohrab et al, 2013; Soccol et al, 2011).

Grado de polimerización (GP): también llamado número de monómeros de glucosa por cadena de celulosa, depende de la historia y el origen de la celulosa. El GP de la celulosa nativa varía entre 8.000 y 10.000 unidades de monómero (Sjöström, 1993).

Cristalinidad: se determinacomo índice de cristalinidad (IC) y se obtienemediante difracción de rayos X. Es utilizado frecuentemente para describir la cantidad relativa de material cristalino en la celulosa (Park et al, 2010). Este índice se basa en un modelo simplificado que considera a la celulosa conformada por una regióncristalina y una región amorfa.

\section{Fermentación}

El proceso de fermentación de hexosas mediante el metabolismo de microorganismos puede ser representado como: $\mathrm{C}_{6} \mathrm{H}_{12} \mathrm{O}_{6} \rightarrow 2 \mathrm{CH}_{3} \mathrm{CH}_{2} \mathrm{OH}+2 \mathrm{CO}_{2}$

El rendimiento teórico es $0,511 \mathrm{~g}$ etanol/ g hexosa. 


\section{Microorganismos}

Tradicionalmente se ha usado las levaduras Saccharomyces cerevisiae y Zymomonas mobilis, ambas son capaces de fermentar eficientemente la glucosa a bioetanol pero no fermentan la xilosa. La levadura $S$. cerevisiae es el microorganismo más empleado para fermentar bioetanol en procesos industriales, entre sus ventajas se encuentran la fermentación anaeróbica de la glucosa y otras hexosas, la elevada productividad de etanol, su tolerancia al etanol e inhibidores presentes en hidrolizados de materiales lignocelulósicos, su osmotolerancia y rango de pHácido, además de ser un microorganismo considerado seguro (Vallejos, 2012).

Los azúcares de cinco carbonos pueden ser fermentados a bioetanol, en cuyo caso es necesario emplear otros microorganismos con capacidad para realizar dicho proceso, como ser las bacterias Escherichia coli o Pichia stipitis. Estos azúcares también pueden utilizarse para obtener productos de mayor valor agregado como ácidos carboxílicos (ejemplo ácido láctico), xilitol o furfural.

\section{Estrategias de fermentación (Balat, 2011)}

- Hidrólisis y fermentación separadas (SHF por sus siglas en inglés): en este tipo de proceso se realizan ambas etapas separadamente. La ventaja es que cada proceso se puede realizar ensus condiciones óptimas, mientras que la desventaja principal es la inhibición de las enzimas (celulasas y $\beta$-glucosidasas) por la liberación de glucosa en el proceso.

- Hidrólisis y fermentación simultáneas (SSF por sus siglas en inglés): como su nombre lo indica, ambos procesos se llevan a cabo simultáneamente, en un mismo reactor. La principal ventaja del proceso SSF es el consumo inmediato de los azúcares por los microorganismos produciendo bajas concentraciones de azúcar en el fermentador, lo que reduce significativamente la inhibición enzimática comparando con un proceso SHF. La principal desventaja del SSF es la temperatura óptima diferente requerida para la sacarificación y para la fermentación, $50{ }^{\circ} \mathrm{C}$ y35 ${ }^{\circ} \mathrm{C}$, respectivamente. Otra ventaja tecnológica incluida en este tipo de configuración es la co- 
fermentación de múltiples azúcares, por ejemplo: sacarificación simultánea de celulosa (a glucosa) y de hemicelulosas (a xilosa), y la co- fermentación de glucosa y xilosa a etanol por microorganismos modificados genéticamente en el mismo cultivo. Es posible encontrar este último esquema como sacarificación y co- fermentación simultánea (SSCF).

- Conversión microbiana directa (DMC por sus siglas en inglés). Este tipo de proceso combina la producción de celulasas, hidrólisis de la celulosa y fermentación de la glucosa en una sola etapa. Las ventajas del proceso son la reducción del número de reactores, la operación simple y la reducción de costos en químicos. Además, implica una reducción en los costos de capital para la compra o la producción separada de las enzimas y los costos operacionales asociados. Las desventajas incluyen los bajos rendimientos de etanol, causados por la formación de subproductos como acetato o lactato, la baja tolerancia de los microorganismos al bioetanol y el limitado crecimiento en el hidrolizado.

\section{Inhibidores de la fermentación}

La elección del pretratamiento de los materiales lignocelulósicos puede resultar en una variedad de inhibidores. Los compuestos predominantes y más investigados al momento son los furanos (furfural e hidroximetilfurfural), los ácidos carboxílicos y los compuestos fenólicos (Mohammad \& Keikhsro, 2011). Su posible formación se observa en el esquema de la Figura 9.

\section{Material lignocelulósico}

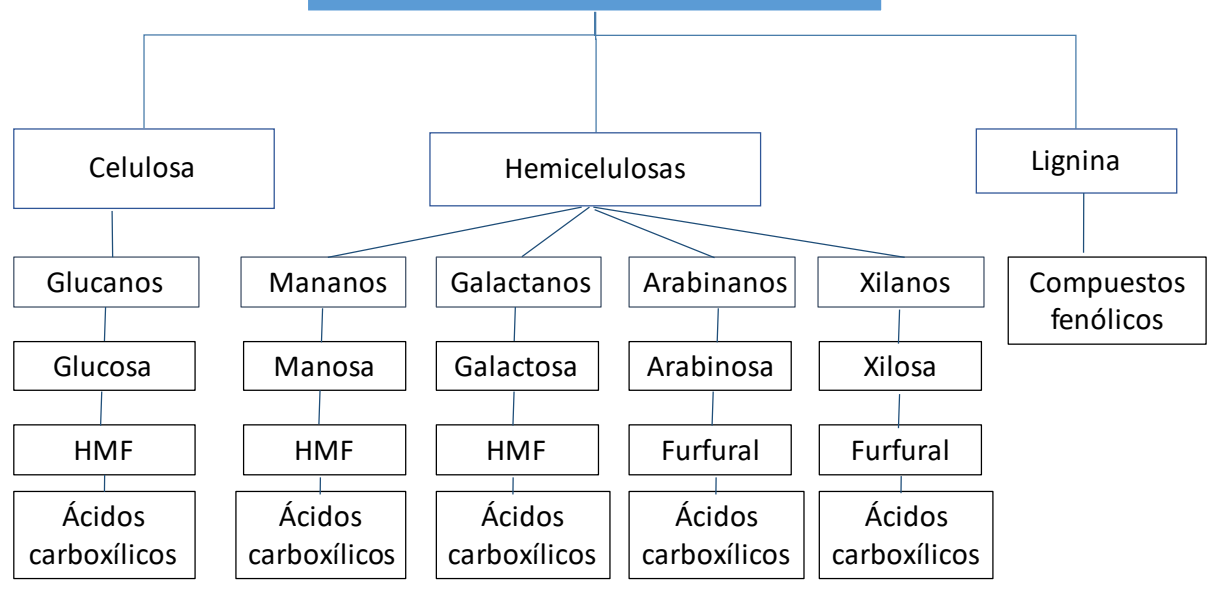

Figura 9. Productos de degradación. 
El furfural, formado a partir de pentosas, es uno de los más importantes inhibidores de la fermentación para muchos microorganismos (Figura 10).

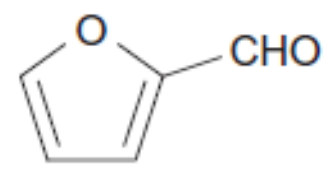

Figura 10.Furfural.

El hidroximetilfurfural (HMF, Figura 11) también es un derivado de la celulosa y otras hexosas.

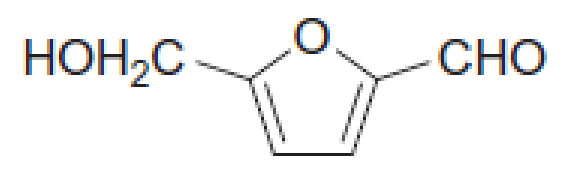

Figura 11. HMF.

Dentro de los ácidos carboxílicos se encuentran el ácido levulínico, el ácido fórmico y el ácido acético (Arora et al, 2013).Este último se forma principalmente a partir de los grupos acetilos.

Compuestos fenólicos: así como se degradan los carbohidratos también lo hace la lignina en la hidrólisis ácida y puede producir un amplio rango de compuestos fenólicos. Es necesario tener en cuenta que estos compuestos fenólicos también se pueden producir a partir de los extractivos. Los de menor peso molecular son los más tóxicos para los microorganismos. El tipo de compuesto depende del pretratamiento aplicado y de la estructura de la lignina. Los productos de degradación de la lignina reportados son: catecol, siringilaldehído, 4-hidroxibenzaldehído, vainillina, ácido vainillico, ácido 4-hidroxibenzoico, alcohol dihidroconiferil, coniferilaldehído y ácido siringico. Estos compuestos se dividen en tres grupos: 4-hidroxibencil $(\mathrm{H})$, guayacil $(\mathrm{G})$ y siringil $(\mathrm{S})$. Las ligninas de coníferas, que son las de interés en este trabajo, producen principalmente fenoles del tipo G (Mohammad \& Keikhsro, 2011). 


\section{CAPÍTULO II. HIPÓTESIS Y OBJETIVOS}

\section{Hipótesis}

La hipótesis del trabajo es que la calidad del material fibroso (específicamente, celulosa de diferente calidad y pureza proveniente de aserrines pretratados) tiene influencia sobre su conversión a bioetanol.

\section{Objetivos}

El objetivo general de este trabajo es encontrar los requisitos de calidad que debe poseer el material celulósico pretratado para su maximizar la conversión a bioetanol mediante procesos técnicamente viables y económicamente y ambientalmente sostenibles.

Los objetivos específicos involucran:

- Caracterizar materiales pretratados obtenidos a partir de aserrín de pino de diferente composición química y calidad.

- Verificar la capacidad de hidrólisis enzimática de los diferentes materiales, con vistas a su conversión a bioetanol.

- Verificar la influencia de la calidad de los diferentes hidrolizados sobre la producción de bioetanol por vía fermentativa.

- Plantear modelos empíricos que relacionen las características químicas de los materiales pretratados con su capacidad de conversión a bioetanol. Se consideran la cristalinidad y la pureza de la celulosa, así como la cantidad y calidad de la lignina y hemicelulosas, entre otros.

Este trabajo se enmarca en el aprovechamiento integral de residuos forestoindustriales de la región del nordeste argentino (NEA) para obtener productos de alto valor, utilizando procesos de baja contaminación y aportando al equilibrio ambiental global del entorno. 


\section{CAPITULO III. MATERIALES Y MÉTODOS}

\section{Materiales}

\section{Materias primas}

Todos los estudios que se presentan en esta tesis se realizaron con aserrín provisto por dos aserraderos de la provincia de Misiones (Argentina); el aserradero Forestal Eldorado ubicado en la zona norte y el aserradero Forestal AM ubicado en la zona sur. Ambos procesan principalmente Pinus elliottii. En todos los casos, para la caracterización de la materia prima se determinó humedad inicial (siendo la misma aproximadamente del 50\% en ambos casos). Luego, el aserrín se secó al aire hasta conseguir una humedad de equilibrio de entre 10 y $12 \%$. Posteriormente, se realizó un fraccionamiento grueso de todo el material para lo cual se utilizaron tamices con aberturas cuadradas de tres tamaños diferentes $(12,5 \mathrm{~mm}, 5 \mathrm{~mm}, 3 \mathrm{~mm})$. En la Tabla 1 se especifica la fracción empleada para cada pretratamiento.

Tabla 1. Fracción empleada para los pretratamientos. P: pasa, R: retenido.

\begin{tabular}{|c|c|c|}
\hline Pretratamiento & Fracción aserrín empleada & $\begin{array}{c}\text { Fuente del material a tratar } \\
\text { (condiciones de elaboración en la } \\
\text { referencia) }\end{array}$ \\
\hline HAD & P $3 \mathrm{~mm}$ & (Stoffel et al, 2014) \\
\hline EV & P $5 \mathrm{~mm} \mathrm{y} \mathrm{R} 3 \mathrm{~mm}$ & (Stoffel et al, 2017) \\
\hline Tratamientos alcalinos & P 3mm y R $80 \mathrm{mesh}(0,177 \mathrm{~mm})$ & (Imlauer et al, 2013) \\
\hline Organosolv (soda-etanol) & P $3 \mathrm{~mm}$ & (Kruyeniski et al, 2015) \\
\hline
\end{tabular}

El rango seleccionado para el pretratamiento con explosión de vapor se seleccionó para evitar compactación en el reactor. En cambio, a la fracción empleada en los tratamientos alcalinos (P 3mm) se le retiraron los finos (P 80 mesh) para evitar el taponamiento de la recirculación del licor.

Los extractivos en etanol, cenizas, lignina y carbohidratos se determinaron siguiendo las normas Laboratory Analytical Procedure (LAP) del National Renewable Energy Laboratory (NREL). La 
cuantificación de los ácidos, productos de degradación y azúcares se realizó por cromatografía líquida (HPLC).

Reactivos, enzimas y levaduras

Los reactivos utilizados fueron $\mathrm{NaOH}$ y $\mathrm{H}_{2} \mathrm{SO}_{4}$, ambos de grado analítico y etanol de grado azeotrópico (farmacéutico). Los patrones utilizados para las curvas de calibración de azúcares (celobiosa, glucosa, xilosa, arabinosa, manosa y galactosa), el standard interno (manitol) y los productos de degradación (furfural, HMF y ácido acético) fueron de Sigma Aldrich.

Se utilizaron enzimas comerciales: celulasas de Trichoderma Reesei y celobiasa de Aspergillus niger, de Sigma Adrich.

Para la fermentación se emplearon levaduras de Saccharomyces cerevisiae, provistas por el Centro de Investigaciónen químcia orgánica-biológica (QUIMOBI) dependiente del Instituto de Modelado e Innovacion Tecnologica (IMIT, UTN-CONICET). Se empleó: medio YDP (Yeast Peptone Dextrose), extracto de levadura, fosfato de potasio y sulfato de magnesio heptahidratado que fueron provistos por el mismo centro.

\section{Métodos}

Caracterización química de muestras sólidas (materias primas y sólidos pretratados)

La caracterización química del aserrín utilizado como materia prima, y de la fracción sólida resultante de los diferentes pretratamientos se llevó a cabo según normas del Laboratory Analytical Procedure, Technical Reports (NREL/TP). Las determinaciones se realizaron por duplicado. Un esquema del procedimiento de caracterización del material puede observarse en la Figura 12. 


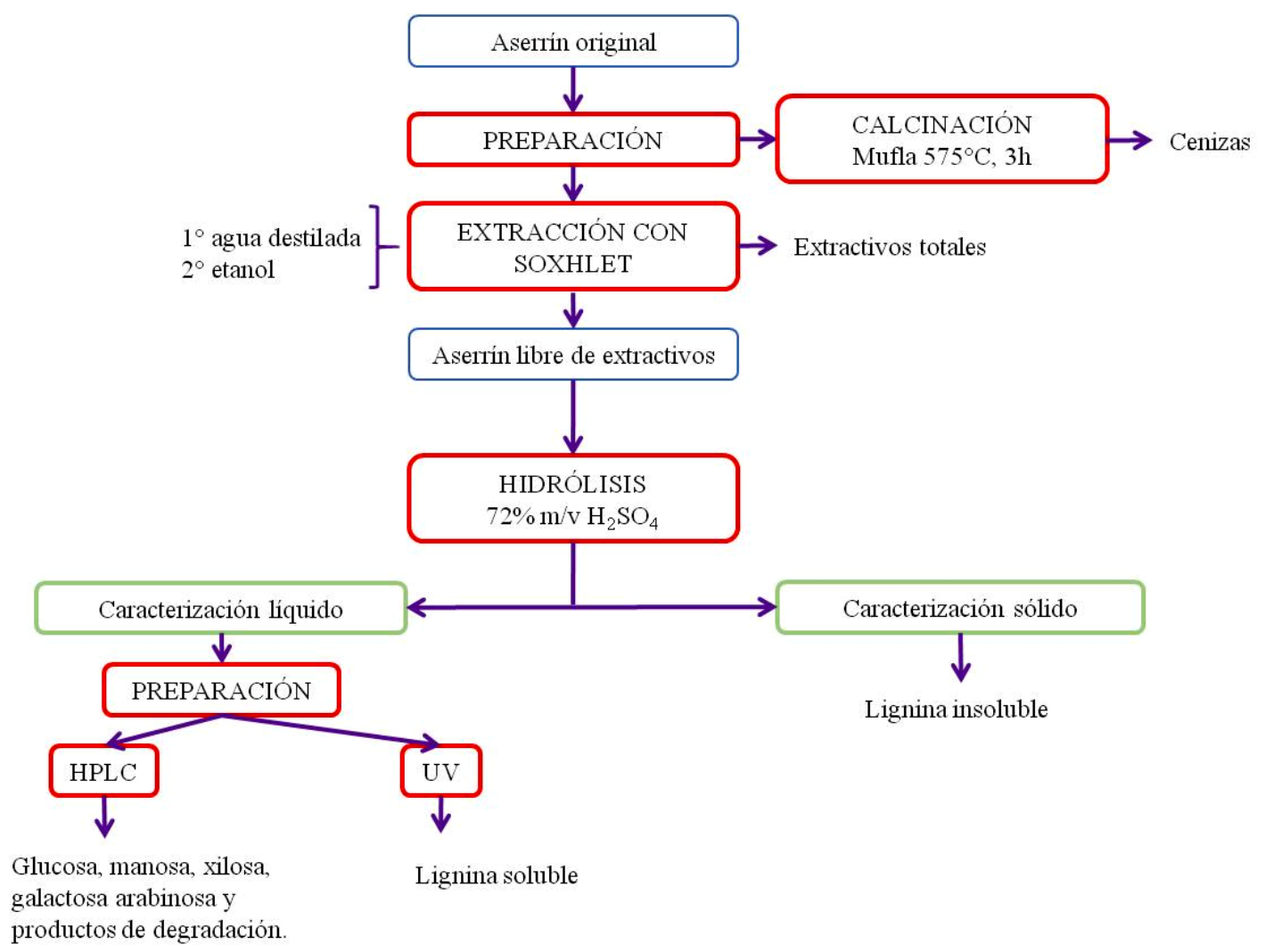

Figura 12. Esquema de caracterización del aserrín, antes y después de los tratamientos.

En la Tabla 2 se listan las normas empleadas para cada determinación.

Tabla 2. Procedimiento y norma NREL/TP correspondiente.

\begin{tabular}{|c|c|}
\hline Procedimiento & Norma NREL/TP \\
\hline Preparación de muestras para análisis de composición & $510-42620$ \\
\hline Determinación de sólidos totales y humedad & $510-42621$ \\
\hline Componentes extraíbles en agua y alcohol etílico & $510-42619$ \\
\hline Contenido de cenizas & $510-42622$ \\
\hline Determinación de carbohidratos estructurales y lignina & $510-42618$ \\
\hline
\end{tabular}

Los productos de degradación: furfural, HMF, ácido fórmico y ácido acético se determinaron por HPLC (Waters Corp. Massachusetts, USA) equipado con un inyector automático y una columna AMINEX-HPX87H, bajo las siguientes condiciones: solución $4 \mathrm{mM}$ de $\mathrm{H}_{2} \mathrm{SO}_{4}$ como eluyente, caudal 
de $0,6 \mathrm{~mL} / \mathrm{min}, 35^{\circ} \mathrm{C}$, y detector de arreglo de diodos (ácidos orgánicos a $210 \mathrm{~nm}$ y furfural e HMF a $254 \mathrm{~nm})$.

Los carbohidratos fueron analizados utilizando HPLC a travésuna columna SHODEX SP810 conectada en serie a una pre-columna deionizadoraBIORAD. Las condiciones utilizadas fueron: agua como eluyente, caudal de $0,6 \mathrm{~mL} / \mathrm{min}, 85^{\circ} \mathrm{C}$, y detector de Índice de Refracción (IR). Las muestras se prepararon neutralizando los hidrolizados empleando hidróxido de bario y agregando manitol como estándar interno para cuantificar la disolución producida en el transcurso de la neutralización de la muestra. Luego de neutralizar la muestra se centrifugó para separar el $\mathrm{BaSO}_{4}$ precipitado durante la reacción de neutralización de la fase líquida. El líquido sobrenadante $(30 \mathrm{~mL})$ se concentró hasta cuatro veces usando un evaporador rotativo hasta un volumen final de $5 \mathrm{~mL}$ aproximadamente. La muestra se colocó en un vial y se congeló hasta el momento de realización del análisis.

La hidrólisis de las cadenas de hemicelulosas implica la adición de una molécula de agua al residuo glucosídico, por lo tanto, es necesario considerar un factor estequiométrico para expresar el peso del componente como polímero en la madera. Para expresar los carbohidratos como homopolímeros (glucanos, mananos, xilanos, arabinanos y galactanos), se aplica la relación: (MM componente MM agua)/(MM componente). Para el caso de las hexosas es $(180-18) / 180=0,9)$ y para las pentosas $(150-18) / 150=0,88$ (Kaar et al, 1991).

\section{Pretratamientos}

Se realizó la hidrólisis enzimática de materiales sometidos a diferentes pretratamientos, según se muestra esquemáticamente en la figura 13. 


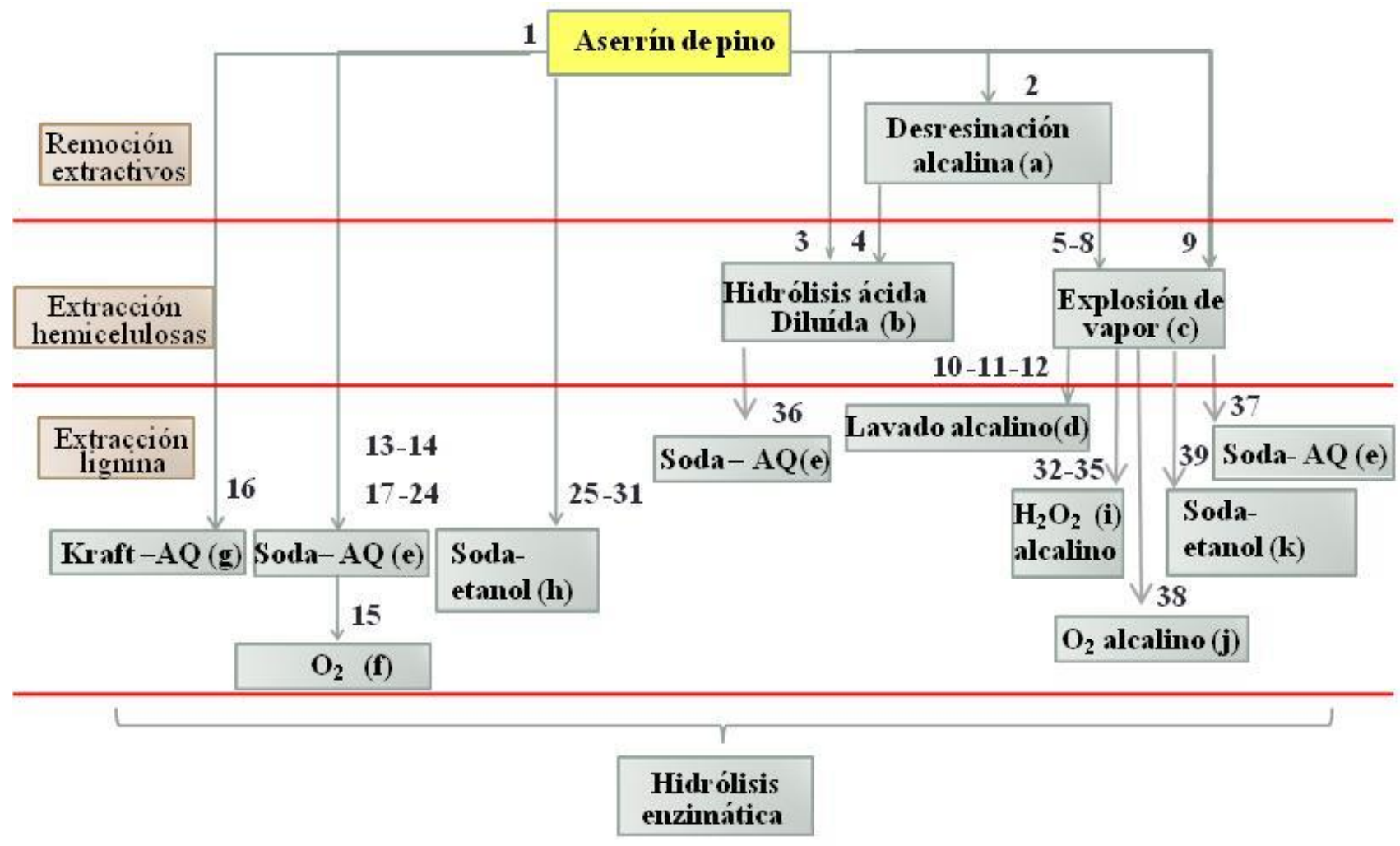

Figura 13. Esquema del origen de los diferentes materiales sometidos a hidrólisis enzimática. Los números especifican los números de experiencia.

La síntesis de los materiales pretratados se presenta en la Tabla 3.

Tabla 3.Condiciones de los pretratamientos de las diferentes muestras.

\begin{tabular}{|c|c|c|c|}
\hline $\mathbf{N}^{\mathbf{o}}$ & Pretratamiento & Condiciones & $\begin{array}{l}\text { Fuente del } \\
\text { material a tratar } \\
\text { (condiciones de } \\
\text { elaboración en } \\
\text { la referencia) }\end{array}$ \\
\hline $\begin{array}{l}1 \\
2 \\
3\end{array}$ & $\begin{array}{c}\text { Sin pretratamiento } \\
\text { Desresinación alcalina } \\
\text { Hidrólisis ácida diluida } \\
\text { Desresinación alcalina + } \\
\text { hidrólisis ácida diluida }\end{array}$ & $\begin{array}{c}--- \\
90{ }^{\circ} \mathrm{C}, 60 \mathrm{~min}, 5 \% \mathrm{smi} \mathrm{NaOH} \\
150{ }^{\circ} \mathrm{C}, 30 \mathrm{~min}, 7,5 \mathrm{~g} / \mathrm{L} \mathrm{H}_{2} \mathrm{SO}_{4} \\
90{ }^{\circ} \mathrm{C}, 60 \mathrm{~min}, 5 \% \mathrm{smi} \mathrm{NaOHy} 150{ }^{\circ} \mathrm{C}+30 \\
\min , 7,5 \mathrm{~g} / \mathrm{L} \mathrm{H}_{2} \mathrm{SO}_{4}\end{array}$ & $\begin{array}{l}\text { (Stoffel et al, } \\
\text { 2014) }\end{array}$ \\
\hline $\begin{array}{l}5 \\
6 \\
7 \\
8\end{array}$ & $\begin{array}{l}\text { Explosión de vapor }^{\text {(a) }} \\
\text { Explosión de vapor }^{\text {(a) }} \\
\text { Explosión de vapor }^{\text {(a) }} \\
\text { Explosión de vapor }^{\text {(a) }}\end{array}$ & 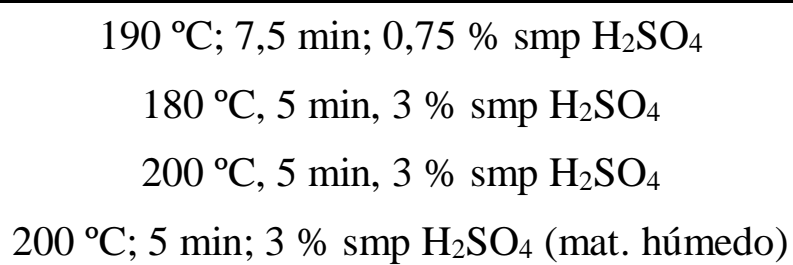 & $\begin{array}{c}\text { (Stoffel et al, } \\
\text { 2017) }\end{array}$ \\
\hline
\end{tabular}




\begin{tabular}{|c|c|c|c|}
\hline 9 & Explosión de vapor & $190{ }^{\circ} \mathrm{C} ; 7,5 \mathrm{~min} ; 0,75 \% \mathrm{smi} \mathrm{H}_{2} \mathrm{SO}_{4}$ & \\
\hline 10 & Explosión de vapor ${ }^{(a)(b)}$ & $180^{\circ} \mathrm{C}, 5 \mathrm{~min}, 3 \% \mathrm{smp} \mathrm{H}_{2} \mathrm{SO}_{4}$ & \\
\hline 11 & Explosión de vapor ${ }^{(a)(b)}$ & $200^{\circ} \mathrm{C}, 5 \mathrm{~min}, 3 \% \mathrm{smp} \mathrm{H}_{2} \mathrm{SO}_{4}$ & \\
\hline 12 & Explosión de vapor ${ }^{(b)}$ & $190^{\circ} \mathrm{C}, 7,5 \mathrm{~min} ; 0,75 \% \mathrm{smi} \mathrm{H}_{2} \mathrm{SO}_{4}$ & \\
\hline 13 & $\mathrm{NaOH}-\mathrm{AQ}^{(\mathrm{c})}$ & $25 \mathrm{~g} / \mathrm{L} \mathrm{NaOH}, 110 \mathrm{~min}, 170^{\circ} \mathrm{C}, \mathrm{RLM}: 10 / 1$ & \\
\hline 14 & $\mathrm{NaOH}-\mathrm{AQ}^{(\mathrm{c})}$ & $25 \mathrm{~g} / \mathrm{L} \mathrm{NaOH}, 170 \mathrm{~min}, 170^{\circ} \mathrm{C}, \mathrm{RLM}: 10 / 1$ & (Im \\
\hline 15 & $\mathrm{NaOH}-\mathrm{AQ}-\mathrm{O}_{2}{ }^{(\mathrm{c})}$ & $\begin{array}{c}25 \mathrm{~g} / \mathrm{L} \mathrm{NaOH}, 170 \mathrm{~min}, 170^{\circ} \mathrm{C}, \mathrm{RLM}: 10 / 1+ \\
120^{\circ} \mathrm{C}, 60 \mathrm{~min}, 10 \% \mathrm{~m} / \mathrm{m}^{+} \text {consistencia, } 5 \% \\
\text { smp } \mathrm{NaOH}, 6 \mathbf{~ k g ~ O} \mathrm{C}_{2} \mathrm{~cm}^{2}\end{array}$ & 2013) \\
\hline 16 & $\mathrm{Kraft}-\mathrm{AQ}^{(\mathrm{c})}$ & $25 \mathrm{~g} / \mathrm{L} \mathrm{NaOH}, 170 \mathrm{~min}, 170^{\circ} \mathrm{C}, \mathrm{RLM}: 10 / 1$ & \multirow{9}{*}{$\begin{array}{l}\text { (Imlauer et al, } \\
\text { 2014) }\end{array}$} \\
\hline 17 & $\mathrm{NaOH}-\mathrm{AQ}^{(\mathrm{c})}$ & $25 \mathrm{~g} / \mathrm{L} \mathrm{NaOH}, 110 \mathrm{~min}, 170^{\circ} \mathrm{C}, \mathrm{RLM}: 10 / 1$ & \\
\hline 18 & $\mathrm{NaOH}-\mathrm{AQ}^{(\mathrm{c})}$ & $25 \mathrm{~g} / \mathrm{L} \mathrm{NaOH}, 170 \mathrm{~min}, 170^{\circ} \mathrm{C}, \mathrm{RLM}: 10 / 1$ & \\
\hline 19 & $\mathrm{NaOH}-\mathrm{AQ}^{(\mathrm{c})}$ & $50 \mathrm{~g} / \mathrm{L} \mathrm{NaOH}, 108 \mathrm{~min}, 170^{\circ} \mathrm{C}, \mathrm{RLM}: 5 / 1$ & \\
\hline 20 & $\mathrm{NaOH}-\mathrm{AQ}^{(\mathrm{c})}$ & $50 \mathrm{~g} / \mathrm{L} \mathrm{NaOH}, 170 \mathrm{~min}, 170^{\circ} \mathrm{C}, \mathrm{RLM}: 5 / 1$ & \\
\hline 21 & $\mathrm{NaOH}-\mathrm{AQ}^{(\mathrm{c})}$ & $37,5 \mathrm{~g} / \mathrm{L} \mathrm{NaOH}, 185 \mathrm{~min}, 170^{\circ} \mathrm{C}$, RLM: $5 / 1$ & \\
\hline 22 & $\mathrm{NaOH}-\mathrm{AQ}^{(\mathrm{c})}$ & $19,8 \mathrm{~g} / \mathrm{L} \mathrm{NaOH}, 140 \mathrm{~min}, 170^{\circ} \mathrm{C}, \mathrm{RLM}: 10 / 1$ & \\
\hline 23 & $\mathrm{NaOH}-\mathrm{AQ}^{(\mathrm{c})}$ & $55,2 \mathrm{~g} / \mathrm{L} \mathrm{NaOH}, 140 \mathrm{~min}, 170^{\circ} \mathrm{C}$, RLM: 5/1 & \\
\hline 24 & $\mathrm{NaOH}-\mathrm{AQ}^{(\mathrm{c})}$ & $37,5 \mathrm{~g} / \mathrm{L} \mathrm{NaOH}, 140 \mathrm{~min}, 170^{\circ} \mathrm{C}$, RLM: $5 / 1$ & \\
\hline 25 & $\mathrm{EtOH}-\mathrm{NaOH}$ & $\begin{array}{c}\text { 35/65 etanol/agua, } 30 \mathrm{~g} / \mathrm{L} \mathrm{NaOH}, 60 \mathrm{~min}, \\
170^{\circ} \mathrm{C} \text {, RLM: } 5 / 1\end{array}$ & \multirow{7}{*}{$\begin{array}{c}\text { (Kruyeniski et al, } \\
\text { 2015) }\end{array}$} \\
\hline 26 & $\mathrm{EtOH}-\mathrm{NaOH}$ & $\begin{array}{c}\text { 35/65 etanol/agua, } 50 \mathrm{~g} / \mathrm{L} \mathrm{NaOH}, 60 \mathrm{~min} \text {, } \\
170^{\circ} \mathrm{C} \text {, RLM: } 5 / 1\end{array}$ & \\
\hline 27 & $\mathrm{EtOH}-\mathrm{NaOH}$ & $\begin{array}{c}\text { 35/65 etanol/agua, } 30 \mathrm{~g} / \mathrm{L} \mathrm{NaOH}, 90 \mathrm{~min} \text {, } \\
170^{\circ} \mathrm{C} \text {, RLM: } 5 / 1\end{array}$ & \\
\hline 28 & $\mathrm{EtOH}-\mathrm{NaOH}$ & $\begin{array}{c}\text { 35/65 etanol/agua, } 50 \mathrm{~g} / \mathrm{L} \mathrm{NaOH}, 90 \mathrm{~min} \text {, } \\
170^{\circ} \mathrm{C} \text {, RLM: } 5 / 1\end{array}$ & \\
\hline 29 & $\mathrm{NaOH}$ & $50 \mathrm{~g} / \mathrm{L} \mathrm{NaOH}, 90 \mathrm{~min}, 170^{\circ} \mathrm{C}, \mathrm{RLM}: 5 / 1$ & \\
\hline 30 & $\mathrm{NaOH}$ & $30 \mathrm{~g} / \mathrm{L} \mathrm{NaOH}, 90 \mathrm{~min}, 170^{\circ} \mathrm{C}, \mathrm{RLM}: 5 / 1$ & \\
\hline 31 & $\mathrm{EtOH}$ & 35/65 etanol/agua, $90 \mathrm{~min}, 170^{\circ} \mathrm{C}$, RLM: 5/1 & \\
\hline 32 & $\mathrm{H}_{2} \mathrm{O}_{2}$ alcalino $^{(\mathrm{d})}$ & $10 \%$ consistencia, $5 \% \operatorname{smp~} \mathrm{H}_{2} \mathrm{O}_{2}, 60 \mathrm{~min}, 90^{\circ} \mathrm{C}$ & \multirow{6}{*}{$\begin{array}{l}\text { (Stoffel R. B., } \\
\text { 2016) }\end{array}$} \\
\hline 33 & $\mathrm{H}_{2} \mathrm{O}_{2}$ alcalino ${ }^{(d)}$ & $\begin{array}{c}10 \% \text { consistencia, } 10 \% \operatorname{smp~} \mathrm{H}_{2} \mathrm{O}_{2}, 60 \mathrm{~min} \text {, } \\
90^{\circ} \mathrm{C}\end{array}$ & \\
\hline 34 & $\mathrm{H}_{2} \mathrm{O}_{2}$ alcalino ${ }^{(\mathrm{d})}$ & $\begin{array}{c}10 \% \text { consistencia, } 5 \% \text { smp } \mathrm{H}_{2} \mathrm{O}_{2}, 120 \mathrm{~min} \text {, } \\
90^{\circ} \mathrm{C}\end{array}$ & \\
\hline 35 & $\mathrm{H}_{2} \mathrm{O}_{2}$ alcalino $^{(\mathrm{d})}$ & $10 \%$ consistencia, $10 \% \mathrm{H}_{2} \mathrm{O}_{2}, 120 \mathrm{~min}, 90^{\circ} \mathrm{C}$ & \\
\hline 36 & $\mathrm{NaOH}-\mathrm{AQ}^{(\mathrm{e})}$ & $55,2 \mathrm{~g} / \mathrm{L} \mathrm{NaOH}, 140 \mathrm{~min}, 170^{\circ} \mathrm{C}, \mathrm{RLM}: 5 / 1$ & \\
\hline 37 & $\mathrm{NaOH}-\mathrm{AQ}^{(\mathrm{d})}$ & $55,2 \mathrm{~g} / \mathrm{L} \mathrm{NaOH}, 140 \mathrm{~min}, 170^{\circ} \mathrm{C}, \mathrm{RLM}: 5 / 1$ & \\
\hline
\end{tabular}




\begin{tabular}{|c|c|c|}
\hline 38 & $\mathrm{NaOH}-\mathrm{O}_{2}{ }^{(\mathrm{d})}$ & $\begin{array}{l}10 \% \text { consistencia, } 15 \% \mathrm{smp} \mathrm{NaOH}, 120 \mathrm{~min} \text {, } \\
100^{\circ} \mathrm{C}, 6 \mathrm{~kg} \mathrm{O}_{2} / \mathrm{cm}^{2}\end{array}$ \\
\hline 39 & $\mathrm{EtOH}-\mathrm{NaOH}^{(\mathrm{d})}$ & $\begin{array}{c}\text { 23/77 etanol/ agua, } 170^{\circ} \mathrm{C}, 140 \mathrm{~min}, 28 \% \text { smp } \\
\text { NaOH, RLM: } 6 / 1\end{array}$ \\
\hline
\end{tabular}

(a) sometido a previa desresinación alcalina $\left(60 \mathrm{~min}, 5 \% \mathrm{smi} \mathrm{NaOH}, 90^{\circ} \mathrm{C}\right)$; ${ }^{\text {(b) }}$ sometido a lavado alcalino posterior $\left(60^{\circ} \mathrm{C}, 60 \mathrm{~min}, 4 \% \mathrm{smp} \mathrm{NaOH}\right)$; $^{(\mathrm{c})} 0,11 \%$ AQsmi; (d) sometido a desresinación alcalina $\left(60 \mathrm{~min}, 5 \% \mathrm{smi} \mathrm{NaOH}, 90^{\circ} \mathrm{C}\right)+\mathrm{EV}\left(200^{\circ} \mathrm{C}, 5 \mathrm{~min}, 3 \% \mathrm{smp} \mathrm{H}_{2} \mathrm{SO}_{4}\right)$; ${ }^{(\mathrm{e})}$ sometido a desresinación alcalina $\left(60 \mathrm{~min}, 5 \% \operatorname{smi~NaOH}, 90^{\circ} \mathrm{C}\right)+\mathrm{HAD}\left(150^{\circ} \mathrm{C}, 30 \mathrm{~min}, 7,5 \mathrm{~g} / \mathrm{L} \mathrm{H}_{2} \mathrm{SO}_{4}\right)$.

Los detalles metodológicos de cada pretratamiento se describen a continuación.

\section{Breve descripción de los pretratamientos}

\section{a) Desresinación alcalina}

La desresinación alcalina fue realizada inicialmente en recipientes de vidrio de $250 \mathrm{~mL}$ calentados en agua caliente por $1 \mathrm{~h}$. Se emplearon 10 gramos (base seca) del aserrín de pino con una RLM (v/m): 10:1 ( $\sin$ agitación). Los recipientes se introdujeron en bolsas plásticas y luego en el baño a la temperatura deseada. Luego de la reacción los recipientes se enfriaron en hielo, y el licor fue separado del sólido por filtración con vacío. A su vez se realizó una prueba a mayor escala en un reactor de 7L (M/K Systems, Inc., Maryland) con recirculación de licor, empleando 500g de aserrín (base seca) con 5L de solución alcalina (RLM (v/m): 10). Al finalizar la reacción se separó el licor del sólido mediante centrifugación. El material sólido fue lavado exhaustivamente con agua.

Para más detalles acerca de las condiciones de cada experiencia de la desresinación alcalina se puede recurrir a Stoffel et al (2014).

Las condiciones de máxima remoción de extractivos, empleadas para las subsecuentes etapas (HAD, $\mathrm{EV}$ ) fueron $60 \mathrm{~min}, 90^{\circ} \mathrm{C}, 5 \% \mathrm{smi} \mathrm{NaOH}$ (Experiencia $\mathrm{N}^{\circ} 2$ ). Esos materiales fueron sometidos posteriormente a hidrólisis enzimática. 


\section{b) Hidrólisis ácida diluida (HAD)}

La etapa ácida se realizó con ácido sulfúrico en reactores de acero inoxidable de $200 \mathrm{~mL}$ calentados en un baño de glicerina (que se encuentra a la misma temperatura que la del pretratamiento). El tratamiento se aplicó al aserrín pretratado con álcali (desresinado) y al aserrín original como control. Se trabajó con 15 g secos de aserrín manteniendo una RLM de 10. Al finalizar la reacción, los reactores fueron enfriados instantáneamente con hielo. Con este sistema de reacción no existen rampas de tiempo de calentamiento y enfriamiento, son instantáneos. El material sólido fue separado del líquido mediante filtración con vacío, luego el material sólido fue lavado para extraer el licor residual. Las muestras líquidas se congelaron hasta su caracterización. Para evaluar este tipo de pretratamiento ácido se utiliza el factor de severidad combinada, que tiene en cuenta el pH además de temperatura y tiempo (factor de severidad). Para conocer las condiciones de cada experiencia de HAD se puede recurrir a Stoffel et al (2014).

Las condiciones de máxima remoción de hemicelulosas correspondientes al material que fue empleado para subsecuentes etapas (deslignificación), y sometido a hidrólisis enzimática fueron: 30 $\min , 150^{\circ} \mathrm{C}, 7,5 \mathrm{~g} / \mathrm{L} \mathrm{H}_{2} \mathrm{SO}_{4}$ (Experiencia $\mathrm{N}^{\circ} 3$ ) y $90{ }^{\circ} \mathrm{C}, 60 \mathrm{~min}, 5 \%$ smi $\mathrm{NaOH}+150{ }^{\circ} \mathrm{C}, 30 \mathrm{~min}, 7,5$ $\mathrm{g} / \mathrm{L} \mathrm{H}_{2} \mathrm{SO}_{4}$ (Experiencia $\left.\mathrm{N}^{\circ} 4\right)$.

\section{c) Explosión de vapor $(E V)$}

Este pretratamiento, como indica la figura 13, fue aplicado al aserrín pretratado con álcali y al aserrín original como control. Se realizó en un reactor de acero inoxidable de 10 L acoplado a una caldera de alta presión y un ciclón para ladescarga del material y de los vapores condensados.

En las experiencias se trataron 280 g de aserrín preimpregnadoscon ácido sulfúrico. La impregnación se realizó colocando el aserrín seco al aire (14\% humedad inicial) en bolsas plásticas y rociando una solución de $\mathrm{H}_{2} \mathrm{SO}_{4}$ hasta alcanzar un contenido de humedad de 50\%, manteniéndolas a temperatura ambiente toda la noche. Se experimentaron distintas condiciones: de temperatura $\left(180^{\circ} \mathrm{C}-200^{\circ} \mathrm{C}\right)$, de tiempo (5 min-10 min) y de concentración de ácido (1\% - 3\% $\left.\mathrm{H}_{2} \mathrm{SO}_{4}\right)$, Stoffel et al (2017). 
Los materiales que fueron posteriormente hidrolizados enzimáticamente se obtuvieron en las siguientes condiciones: experiencia 5 (7,5 minutos, $190{ }^{\circ} \mathrm{C}$ y $\left.0,75 \% \mathrm{H}_{2} \mathrm{SO}_{4}\right)$, experiencia $6(5$ minutos, $180{ }^{\circ} \mathrm{C}$ y $\left.3 \% \mathrm{H}_{2} \mathrm{SO}_{4}\right)$, experiencias 7 y 8 (5 minutos, $200{ }^{\circ} \mathrm{C}$ y $3 \% \mathrm{H}_{2} \mathrm{SO}_{4}$, en la experiencia 8 se empleó material húmedo). Todas las experiencias mencionadas anteriormente se realizaron sobre material desresinado, mientras que la $9\left(7,5\right.$ minutos, $190^{\circ} \mathrm{C}$ y $\left.0,75 \% \mathrm{H}_{2} \mathrm{SO}_{4}\right)$ se realizó sobre aserrín original. Como se mencionó, en este tipo de pretratamiento ácido se utiliza el factor de severidad combinada como factor de caracterización de las condiciones de proceso. Luego de la descompresión, el material sólido fue separado del licor por filtración a vacío y posteriormente lavado con agua mediante agitación mecánica.

\section{d) Lavado alcalino}

En algunos casos, elmaterial sólido proveniente de la EV se lavó adicionalmente con álcali. Los materiales con lavado alcalino posterior fueron: experiencia 10 (5min, $180{ }^{\circ} \mathrm{C}, 3 \% \mathrm{H}_{2} \mathrm{SO}_{4}$ ), experiencia $11\left(5 \mathrm{~min}, 200{ }^{\circ} \mathrm{C}, 3 \% \mathrm{H}_{2} \mathrm{SO}_{4}\right)$ y experiencia $12\left(7,5 \mathrm{~min}, 190{ }^{\circ} \mathrm{C}, 0,75 \% \mathrm{H}_{2} \mathrm{SO}_{4}\right)$; las experiencias 10 y 11 fueron previamente desresinadas, mientras que la 12 se realizó sobre aserrín original. Las condiciones del lavado alcalino fueron: temperatura de $60^{\circ} \mathrm{C} ; 0,4 \% \mathrm{smp} \mathrm{NaOH}$ y tiempo de 60 minutos Stoffel et al (2017). Todos los materiales mencionados fueron sometidos posteriormente a la hidrólisis enzimática.

\section{e) Deslignificación con Soda $-A Q$}

Las experiencias soda -AQ se realizaron variando la concentración álcali y el tiempo, con condiciones fijas: $0,11 \%$ AQsmi y $170^{\circ} \mathrm{C}$, variando la RLM de 5/1 a 10/1para alcanzar la carga alcalina deseada. Como variable se utilizó el factor $\mathrm{H}$ adaptado a procesos a la soda, que se calcula como (Ecuación 1) (Reguant et al, 1997): 


$$
H(h)=3,15 x 10^{20} x \int_{0}^{t(h)} e^{\left(\frac{-17614}{T(K)}\right)} d t
$$

\section{Ecuación 1}

El tratamiento se llevó a cabo en un digestor sin agitación de acero inoxidable, de 1 L de capacidad, con baño térmico (Imlauer et al, 2014). Posteriormente al tratamiento se separó la fracción líquida de la sólida mediante filtración y se lavó el material sólido. Las experiencias se realizaron variando el factor $\mathrm{H}$ y la concentración de hidróxido de sodio. Por ejemplo, se utilizó un factor de H 3000 y se varió $\mathrm{NaOH}(25,50 \mathrm{~g} / \mathrm{L})$ en las experiencias 13, 17 y 19. En las experiencias 14, 18 y 20; el factor H fue 4700 y se varió $\mathrm{NaOH}(25,50 \mathrm{~g} / \mathrm{L})$. En la experiencia 21 se empleó un factor $\mathrm{H} 5052$ y 37,5 g/L de $\mathrm{NaOH}$. En las experiencias 21, 22 y 23 el factor $\mathrm{H}$ fue 3850, variando la concentración de álcali $(19,82,55,2$ y $37,5 \mathrm{~g} / \mathrm{L})$.

También se deslignificaron con soda-AQ los materiales sometidos a desresinación alcalina $\left(90^{\circ} \mathrm{C}, 60\right.$ min, $5 \%$ smi $\mathrm{NaOH})$ y posteriormente a $\mathrm{HAD}\left(150^{\circ} \mathrm{C}, 30 \mathrm{~min}, 7,5 \mathrm{~g} / \mathrm{L} \mathrm{H}_{2} \mathrm{SO}_{4}\right)$ o $\mathrm{EV}\left(200^{\circ} \mathrm{C}, 5 \mathrm{~min}\right.$, $3 \% \mathrm{H}_{2} \mathrm{SO}_{4}$ ), correspondiendo a las experiencias 36 y 37 respectivamente. Las condiciones de deslignificación fueron: factor H 3850, 55,2 g/L NaOH y RLM 5/1 (Stoffel R. B., 2016).

Los materiales obtenidos de los pretratamientos antes detallados se sometieron a hidrólisis enzimática.

f) Deslignificación Soda-AQ-O $\mathrm{O}_{2}$

Se realizó una experiencia soda $-\mathrm{AQ}-\mathrm{O}_{2}$ en dos etapas. Ambas se llevaron a cabo en un digestor de 4L con agitación (Imlauer et al, 2013). Posteriormente a la etapa de soda-AQ parte de los sólidos resultantes de la primera etapa (sin filtrar ni lavar) se sometieron a la etapa de oxígeno. Las condiciones de la primera etapa fueron: $25 \mathrm{~g} / \mathrm{L} \mathrm{NaOH}$, RLM: $10,170^{\circ} \mathrm{C}, 0,11 \%$ smi $\mathrm{AQ}$, factor $\mathrm{H}$ de 4700 y de la segunda: $120^{\circ} \mathrm{C}, 60 \mathrm{~min}$, consistencia $10 \% \mathrm{~m} / \mathrm{m}, 5 \% \mathrm{smp} \mathrm{NaOH}$ y $6 \mathrm{~kg} \mathrm{O} / \mathrm{cm}^{2}$. 


\section{g) Deslignificación Kraft $-A Q$}

El tratamiento se llevó a cabo con una RLM igual a 10 en un digestor sin agitación de acero inoxidable, de $1 \mathrm{~L}$ de capacidad, con baño térmico. Las condiciones de dicha experiencia, que corresponde a la $\mathrm{N}^{\circ} 16$ fueron: factor $\mathrm{H} 2500,170^{\circ} \mathrm{C}, 0,11 \%$ AQ smi, $25 \mathrm{~g} / \mathrm{L} \mathrm{NaOH}$ y sulfidez de $20 \%$ smi (Imlauer et al, 2014).

El factor H para el proceso kraft se calcula según la ecuación 2 (Grace, Malcom, \& Kocurek, 1989).

$$
H(h)=\int_{0}^{t(h)} e^{\left(43,20-\frac{16113}{T(t)}\right)} d t
$$

\section{Ecuación 2}

\section{h) Deslignificación soda- etanol}

El pretratamiento soda-etanol fue llevado a cabo en un reactor de acero inoxidable (Figura 14) de 200mL cantado en baño de glicerina, donde se emplearon $20 \mathrm{~g}$ de aserrín (base seca) y $100 \mathrm{~mL}$ de 35:65 (v/v) etanol/ agua. La RLM fue 5:1 (v/m). Se varió la carga alcalina en 15 y 25\% smi y el tiempo en 60 y 90 minutos; estas experiencias se realizaron por duplicado. Las experiencias 25 y 26 se realizaron a menor tiempo (60 minutos) variando carga alcalina (15 y $25 \% \mathrm{smi})$, mientras que las experiencias 27 y 28 se realizaron a mayor tiempo (90 minutos) variando la carga alcalina entre 15 y 25\%. Tres experiencias adicionales fueron realizadas para evaluar el efecto de los reactivos separadamente (todas durante 90 minutos a temperatura máxima), dos sin etanol (experiencias 29 y 30) y una sin $\mathrm{NaOH}$ (experiencia 31). La temperatura máxima fue de $170^{\circ} \mathrm{C}$, el tiempo para alcanzar dicha temperatura fue de 20 minutos. 


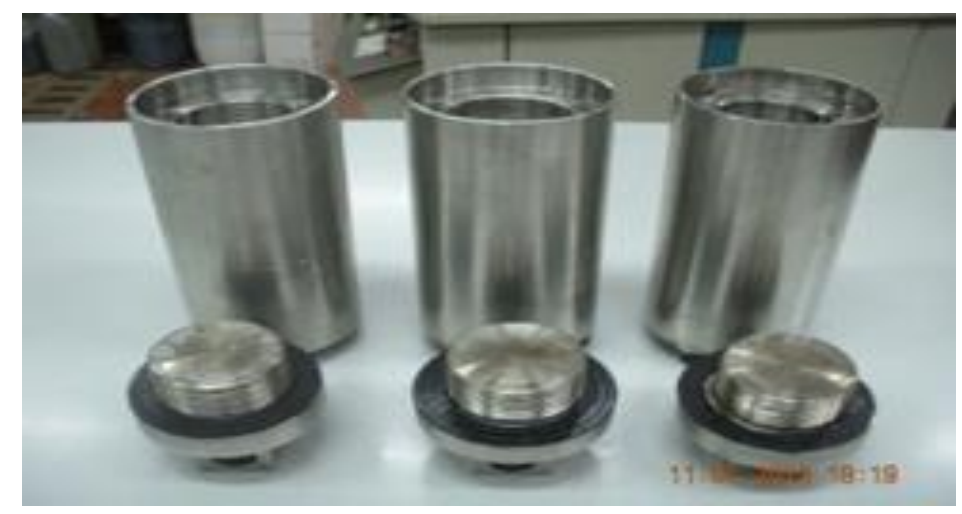

Figura 14. Reactores empleados en los tratamientos soda- etanol.

Al finalizar el tratamiento, el reactor fue enfriado en un baño de agua fría. El licor y el sólido fueron separados por filtración. El sólido fue lavado con agua y con una mezcla de agua y etanol, filtrado empleando papel de filtro y luego almacenado en bolsas plásticas a $4^{\circ} \mathrm{C}$.

\section{i) Deslignificación con peróxido de hidrógeno en medio alcalino de materiales pretratados con} ácido

Se aplicó un tratamiento con peróxido de hidrógenoa la fracción sólida resultante de la secuencia de fraccionamiento desresinación-EV $\left(90^{\circ} \mathrm{C}, 60 \mathrm{~min}, 5 \% \mathrm{smi} \mathrm{NaOH}+\mathrm{EV}\right.$ a $\left.200^{\circ} \mathrm{C}, 5 \mathrm{~min}, 3 \% \mathrm{H}_{2} \mathrm{SO}_{4}\right)$. Se realizaron 4 experiencias, donde se varió (en dos niveles) la concentración de peróxido de hidrógeno y el tiempo. Las experiencias 32 y 33 se realizaron con tiempo de 60 minutos y variando el peróxido entre 5 y 10\%, mientras que las experiencias 34 y 35 duraron 120 minutos variando peróxido en los niveles descriptos.

El pretratamiento se realizó en Erlenmeyers con 5 g secos de material a $10 \%(\mathrm{~m} / \mathrm{m})$ consistencia, a $90^{\circ} \mathrm{C}$ en un baño de agua caliente con agitación y el pH se ajustó a 11,5 con $\mathrm{NaOH}$. También se adicionó $0,1 \%$ sobre base seca de un compuesto quelante (DTPMPA), para evitar la descomposición del $\mathrm{H}_{2} \mathrm{O}_{2}$. Finalizada la reacción, se separaron las fracciones (sólida y líquida) mediante filtración al vacío, y el material sólido fue lavado con agua (Stoffel R. B., 2016). 
j) Deslignificación con oxígeno alcalino de materiales pretratados con ácido

El tratamiento con oxígeno también fue aplicado a la fracción sólida resultante de la secuencia de fraccionamiento: alcalina $\left(90^{\circ} \mathrm{C}, 60 \mathrm{~min}, 5 \% \mathrm{smi} \mathrm{NaOH}\right)$ seguida de $\mathrm{EV}\left(200^{\circ} \mathrm{C}, 5 \mathrm{~min}, 3 \% \mathrm{H}_{2} \mathrm{SO}_{4}\right)$. Se colocaron $80 \mathrm{~g}$ secos del material sólido mencionado previamente en el reactor, junto con $\mathrm{NaOH}$ y agua a una consistencia de $10 \%$ (se adicionó $0,1 \%$ de $\mathrm{MgSO}_{4}$ para evitar la degradación de la celulosa). Las condiciones de deslignificación (experiencia 38) fueron: $120 \mathrm{~min}, 100^{\circ} \mathrm{C}, 15 \% \mathrm{smp}$ $\mathrm{NaOH}$ y $6 \mathrm{~kg} \mathrm{O}_{2} / \mathrm{cm}^{2}$ de presión (Stoffel R. B., 2016). Al finalizar la reacción, el material sólido se filtró con vacío y se lavó con agua.

\section{k) Deslignificación $\mathrm{NaOH}$ - etanol de materiales pretratados con ácido}

El tratamiento organosolv alcalino también fue aplicado a la fracción sólida resultante de la secuencia de fraccionamiento: desresinación alcalina $\left(90{ }^{\circ} \mathrm{C}, 5 \% \mathrm{smi}\right.$, 60minutos $)+\mathrm{EV}\left(200^{\circ} \mathrm{C}\right.$, 5minutos, $3 \% \mathrm{H}_{2} \mathrm{SO}_{4}$ ), correspondiendo a la experiencia 39. Las condiciones aplicadas en esta deslignificación fueron: 140 minutos, $170^{\circ} \mathrm{C}, 28 \%$ smp $\mathrm{NaOH}$, relación etanol/agua de 23/77 y RLM igual a 6, con 30 minutos rampa de calentamiento (Stoffel R. B., 2016).

\section{Cristalinidad}

La cristalinidad del aserrín original y pretratado fue determinada mediante difracción de Rayos X. El aserrín fue molido (Figura 15) y secado a $40^{\circ} \mathrm{C}$ durante $48 \mathrm{~h}$. La fracción que pasa un tamiz de 80 mesh $(0,177 \mathrm{~mm})$ fue utilizada para el análisis. 


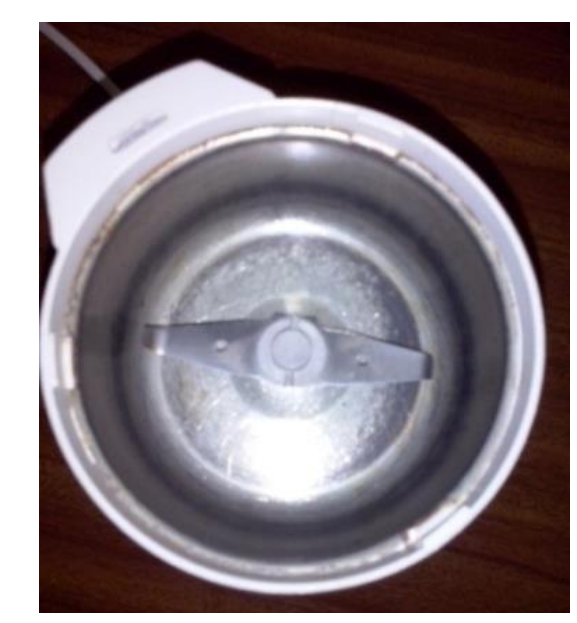

Figura 15. Molino utilizadopara acondicionar el material.

Para la obtención de los espectros correspondientes se utilizó un equipo de Difracción Philips X’ Pert- MDP con radiación de cobalto. La cantidad de muestra utilizada fue la necesaria para llenar el porta muestra. Los datos de difracción se obtuvieron por un modo de escaneado por pasos con una velocidad de barrido de 0,025 grados $(2 \theta) / \min$ en el rango de $5^{\circ}$ a $45^{\circ}$ grados $(2 \theta)$. La cristalinidad se determinó mediante el método de Segal, que permite determinar la cristalinidad relativa de la celulosa. Para su aplicación se asume que hay dos componentes del material celulósico: cristalino y no cristalino o amorfo. La cantidad de material cristalino está representada por la altura del pico más alto de difracción $\left(\mathrm{I}_{002}\right)$ y la región amorfa está representada por la altura del pico de la menor intensidad $\left(\mathrm{I}_{\mathrm{am}}\right)$ entre los picos principales. El índice de cristalinidad (IC) es simplemente la diferencia entre estos dos picos, dividido por la intensidad del pico más alto (French \& Cintrón, 2013), según la ecuación 3:

$$
I C=\left(\frac{I_{002}-I_{a m}}{I_{002}}\right) \times 100
$$

\section{Ecuación 3}

Los picos $\mathrm{I}_{002}$ e $\mathrm{I}_{\mathrm{am}}$ corresponden a $2 \theta=26^{\circ}$ y $21,5^{\circ}$. En la Figura 16 se observa un ejemplo de difractograma y los picos $\mathrm{I}_{002}$ e $\mathrm{I}_{\mathrm{am}}$. 


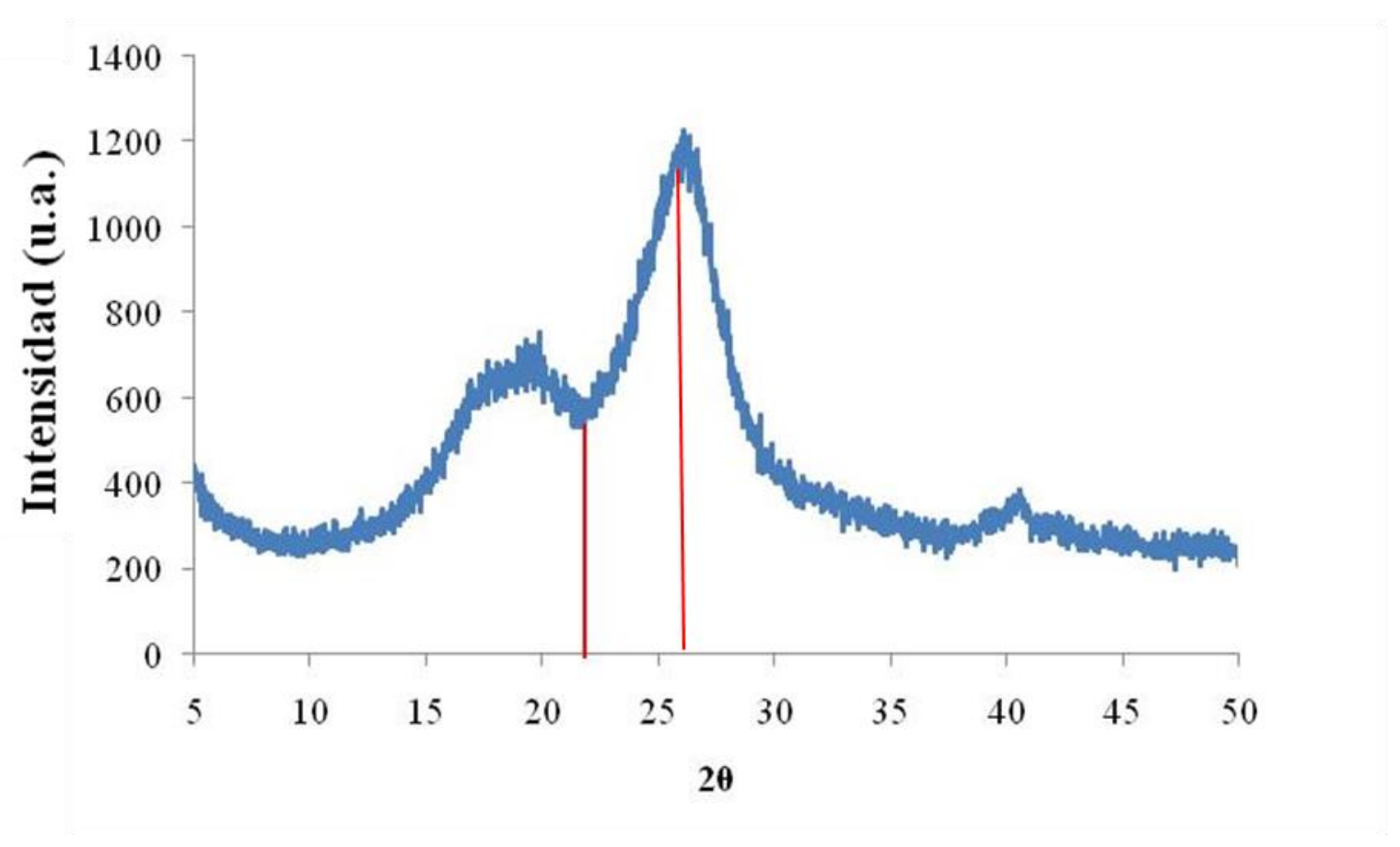

Figura 16. Ejemplo de difractograma.

\section{Porosidad}

La distribución del volumen de poro ha sido estudiada empleando la termoporosimetría (TP) mediante DSC (Differential Scanning Calorimetry), que es una técnica que permite determinar la distribución de tamaño de poros nanométricos en muestras saturadas en agua. Está basada en la depresión de la temperatura en el cambio de fase dentro del poro. El volumen de poro es derivado de la medición de los flujos de calor debido a la transición de fase. Las mediciones de TP-DSC fueron realizadas en un instrumento TA Q100 equipado con sistema de refrigeración (TA Refrigerated Cooling System 90). Se prepararon muestras húmedas de 0,5-2 mg (base seca) dentro de los platillos de aluminio Tzero y se sellaron herméticamente.

La técnica se aplicó de acuerdo con los procedimientos detallados en los artículos de Driemeier et al (2012) y Park et al (2006). Las muestras fueron inicialmente congeladas a $-70{ }^{\circ} \mathrm{C}$ y se fueron calentando en etapas de $5{ }^{\circ} \mathrm{C}$, fundiendo de manera controlada el hielo formado. La fusión de hielo se detectó calorimétricamente y se convirtió a masa de hielo. La fusión de hielo por debajo de $0{ }^{\circ} \mathrm{C}$ 
se debe a la fusión de hielo en los poros nanométricos, con diámetros de poros $\theta$ estimados a partir de la depresión de la temperatura de fusión $\Delta \mathrm{T}$ utilizando la relación de Gibbs-Thomson, $\theta=-$ $2 \mathrm{Kc} / \Delta \mathrm{T}$, donde $\mathrm{Kc}=19,8 \mathrm{~nm} \mathrm{~K}$. Las muestras se insertan en platillos de aluminio que son inmediatamente sellados con tapas herméticas y luego se pesan. Por diferencia entre el peso total y el peso del recipiente se calcula el peso de la muestra húmeda. Concluido el análisis, se perfora la tapa, se seca en estufa a $105^{\circ} \mathrm{C}$ por dos horas y se determina el peso de material seco.

El termograma resultante que luego es analizado se observa en la Figura 17 a.

El resultado de la técnica TP-DSC es una masa acumulativa de hielo confinado (llamado agua unida congelada, "freezing bound water", FBW) en función de $\theta$ (Figura 17 b). Para obtener la distribución de tamaño de poros, se divide la diferencia entre valores vecinos en la distribución acumulativa por la diferencia de valores de tamaño de poro (Figura 17 c) (UserCom 2/2000, 2016).
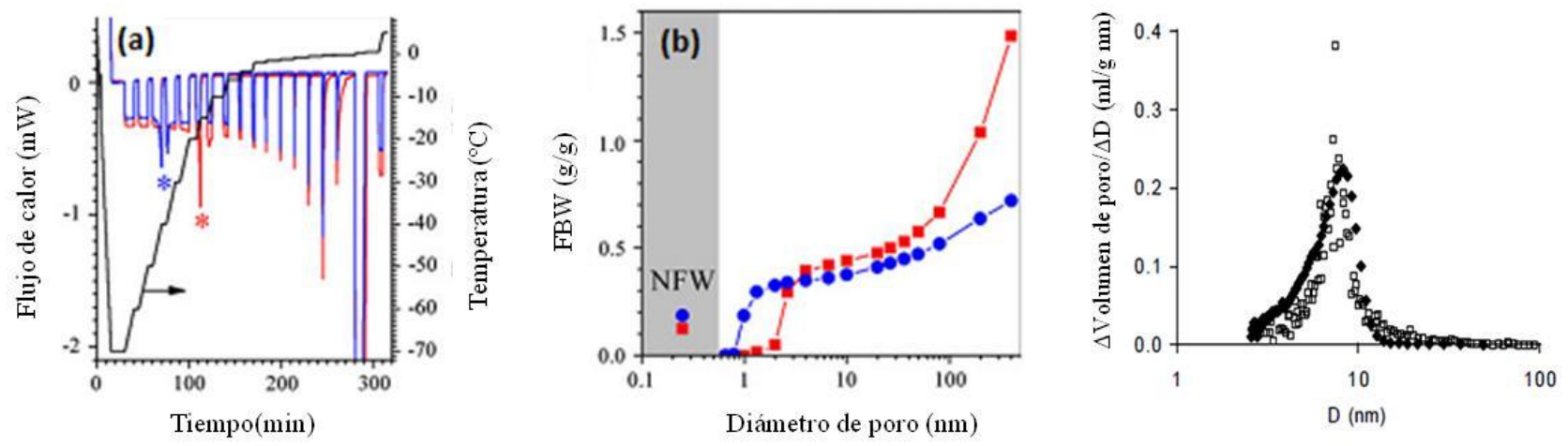

Figura 17. a) Termograma obtenido durante el análisis TP-DSC. b) Luego del análisis de los resultados. c) Ejemplo distribución tamaño de poros.

\section{Hidrólisis enzimática}

Los materiales sin tratamiento y pretratados fueron sacarificados por hidrólisis enzimática (HE), siguiendo la norma NREL-LAP (NREL/TP-510-42629) (Selig et al, 2008). La actividad de las celulasas es expresada en términos de unidades de papel de filtro (Filter Paper Units, FPU) por mililitro de solución enzimática sin diluir. La actividad de la $\beta$-glucosidasa se expresa en IU 
(International Units) que se define como la cantidad de enzima requerida para liberar un $\mu$ mol de azúcar reductor por minuto en condiciones estándares.

Los ensayos de HE se realizaron a $2 \%$ de consistencia (porcentaje de materia seca), 120rpm, pH 4,8 y $50^{\circ} \mathrm{C}$; con una carga enzimática de $20 \mathrm{FPU} / \mathrm{g}$ glucanos (celulasas) y $40 \mathrm{IU} / \mathrm{g}$ glucanos $(\beta$ glucosidasas). Las hidrólisis se llevaron a cabo en Erlenmeyers de vidrio de $50 \mathrm{~mL}$ manteniendo la temperatura y agitación en un baño térmico con agitación (Figura 18). Se pesó $1 \mathrm{~g}$ seco de material y se llevó a un peso final de 50 g con una solución buffer citrato de sodio 0,05 M, pH 4,8 (ácido cítrico más citrato de potasio). Se hizo vacío para evitar que el aire presente en el material sólido sea un obstáculo en el contacto entre el líquido y el material pretratado. Luego se agregó el volumen apropiado de enzimas con micropipeta. Se monitoreó la reacción cada 24 horas hasta las 72 horas. Se realizaron las experiencias por duplicado.

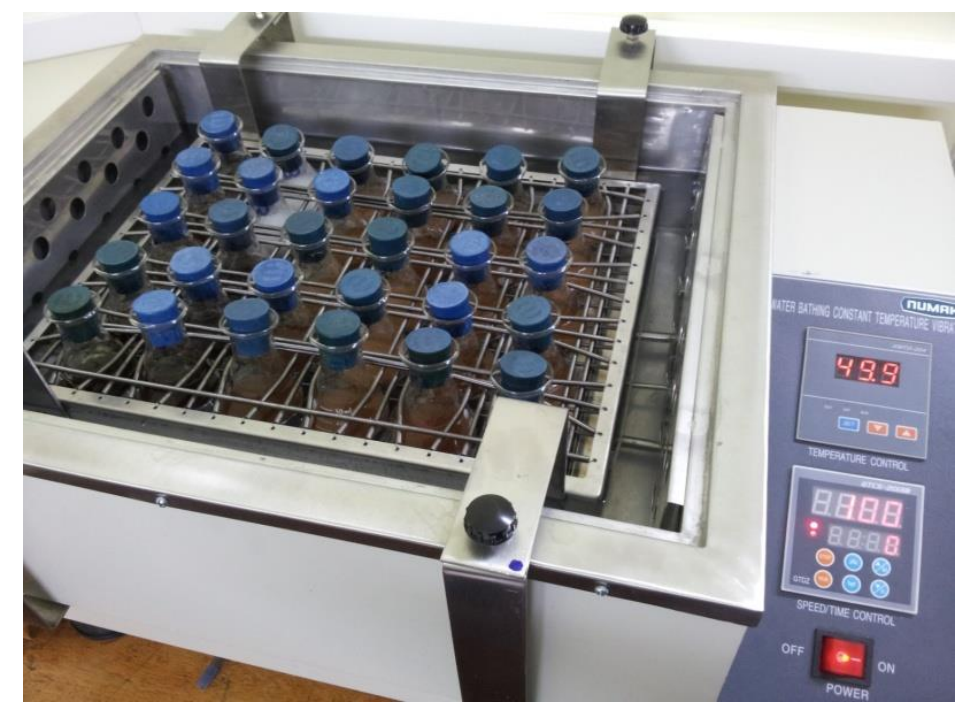

Figura 18. Hidrólisis enzimática en proceso.

Los rendimientos de la hidrólisis se calcularon a diferentes tiempos (24, 48 y 72 horas) como indica la ecuación 4.

$$
\operatorname{RHE}(\%)=\frac{\text { g glucosax } 0,9}{\text { g glucanos en la biomasa inicial }} \times 100 \quad \text { Ecuación } 4
$$


Se multiplica por el factor estequiométrico 0,9 para expresar la concentración de glucosa como glucanos.

\section{Actividades enzimáticas}

Como paso previo al desarrollo de las reacciones de hidrólisis enzimática se determinó la actividad enzimática de las enzimas comerciales (Figura 19).

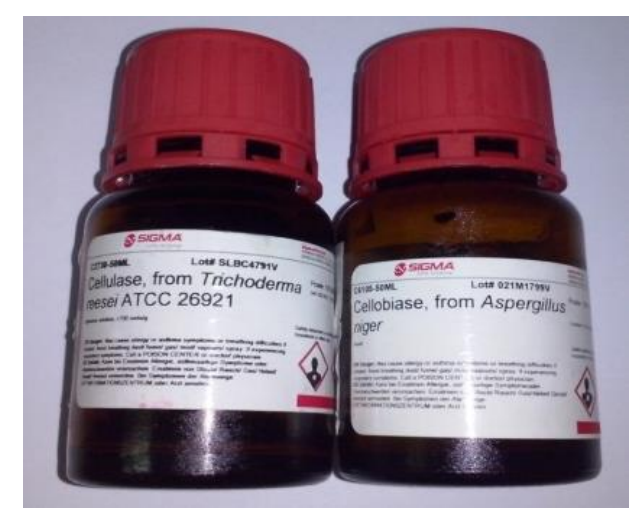

Figura 19. Frascos de enzimas comerciales.

\section{$\underline{\text { Actividad de las celulasas }}$}

La actividad de las celulasas se determinó de acuerdo con la norma NREL/TP-510-42628. Esta norma cuantifica la acción conjunta de las tres enzimas (EGs, BGLs y CBHs) mediante la técnica del papel de filtro (Ghose, 1987). Se preparó una solución madre de enzimas (dilución 1:20) y luego se realizaron diferentes diluciones de la misma, se incubaron $0,3 \mathrm{~mL}$ de cada dilución enzimática con $0,03 \mathrm{~g}$ de papel de filtro Whatman $\mathrm{N}^{\circ} 1$ y $0,6 \mathrm{~mL}^{2}$ de buffer acetato de sodio $50 \mathrm{mM}(\mathrm{pH} 4,8)$ a $50^{\circ} \mathrm{C}$ durante 60min. Se hizo cada dilución por triplicado y adicionalmente se preparó un blanco del buffer, un control de la enzima y un control del sustrato.Al final del tiempo se interrumpió la reacción con

\footnotetext{
${ }^{2}$ Se hizo una reducción de escala original de la norma (6/10), para adaptar a las cubetas disponibles del espectrofotómetro.
} 
1,8mL de DNS (ácido dinitrosalicílico) y luego se hirvió durante 5 minutos. Se midió la absorbancia a 540nm. El método del DNS mide los azúcares reductores liberados, usando glucosa como estándar (Miller, 1959).

El procedimiento ha sidodiseñado para medir laactividad de las celulasasen términosde"Unidades de Papel de Filtro" (FPU) por mililitro desolución original de enzima (sin diluir). Esta unidad mide la cantidad de enzima que es necesaria para producir $2 \mathrm{mg}$ de azúcar reductor a partir de $50 \mathrm{mg}$ de papel de filtroWhatman $\mathrm{N}^{\mathrm{o}} 1$ (4\% de conversión) en 60minutos de reacción, en las condiciones óptimas de operación de la enzima.

\section{$\underline{\text { Actividad de las } \beta \text {-glucosidasas }}$}

La actividad de las $\beta$-glucosidasas se determinó por su capacidad de hidrolizar el p-nitrofenol- $\beta$-Dglucopiranósido (p-NPG) a 4-nitrofenol (p-NP). La metodología consiste en agregar $2 \mathrm{~mL}$ de solución $1 \mathrm{mmol} / \mathrm{L}$ de $\mathrm{p}$-NPG e inmediatamente $0,5 \mathrm{~mL}$ de diferentes diluciones de enzima, incubar 30 min a $50^{\circ} \mathrm{C}$, detener la reacción con $2,5 \mathrm{~mL} \mathrm{Na}_{2} \mathrm{CO}_{3}$, y medir la absorbancia a 400nm (Matsuura et $a l, 1995)$. Las muestras se realizan por triplicado y adicionalmente se prepara un blanco para la curva de calibración y el control del sustrato y de la enzima.

\section{Fermentación}

Para la selección de muestras a fermentar se consideraron hidrolizados enzimáticos de pretratamientos ácidos y alcalinos, debido a que generan licores que posiblemente posean distintos inhibidores.

El cultivo de Saccharomyces cerevisiae se compuso de 50mL de medio YDP (dextrosa 10 g/L, peptona de carne $10 \mathrm{~g} / \mathrm{L}$ y extracto de levadura $10 \mathrm{~g} / \mathrm{L}$ ). El inóculo fue autoclavado a $120^{\circ} \mathrm{C}$ durante 60 minutos. Se determinó la tasa de crecimiento mediante cámara de Neubauer. 
La fermentación de las muestras de hidrolizados seleccionadas de la HE fueron llevadas a cabo a 30 ${ }^{\circ} \mathrm{C}$, pH 4,8 en condiciones anaeróbicas durante $48 \mathrm{~h}$. Las experiencias se llevaron a cabo en Erlenmeyers de $100 \mathrm{~mL}$ cerrados en la parte superior con papel de aluminio, previamente esterilizados. Los hidrolizados fueron enriquecidos con los siguientes micronutrientes: extracto de levadura $0,5 \mathrm{~g} / \mathrm{L}$, fosfato de potasio $0,025 \mathrm{~g} / \mathrm{L}$ y sulfato de magnesio heptahidratado $0,25 \mathrm{~g} / \mathrm{L}$. Cada muestra fue inoculada con $10 \%(\mathrm{~m} / \mathrm{m})$ del cultivo de crecimiento. El rendimiento de etanol (porcentaje sobre el máximo teórico) fue calculado acorde a la ecuación 5:

$$
\text { Rendimiento etanol } \%=\frac{[\text { etanol producido }(g / L)]}{[0,51 \times \text { glucosa en la muestra }(g / L)]} x 100
$$

Ecuación 5

Donde 0,51 es un factor estequiométrico

El etanol y el contenido de glucosa residual fueron medidos con HPLC, utilizando la columna AMINEX HPX-87H mencionada anteriormente, con las condiciones: fase móvil $4 \mathrm{mM} \mathrm{H}_{2} \mathrm{SO}_{4}$, 0,6 $\mathrm{mL} / \mathrm{min}, 35^{\circ} \mathrm{C}$, detector índice de refracción.

\section{Análisis estadístico}

Los resultados obtenidos se analizaron estadísticamente utilizando el programa STATGRAPHICS CenturionXV.II. Se realizaron, según el caso, comparaciones de medias y análisis de varianza (ANOVA). Se buscaron correlaciones entre factores (contenido lignina, hemicelulosas, IC, entre otros) frente al rendimiento de la hidrólisis enzimática. Se realizaron ajustes de regresión con líneas de tendencia entre el rendimiento de la hidrólisis enzimática y los componentes químicos de los materiales. El nivel de confianza empleado fue en todos los casos igual a $95 \%$. 


\section{CAPITULO IV. RESULTADOS Y DISCUSIÓN}

\section{Materias primas}

\section{Caracterización de las enzimas}

$\underline{\text { Actividad enzimática de las celulasas }}$

Para determinar la actividad de las celulasas, las dilucionesa partir de la "solución madre" se observan en la Tabla 4. La "solución madre" de celulasas es una dilución 1:20 del complejo enzimático.

Tabla 4. Diluciones empleadas para determinar actividad celulasas.

\begin{tabular}{|c|c|c|c|c|c|c|}
\hline $\mathbf{N}^{\mathbf{0}}$ & 1 & 2 & 3 & 4 & 5 & 6 \\
\hline Dilución & 100 & 133,33 & 160 & 200 & 400 & 500 \\
\hline
\end{tabular}

En la Figura 20se observa el gráfico resultante, donde el valor de interés para la dilución empleada es la liberación de 1,2mg de glucosa (por el cambio de escala), correspondiendo 0,00722 de “concentración de la enzima".

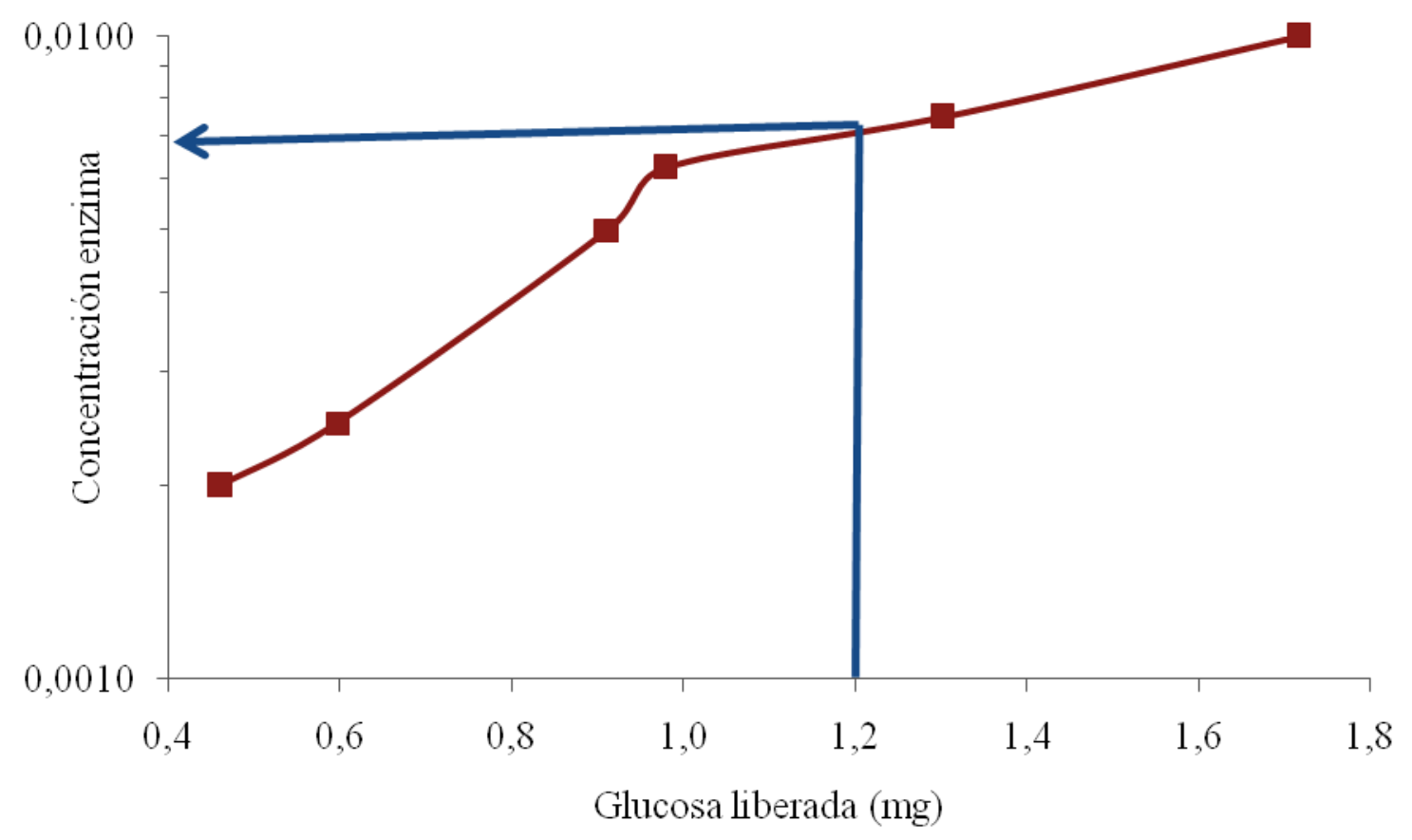

Figura 20. Gráfico para la determinación de la actividad de las celulasas. 
Para calcular la actividad de las celulasas se recurre a la ecuación 6.

Actividad celulasas $=\frac{0,37}{[\text { Enzima }] \text { que libera 1,2mg glucosa }}=\frac{0,37}{0,00722}=51 \mathrm{FPU} / \mathrm{mL} \quad$ Ecuación 6

Donde el valor 0,37 proviene de la ecuación 7.

$0,37 \mu \mathrm{mol} / \min m L=\frac{1,2 \text { mgglucosa }}{0,3 m L \text { dilución enzimax } 60 \text { minutos }} \quad$ Ecuación 7

Este valor es coincidente con los valores encontrados por otros autores para celulasas comerciales (Kumar et al, 2002).

Actividad $\beta$-glucosidasas o celobiasas

Se logran mejores resultados de sacarificación con la adición de $\beta$-glucosidasas a un complejo de celulasas de $T$. reesei. Las $\beta$-glucosidasas hidrolizan la celobiosa, inhibidora de la actividad de las celulasas (Sun \& Cheng, 2002). Las celobiasas empleadas fueron de Aspergillus Niger.

Se realizaron las diluciones que se observan en la Tabla 5a partir de una solución madre de las enzimas $(50 \mu \mathrm{L}$ en $50 \mathrm{~mL}$ de solución buffer $)$.

Tabla 5. Diluciones realizadas con la solución madre de las celobiasas para determinar actividad.

\begin{tabular}{|c|c|c|c|c|c|}
\hline $\mathbf{N}^{\mathbf{0}}$ & 1 & 2 & 3 & 4 & 5 \\
\hline FD (factor de dilución) & 10.000 & 20.000 & 40.000 & 50.000 & 10.000 \\
\hline
\end{tabular}

Las diluciones 2, 3, 4 y 5 están en el rango de la calibración y lectura espectrofotómetro, pero para disminuir el error se considera para el cálculo la de menor dilución (20.000). La actividad se calcula según la ecuación 8.

Actividad $\beta-$ glucosidasas $(U I)=\frac{[p-N P] \times F D x V r}{t \times V e}=\frac{0,102 \times 20.000 \times 2,5}{30 \times 0,5}=339$ UI Ecuación 8 
Donde:

[p-NP]: es la concentración del p-NP en $\mu \mathrm{mol} / \mathrm{mL}$

FD: factor de dilución

Vr: volumen de reacción $(\mathrm{mL})$

Ve: volumen de la enzima $(\mathrm{mL})$

$\mathrm{t}$ : tiempo (minutos)

UI: $\mu \mathrm{mol} / \min \mathrm{mL}$

Nuevamente, el valor hallado es similar al valor encontrado en otro trabajo para $\beta$-glucosidasas comerciales (Kumar et al, 2010).

\section{Caracterización física y química de la materia prima}

El empleo de aserrín presenta una ventaja adicional respecto del uso de chips u otro tipo de residuo de mayor tamaño en lo que respecta a su granulometría, ya que en los procesos de fraccionamiento el tamaño inicial de partícula es un factor importante en la efectividad de la penetración de los reactivos y la disolución de las fraccionesde la madera.

Como vemos en la Tabla 6, en ambos casos la fracción que pasa aberturas de 3mm (P 3mm) es la de mayor proporción.

Tabla 6. Resultados caracterización física según tamaño tamices (R: retenido, P: pasa) para cada aserrín proveniente de cada aserradero.

\begin{tabular}{|c|c|c|c|c|}
\hline \multirow{2}{*}{ Aserradero } & \multicolumn{4}{|c|}{ Fracciones (\%) } \\
\cline { 2 - 5 } & R 12,5 $\mathbf{~ m m}$ & R 5 $\mathbf{~ m}$ & R 3 $\mathbf{~ m m}$ & P 3 $\mathbf{~ m}$ \\
\hline Forestal Eldorado & 2,0 & 14,9 & 26,0 & 57,1 \\
\hline Forestal AM & 2,3 & 4,2 & 27,7 & 65,9 \\
\hline
\end{tabular}

La Tabla 7 muestra el análisis químico de los aserrines. Si bien en el trabajo se considera a los glucanos como celulosa, una fracción pequeña de los mismos (aproximadamente el 2\%) proviene de las hemicelulosas. 
La composición es coincidente con la composición típica de una conífera, con un alto contenido de lignina insoluble y de hexosas (Zhu et al, 2009; Amiri \& Karimi, 2016).

Tabla 7. Análisis químico de los aserrines según el origen.

\begin{tabular}{|c|c|c|}
\hline Componente (\% smi) & Forestal Eldorado & Forestal AM \\
\hline Glucanos & 46,62 & 39,85 \\
\hline Xilanos & 7,30 & 6,50 \\
\hline Galactanos & 2,24 & 1,99 \\
\hline Arabinanos & 1,13 & 1,34 \\
\hline Mananos & 10,18 & 10,68 \\
\hline Acetilos & 1,13 & 1,81 \\
\hline Lignina insoluble en ácido & 27,22 & 30,48 \\
\hline Lignina soluble en ácido & 0,45 & 0,93 \\
\hline Extractivos en agua & 1,24 & 1,24 \\
\hline Extractivos en alcohol & 3,47 & 2,28 \\
\hline Cenizas & 0,26 & 0,26 \\
\hline
\end{tabular}

El rendimiento de hidrólisis enzimática (a las 72h) de ambos aserrines sin pretratar fue bajo, 3,80\% para Forestal Eldorado y 5,40\% para Forestal AM. Este comportamiento se explica por la presencia de todos los componentes químicos, lo que es un impedimento para que las enzimas tomen contacto pleno con la celulosa. Estos resultados son próximos a los obtenidos por otros autores para pino, por ejemplo, un valor reportado para Pinus strobes L.es 10,2\% (Tian et al, 2016) y para aserrín de pino amarillo del sur es 12,8\% (Kim \& Hong, 2001).

\section{Pretratamientos y respuesta a la hidrólisis enzimática}

Las caracterizacionesrealizadas mediante HPLC usando la columna SHODEX se observan en la Tabla 8 y las que se realizaron empleando la columna AMINEX en la Tabla 9. Ambas tablas incluyen también la digestibilidad a las 72 horas. 
Tabla 8. Caracterización química de las muestras sometidas a diferentes pretratamientos determinada mediante HPLC usando la Columna Shodex.

\begin{tabular}{|c|c|c|c|c|c|c|c|}
\hline $\begin{array}{c}\text { Experiencia } \\
\mathrm{N}^{\mathrm{o}}\end{array}$ & $\begin{array}{l}\text { Glucanos } \\
\text { (\% smp) }\end{array}$ & $\begin{array}{l}\text { Xilanos } \\
\text { (\% smp) }\end{array}$ & $\begin{array}{l}\text { Mananos } \\
\text { (\% smp) }\end{array}$ & $\begin{array}{c}\text { Galactanos } \\
\text { (\% smp) }\end{array}$ & $\begin{array}{c}\text { Arabinanos } \\
\text { (\% smp) }\end{array}$ & $\begin{array}{l}\text { Lignina } \\
\text { (\% smp) }\end{array}$ & $\begin{array}{c}\text { RHE } \\
(\%)\end{array}$ \\
\hline 2 & 44,88 & 6,97 & 10,13 & 0,00 & 0,00 & 28,65 & 4,5 \\
\hline 3 & 52,20 & 2,80 & 2,67 & 0,00 & 0,00 & 39,25 & 7,7 \\
\hline 4 & 52,25 & 2,59 & 5,59 & 0,00 & 0,00 & 36,56 & 7,5 \\
\hline 5 & 48,40 & 3,40 & 9,60 & 0,00 & 0,00 & 35,40 & 5,4 \\
\hline 6 & 51,01 & 1,72 & 3,51 & 0,00 & 0,00 & 39,90 & 11,7 \\
\hline 7 & 52,53 & 0,75 & 2,07 & 0,00 & 0,00 & 42,50 & 24,1 \\
\hline 8 & 42,60 & 0,00 & 1,30 & 0,00 & 0,00 & 49,86 & 20,3 \\
\hline 9 & 48,60 & 0,90 & 1,00 & 0,10 & 0,00 & 43,81 & 17,3 \\
\hline 10 & 53,60 & 1,50 & 2,70 & 0,00 & 0,00 & 39,90 & 10,7 \\
\hline 11 & 55,00 & 0,90 & 2,30 & 0,00 & 0,00 & 39,40 & 11,0 \\
\hline 12 & 53,40 & 1,40 & 0,90 & 0,00 & 0,00 & 40,60 & 12,9 \\
\hline 13 & 65,13 & 6,78 & 5,37 & 0,66 & 0,36 & 10,90 & 62,7 \\
\hline 14 & 67,55 & 6,88 & 4,83 & 0,00 & 0,00 & 6,90 & 87,8 \\
\hline 15 & 70,10 & 6,86 & 4,82 & 0,00 & 0,00 & 6,50 & 72,0 \\
\hline 16 & 74,68 & 7,20 & 4,77 & 0,00 & 0,00 & 3,80 & 100,0 \\
\hline 17 & 58,60 & 7,32 & 5,83 & 0,95 & 0,71 & 14,10 & 56,9 \\
\hline 18 & 72,80 & 8,20 & 7,19 & 1,24 & 0,00 & 9,10 & 68,3 \\
\hline 19 & 75,80 & 6,84 & 9,64 & 1,61 & 0,00 & 5,60 & 89,3 \\
\hline 20 & 75,20 & 6,47 & 7,97 & 0,96 & 0,00 & 4,60 & 92,0 \\
\hline 21 & 77,40 & 9,54 & 8,41 & 1,41 & 0,00 & 6,80 & 76,1 \\
\hline 22 & 62,20 & 7,56 & 6,37 & 1,57 & 1,11 & 15,20 & 55,1 \\
\hline 23 & 81,00 & 7,23 & 8,89 & 0,80 & 0,00 & 4,00 & 96,9 \\
\hline 24 & 68,70 & 7,64 & 7,82 & 0,95 & 0,00 & 8,10 & 76,2 \\
\hline 25 & 58,75 & 8,74 & 7,80 & 1,25 & 0,00 & 19,49 & 27,4 \\
\hline 26 & 70,25 & 7,78 & 10,04 & 0,41 & 0,00 & 6,41 & 91,1 \\
\hline 27 & 60,41 & 8,53 & 6,67 & 1,36 & 0,66 & 17,90 & 29,5 \\
\hline 28 & 70,41 & 6,78 & 9,60 & 1,02 & 0,00 & 5,28 & 89,2 \\
\hline 29 & 63,30 & 5,54 & 6,99 & 1,25 & 0,00 & 16,05 & 40,4 \\
\hline 30 & 50,75 & 6,69 & 5,11 & 1,24 & 0,68 & 27,64 & 14,2 \\
\hline 31 & 51,99 & 4,68 & 6,89 & 1,08 & 0,00 & 30,40 & 8,7 \\
\hline
\end{tabular}


Tabla 9. Caracterización química de los las muestras sometidas a diferentes pretratamientos de las diferentes muestras, determinada mediante HPLC usando la columna AMINEX.

\begin{tabular}{|c|c|c|c|c|}
\hline $\begin{array}{c}\text { Experiencia } \\
\mathbf{N}^{\mathbf{0}}\end{array}$ & $\begin{array}{c}\text { Glucanos } \\
(\boldsymbol{\%} \mathbf{s m p})\end{array}$ & $\begin{array}{c}\text { Hemicelulosas } \\
(\boldsymbol{\%} \mathbf{s m p})\end{array}$ & $\begin{array}{c}\text { Lignina } \\
(\boldsymbol{\%} \mathbf{s m p})\end{array}$ & $\begin{array}{c}\text { RHE } \\
(\boldsymbol{\%})\end{array}$ \\
\hline 32 & 49,10 & 2,42 & 45,14 & 21,2 \\
\hline 33 & 47,25 & 2,68 & 44,88 & 20,7 \\
\hline 34 & 45,74 & 1,74 & 45,14 & 22,5 \\
\hline 35 & 46,69 & 1,71 & 44,13 & 27,5 \\
\hline 36 & 60,21 & 2,050 & 41,78 & 8,5 \\
\hline 37 & 45,55 & 0,56 & 44,18 & 29,9 \\
\hline 38 & 47,69 & 1,75 & 42,23 & 25,4 \\
\hline 39 & 48,09 & 0,89 & & 36,0 \\
\hline
\end{tabular}

\section{Efecto del tiempo de hidrólisis}

Comparando las digestibilidades para diferentes tiempos (24, 48 y 72 horas) mediante un test de muestras apareadas (Area, 2012), el análisis estadístico indica que se rechaza la hipótesis nula (diferencia igual a cero), es decir, que existen diferencias estadísticamente significativas en el rendimiento de la hidrólisis enzimática según el tiempo transcurrido en la hidrólisis (Figura 21). Los incrementos del RHE (calculados sobre el valor inicial) son mayores en el rango de 24 a 48 horas (entre 17-43\%) que en el rango de 48 a 72 horas (3-17\%), en este último caso los mayores porcentajes se dan en las muestras deslignificadas. 


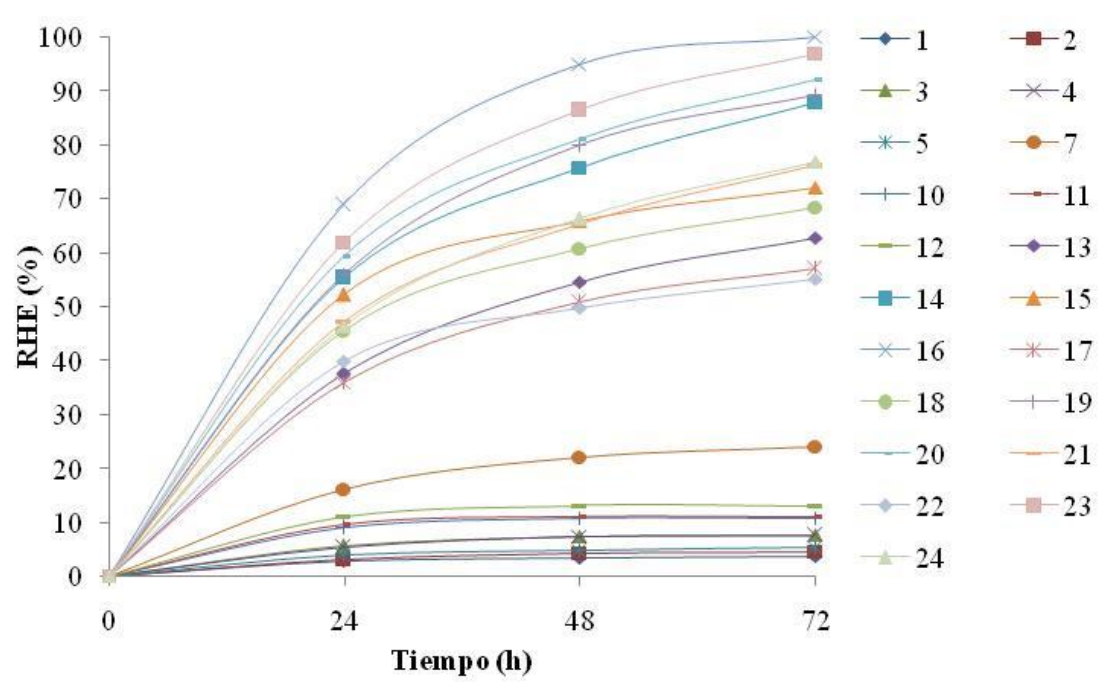

Figura 21. Digestibilidad en función del tiempo de hidrólisis enzimática.

\section{Digestibilidad de cada pretratamiento}

\section{a) Desresinación alcalina}

Se realizó la sacarificación únicamente del punto óptimo $\left(90{ }^{\circ} \mathrm{C}, 60 \mathrm{~min}\right.$ y $5 \%$ smi $\left.\mathrm{NaOH}\right)$, prácticamente libre de extractivos (se extrajo el 90,7\% smi de los extractivos), (Stoffel et al, 2014). El rendimiento de la hidrólisis enzimática de esta experiencia fue de $4,5 \%$, por lo que su puede concluir (comparando con el rendimiento del material sin pretratamiento alguno) que la aplicación de estaetapa no produce un efecto significativo sobre la digestibilidad. Esto es esperable ya que la desresinación se aplicó en parte para facilitar las etapas ácidas posteriores, no para aumentar la digestibilidad. Adicionalmente, en el marco de la biorrefinería, la aplicación de dicha etapa separa una fracción del aserrín que puede ser aprovechada posteriormente.

\section{b) Hidrólisis ácida diluida (HAD)}

La remoción de hemicelulosas del material resultó diferente en el caso del aserrín original con respecto al aserrín previamente desresinado, siendo $74 \%$ smi, y 57\% smirespectivamente. Sin embargo, losrendimientos de la hidrólisis enzimática de ambos materiales fueron muy próximos, de 
7,7 y $7,5 \%$ respectivamente. Se han reportado mejores resultados aplicando HAD con ácido sulfúrico, como se observa en la Tabla 10.

Tabla 10. Comparación entre coníferas pretratados con etapa ácida.

\begin{tabular}{|c|c|c|c|c|c|}
\hline $\begin{array}{c}\text { Materia } \\
\text { prima }\end{array}$ & Origen & $\begin{array}{c}\text { Condiciones } \\
\text { pretratamiento }\end{array}$ & Condiciones HE & $\begin{array}{l}\text { Máximo } \\
\text { RHE (\%) }\end{array}$ & Referencia \\
\hline $\begin{array}{l}\text { Douglas fir } \\
\text { chips }\end{array}$ & EEUU & $\begin{array}{l}\text { a) } 200{ }^{\circ} \mathrm{C}, 30 \mathrm{~min} \text {, } \\
1 \% \text { bs } \mathrm{H}_{2} \mathrm{SO}_{4} \\
\text { b) molienda }\end{array}$ & $\begin{array}{c}20 \mathrm{FPU} / \mathrm{g} \\
\text { celulosa, } \mathrm{pH} 4,8, \\
50^{\circ} \mathrm{C}, 96 \mathrm{~h}\end{array}$ & $\begin{array}{c}\text { a) } 66 \% \\
\text { a + b) } 86,6 \%\end{array}$ & $\begin{array}{c}\text { (Alvarez- } \\
\text { Vasco et al, } \\
2015)\end{array}$ \\
\hline $\begin{array}{c}\text { Mezcla } \\
\text { coníferas } \\
\text { (Pinus rigida y } \\
\text { densiflora) } \\
\text { chips } \\
\end{array}$ & Korea & $\begin{array}{l}\text { Previamente molido. } \\
\text { Hidrólisis ácida } \\
\left(\mathrm{H}_{2} \mathrm{SO}_{4}\right) \text { a } 180^{\circ} \mathrm{C}, \mathrm{pH} \\
1,63 ; 60 \text { minutos }\end{array}$ & $\begin{array}{l}20 \mathrm{FPU} / \mathrm{g} \text { celulosa } \\
\text { y } 80 \mathrm{pNPG} \mathrm{U/g}, \\
\mathrm{pH} 4,8,50^{\circ} \mathrm{C}, 96 \mathrm{~h}\end{array}$ & $46,67 \%$ & $\begin{array}{c}\text { (Lim \& Lee, } \\
\text { 2013) }\end{array}$ \\
\hline Pinus taeda & EEUU & $\begin{array}{l}\text { Previamente molido. } \\
\text { a) } 1 \% \mathrm{~m} / \mathrm{m} \mathrm{H}_{2} \mathrm{SO}_{4} \\
180^{\circ} \mathrm{C}, 30 \mathrm{~min} \\
\text { b) } 5 \% \mathrm{~m} / \mathrm{m} \mathrm{SO}_{2} \\
180^{\circ} \mathrm{C}, 30 \mathrm{~min}\end{array}$ & $\begin{array}{c}20 \mathrm{FPU} / \mathrm{g} \\
\text { celulosa y } 40 \mathrm{IU} / \\
\mathrm{g} \text { celulosa, } 50^{\circ} \mathrm{C}, \\
72 \mathrm{~h}\end{array}$ & $\begin{aligned} \text { a) } & \approx 44 \% \text { b) } \\
& \approx 49 \%\end{aligned}$ & $\begin{array}{l}\text { (Huang \& } \\
\text { Ragauskas, } \\
\text { 2012) }\end{array}$ \\
\hline Pinus elliottii & Argentina & $\begin{array}{c}200^{\circ} \mathrm{C}, 30 \mathrm{~min} y \\
7,5 \mathrm{~g} / \mathrm{L} \mathrm{H}_{2} \mathrm{SO}_{4}\end{array}$ & $\begin{array}{c}20 \mathrm{FPU} / \mathrm{g} \\
\text { glucanos y 40IU/ } \\
\text { g glucanos, pH } \\
4,8,50^{\circ} \mathrm{C}, 72 \mathrm{~h}\end{array}$ & $7,70 \%$ & Este trabajo \\
\hline
\end{tabular}

En todos los pretratamientos mencionados en la Tabla 10 las temperaturas estudiadas fueron superiores a $170^{\circ} \mathrm{C}$. Por otra parte, todos los resultados reportados en la bibliografía indican un rendimiento de extracción de hemicelulosas del 100\%, mientras que en el presente estudio fue del $74 \%$ smi. Es necesario tener en cuenta que en dos de los trabajos se muele el material previamente al pretratamiento, lo que también puede contribuir a una mejora en la hidrólisis enzimática posterior, pero implicando mayor consumo energético. Alvarez-Vasco et al (2015) también emplean el molino, pero previo a la sacarificación (no al pretratamiento), y como se denota en la tabla, obtienen un mejor rendimiento para dicho material. Es necesario especificar que el material empleado en este trabajo para la hidrólisis ácida diluida fue la fracción de aserrín que pasa $3 \mathrm{~mm}$, sin embargo el material que emplean, por ejemplo, Lim y Lee (2013) es harina de madera, con un tamaño entre 40 mesh $(0,40 \mathrm{~mm})$ y 60 mesh $(0,25 \mathrm{~mm})$. 
c) Explosión de vapor (EV)

En la Tabla 11 se puede observar el mejor resultado obtenido con el material pretratado con explosión de vapor (sin deslignificación posterior) frente a coníferas sometidas a pretratamientos similares.

Tabla 11. Comparación entre coníferas pretratados con explosión de vapor.

\begin{tabular}{|c|c|c|c|c|c|}
\hline $\begin{array}{c}\text { Materia } \\
\text { prima }\end{array}$ & Origen & $\begin{array}{c}\text { Condiciones } \\
\text { pretratamiento }\end{array}$ & Condiciones HE & $\begin{array}{l}\text { Máximo } \\
\text { RHE (\%) }\end{array}$ & Referencia \\
\hline Cedar chips & Japón & $\begin{array}{c}5 \text { min a } 258^{\circ} \mathrm{C}(45 \\
\text { atm })+1 \mathrm{~min} \\
\text { molienda }(25000 \\
\text { rmp })\end{array}$ & $\begin{array}{c}\text { 22,4 FPU/g sustrato y } \\
26,4 \mathrm{IU} / \mathrm{g} \text { sustrato, } \mathrm{pH} \\
5,50^{\circ} \mathrm{C}, 120 \mathrm{~h}\end{array}$ & $93 \%$ & $\begin{array}{c}\text { (Asada et al, } \\
\text { 2015) }\end{array}$ \\
\hline $\begin{array}{c}\text { Pinus } \\
\text { radiata } \\
\text { wood chips }\end{array}$ & $\begin{array}{l}\text { Nueva } \\
\text { Zelanda }\end{array}$ & $\begin{array}{l}\mathrm{SO}_{2}(2,55 \% \mathrm{w} / \mathrm{v}) \\
215^{\circ} \mathrm{C}, 3 \mathrm{~min}\end{array}$ & $\begin{array}{l}\text { celulasas y celobiasas, } \\
\mathrm{pH} 4,8,50^{\circ} \mathrm{C}, 24 \mathrm{~h}\end{array}$ & $84 \%$ & $\begin{array}{l}\text { (Donaldson } e t \\
a l, 1988)\end{array}$ \\
\hline $\begin{array}{c}\text { Douglas-fir } \\
\text { y } \\
\text { Lodgepole } \\
\text { pine chips }\end{array}$ & Canadá & $\begin{array}{l}\mathrm{SO}_{2}(4 \% \mathrm{~m} / \mathrm{m}) \\
200^{\circ} \mathrm{C}, 5 \mathrm{~min} .\end{array}$ & $\begin{array}{l}\text { a) } 20 \mathrm{FPU} / \mathrm{g} \text { celulosa y } \\
40 \mathrm{CBU} / \mathrm{g} \text { celulosa } \\
\text { b) } 5 \mathrm{FPU} / \mathrm{g} \text { celulosa y } \\
10 \mathrm{CBU} / \mathrm{g} \text { celulosa. A } \\
50{ }^{\circ} \mathrm{C}, \mathrm{pH} 4,8 ; 72 \mathrm{~h}\end{array}$ & $\begin{array}{l}\text { a) } 60- \\
72 \% \text {;b) } 18- \\
27 \% \text {. }\end{array}$ & $\begin{array}{c}\text { (Kumar et al, } \\
\text { 2010) }\end{array}$ \\
\hline $\begin{array}{l}\text { Pinus } \\
\text { radiata } \\
\text { chips }\end{array}$ & $\begin{array}{l}\text { Nueva } \\
\text { Zelanda }\end{array}$ & $\begin{array}{l}215^{\circ} \mathrm{C}, 3 \mathrm{~min}, \\
2,55 \% \mathrm{SO}_{2}\end{array}$ & $\begin{array}{c}20 \mathrm{FPU} / \mathrm{g} \text { material } \\
\text { pretratado y } 25 \mathrm{U} / \mathrm{g} \\
\text { material pretratado, } \mathrm{pH} \\
4,8,50^{\circ} \mathrm{C}, 24 \mathrm{~h}\end{array}$ & $99,80 \%$ & $\begin{array}{c}\text { (Wong et al, } \\
1988 \text { ) }\end{array}$ \\
\hline $\begin{array}{l}\text { Pinus } \\
\text { elliottii }\end{array}$ & Argentina & $\begin{array}{c}200^{\circ} \mathrm{C}, 5 \min \text { y } 3 \% \\
\mathrm{H}_{2} \mathrm{SO}_{4}\end{array}$ & $\begin{array}{l}20 \mathrm{FPU} / \mathrm{g} \text { glucanos y } \\
\text { 40IU/g glucanos, } \mathrm{pH} \\
\quad 4,8,50^{\circ} \mathrm{C}, 72 \mathrm{~h}\end{array}$ & $24,10 \%$ & Este trabajo \\
\hline
\end{tabular}

Al comparar los resultados es necesario prestar especial atención sobre qué base fue calculada la carga enzimática. Un material sólido pretratado mediante explosión de vapor posee en general un contenido de glucanos entre 40-55\%. Por ejemplo, si la carga enzimática se calculó sobre $1 \mathrm{~g}$ de sustrato o sobre $1 \mathrm{~g}$ material pretratado y no sobre la cantidad de glucanos o celulosa $(0,5 \mathrm{~g}$ aproximadamente), en realidad se está agregando aproximadamente el doble que si la base fuese glucanos o celulosa. De este análisis se percibe que Asada et al (2015) y Wong et al (1988) usan el doble aproximadamente de enzimas que la cantidad utilizada en el presente trabajo. 
Otro detalle importante a tener en cuenta es que la composición de la biomasa influye sobre la eficiencia de la EV (Duque et al, 2016), y como puede notarse en la tabla, pese a que son todas coníferas, no pertenecen a la misma especie.

El primer trabajo de la Tabla 11, corresponde a un tratamiento de EV autocatalizado, ya que se libera ácido acético de los grupos acetilos. En ese trabajo, los autores muelen el material luego del tratamiento de explosión de vapor, lo que mejora el área superficial y se obtiene un alto rendimiento en la sacarificación; pero los costos de energía son significativos (Asada et al, 2015).

Los demás tratamientos emplean $\mathrm{SO}_{2} \mathrm{O}_{2} \mathrm{H}_{2}$ como catalizador, ya que las coníferastienen poca capacidad de autohidrólisis por su escasa cantidad de grupos acetilos en las hemicelulosas. Se observa que los tratamientos de EV con dióxido de azufre mejoran notablemente la hidrólisis enzimática. Entre las ventajas del $\mathrm{SO}_{2}$ (gaseoso) se encuentran su facilidad para penetrar el material, obteniendo una distribución del químico uniforme. Algunos autores compararon el desempeño de ambos catalizadores, y confirmaron la superioridad del dióxido de azufre. La adición de ácido sulfúrico diluido conlleva a un mayor consumo de vapor para alcanzar la temperatura deseada, debido al mayor contenido de humedad en la biomasa impregnada (Duque et al, 2016).

Una posible explicación para el bajo rendimiento de hidrólisis obtenido es el contenido de lignina (ya que prácticamente no hay remoción), y dicho componente en coníferas pretratadadas con explosión de vapor puede restringir el hinchamiento del sustrato, actuando como una barrera para las enzimas.También puede unirse improductivamente a las enzimas reduciendo, por ende, la cantidad de enzimas disponible para hidrolizar el sustrato (Kumar et al, 2010).

\section{d) Lavado alcalino}

Los resultados obtenidos para las mismas condiciones de explosión de vapor, pero con un posterior lavado adicional (alcalino) se observan en la Tabla 12. 
Tabla 12. Comparación del RHE del material pretratado con EVconsiderando el tipo de lavado posterior.

\begin{tabular}{|l|c|c|}
\hline \multirow{2}{*}{ Condiciones EV } & \multicolumn{2}{|c|}{ RHE (\%) } \\
\cline { 2 - 3 } & sin lavado alcalino & con lavado alcalino \\
\hline $180^{\circ} \mathrm{C}, 5 \mathrm{~min}, 3 \% \mathrm{smpH}_{2} \mathrm{SO}_{4}{ }^{\mathrm{a}}$ & 11,72 & 10,70 \\
\hline $200^{\circ} \mathrm{C}, 5 \mathrm{~min}, 3 \% \mathrm{smp} \mathrm{H}_{2} \mathrm{SO}_{4}{ }^{\mathrm{a}}$ & 24,10 & 11,00 \\
\hline $190^{\circ} \mathrm{C} ; 7,5 \mathrm{~min} ; 0,75 \% \mathrm{smi} \mathrm{H}_{2} \mathrm{SO}_{4}$ & 17,20 & 12,90 \\
\hline
\end{tabular}

${ }^{\mathrm{a}}$ sometido a previa desresinación alcalina.

Como se observaen la tabla, en todos los casos el lavado alcalino actuó en detrimento de la digestibilidad, la cual descendió a valores de $9 \%$ a $54 \%$ del valor inicial. Este resultado es coincidente con el hallado por otros autores para el lavado en condiciones suaves con $\mathrm{NaOH}$. Por ejemplo, en el trabajo de Wong et al (1988), la digestibilidad del experimento mencionado previamente $\left(215^{\circ} \mathrm{C}, 3 \mathrm{~min}\right.$ y $2,55 \% \mathrm{SO}_{2}$ ) disminuye de $99,8 \%$ a $28,8 \%$ (ambos $24 \mathrm{~h}$ ); en el de Donaldson et al (1988) también se observa una marcada disminución de la digestibilidad, de 84\% a 29\%. Una justificación posible es que partículas de lignina (que no son extraídas) se redepositan sobre regiones accesibles de las microfibrilas de celulosa, bloqueando accesibilidad y por lo tanto disminuyendo la digestibilidad (Wang et al, 2015).

En estudios que comparan el lavado alcalino de EV catalizada con $\mathrm{H}_{2} \mathrm{SO}_{4}$ frente a EV catalizada con $\mathrm{SO}_{2}$, se infiere que la lignina del tratamiento con ácido está más condensada que la lignina tratada con $\mathrm{SO}_{2}$, dados los porcentajes de extracciones que obtienen (Mackie et al, 1985).

e) Deslignificaciones con Soda $-A Q($ e) y Kraft $-A Q(g)$

Dado que ambos tratamientos son alcalinos y deslignificantes se tratarán conjuntamente. Es necesario tener en cuenta que la efectividad del pretratamiento alcalino depende tanto del sustrato como de las condiciones empleadas. Von Schenck et al (2013), trabajando con pino (Pinus sylvestris), encontraron que las mejores condiciones para pretratar el material con vistas a su 
conversión a bioetanol consisten en un pretratamiento alcalino con una carga alcalina entre 20-21\% a $180^{\circ} \mathrm{C}$ por $220-240$ minutos, con un contenido final de 5-5,5\% de lignina en la pulpa. Este contenido de lignina residual es considerado“óptimo” por los autores ya que conuna mayor deslignificación la pérdida de carbohidratos es substancial (Von Schenck et al, 2013).

Todas las coníferas especificadas en la Tabla 13 presentan contenidos de lignina entre 4 y 5,8\%, estando aproximadamente en el rango que propone en trabajo anteriormente mencionado. Se cree que el mecanismo del tratamiento alcalino es la solvatación y saponificación de enlaces ester intermoleculares entre xilanos, lignina y otras hemicelulosas. La solvatación y saponificación causan la remoción de estos enlaces y mejoran la porosidad del material. Esto está en concordancia con los resultados obtenidos en el primer trabajo de la Tabla 13 (con paja de trigo). Los autores observan que para el mismo contenido de lignina residual se obtienen digestibilidades diferentes, lo cual atribuyen al complejo lignina carbohidratos (CLC), ya que encuentran menos subestructura y uniones CLC en la lignina residual del pulpado kraft.

Aunque el resultado de Charles (2002) sea menor, es necesario tener en cuenta que no aclara específicamente que conífera empleó en sus experiencias, y además, la carga enzimática es baja en comparación con los otros trabajos, dado que aún si la expresáramos por gramos de glucanos sería aproximadamente 7FPU /g glucanos.

En el presente trabajo se obtuvieron los mejores resultados de HE con un pulpado kraft de coníferas. Dado que en los otros trabajos se omiten las condiciones de pulpado o se utilizan pulpas industriales, una posible explicación, es el empleo de AQ. Este aditivo es un catalizador de la reacción de deslignificación, es decir, hace posible que la misma tenga lugar a mayor velocidad, actuando a su vez sobre los carbohidratos, ya que oxida los grupos reductores finales, protegiéndolos de la reacción de peeling. 
Tabla 13. Comparación entre materiales sometidos a pretratamiento alcalino.

\begin{tabular}{|c|c|c|c|c|c|}
\hline $\begin{array}{c}\text { Materia } \\
\text { prima }\end{array}$ & Origen & $\begin{array}{c}\text { Condiciones } \\
\text { pretratamiento }\end{array}$ & Condiciones HE & $\begin{array}{c}\text { Máximo } \\
\text { RHE (\%) }\end{array}$ & Referencia \\
\hline $\begin{array}{l}\text { Paja de } \\
\text { trigo } \\
\text { molida }\end{array}$ & China & $\begin{array}{l}\text { a)soda-AQ: } 15 \% \mathrm{NaOH} \text {, } \\
0,05 \% \mathrm{AQ}, 160^{\circ} \mathrm{C}, 30 \mathrm{~min} \\
\text { b)Kraft: } 17 \% \mathrm{NaOH}, 25 \% \\
\text { sulfidez, } 160^{\circ} \mathrm{C}, 60 \mathrm{~min}\end{array}$ & $\begin{array}{c}50^{\circ} \mathrm{C}, 20 \mathrm{FPU} / \mathrm{g} \\
\text { sustrato, } \mathrm{pH} 4,8 \\
72 \mathrm{~h}\end{array}$ & $\begin{array}{l}\text { a) } 79,5 \% \\
\text { b) } 95,8\end{array}$ & $\begin{array}{c}\text { (Yang et al, } \\
\text { 2016) }\end{array}$ \\
\hline Coníferas & Canadá & Kraft & $\begin{array}{c}45^{\circ} \mathrm{C}, 5 \mathrm{FPU} / \mathrm{g} \\
\text { pulpa y50 CBU/g } \\
\text { pulpa, pH } 4,8,48 \\
\text { h }\end{array}$ & $51 \%$ & $\begin{array}{c}\text { (Charles, } \\
\text { 2002) }\end{array}$ \\
\hline $\begin{array}{l}\text { Pinus } \\
\text { sylvestrii } \\
\text { chips }\end{array}$ & Polonia & Kraft & $\begin{array}{c}\text { celulasas más } \\
\text { xilanasas }{ }^{\mathrm{a},}, 50^{\circ} \mathrm{C}, \\
48 \mathrm{~h}\end{array}$ & $70,7 \%$ & $\begin{array}{c}\text { (Przybysz } \\
\text { Buzała et al, } \\
\text { 2017) }\end{array}$ \\
\hline $\begin{array}{l}\text { Pinus } \\
\text { elliottii }\end{array}$ & Argentina & $\begin{array}{l}\text { a) Kraft -AQ, H 2500, } 25 \\
\text { g/L NaOH, } 170 \text { min, } 20 \% \\
\text { sulfidez } \\
\text { b) Soda-AQ, H } 3850,55,2 \\
\text { g/L, } 140 \text { min } \\
\text { c) soda AQ, H } 3000, \\
50 \text { g/L, } 108 \text { min. a, b y c } \\
0,11 \% \text { AQ y } 170^{\circ} \mathrm{C}\end{array}$ & $\begin{array}{c}50^{\circ} \mathrm{C}, 20 \mathrm{FPU} / \mathrm{g} \\
\text { glucanos y } 40 \\
\mathrm{IU} / \mathrm{g} \text { glucanos, } \\
\mathrm{pH} 4,8,72 \mathrm{~h}\end{array}$ & $\begin{array}{l}\text { a) } 100 \% \text { b) } \\
97 \% \text { c) } \\
89,3 \%\end{array}$ & Este trabajo \\
\hline
\end{tabular}

a80,6 U/mL, 112,1 FPU/ mL y 192,5 U/mL, se diluyó 6 veces para mezclar con sustrato.

Se observa en el última fila de la tabla, que para obtener digestibilidades análogas al pulpado kraft es necesario emplear una concentración de hidróxido de sodio del doble o mayor cuando se emplea un tratamiento a la soda-AQ, por lo cual es necesario realizar un análisis más minucioso, considerando costo de reactivos $\left(\mathrm{NaOH}\right.$ y $\left.\mathrm{Na}_{2} \mathrm{~S}\right)$ entre otros. Además, como el pulpado químico predominante a nivel global es el pulpado kraft, integrar una planta de producción de etanol a una planta existente disminuiría costos de inversión, debido a los procesos de recuperación de químicos y energía preexistentes (Von Schenck et al, 2013). Sin embargo, el proceso a la soda-AQ no utiliza azufre, por lo cual no genera olores desagradables en comparación con el olor típico del proceso Kraft (producto 
de los compuestos reducidos de azufre). Por este motivo, es más adecuado para plantas de pequeña escala como las de tratamiento de aserrín, ya que tendría una menor inversión en control ambiental.

\section{f) Deslignificación soda- $A Q-\mathrm{O}_{2}$}

El empleo de oxígeno para la remoción de la lignina surge de las industrias de pulpa, donde se lo usa como primera etapa de blanqueo con ese mismo objetivo.

El mecanismo de la deslignificación con oxígeno involucra reacciones de radicales libres, donde los grupos fenólicos libres de la lignina juegan un rol crucial. Cuando este proceso se realiza en medio alcalino, el grupo fenólico puede ser ionizado a ión fenóxido. Dichos iones son susceptibles al oxígeno molecular, dando lugar a la formación de radicales fenoxi. La propagación de este radical causa consecutiva ruptura de la estructura de la lignina, obteniéndose productos de degradación de la misma (Pan et al, 2004).

Algunos resultados de la influencia de la deslignificación con oxígeno sobre la hidrólisis enzimática se muestran en la Tabla 14.

Las disminuciones en el contenido de lignina reportadas por los autores son cercanas al $50 \%$ en pulpas kraft, del $30 \%$ en los rechazos refinados y $25 \%$ gracias a la etapa de oxígeno en este trabajo. La deslignificación con oxígeno ha mejorado los rendimientos de la hidrólisis enzimática en todos los casos señalados en la Tabla 17, ya sea que se aplique después de un tratamiento alcalino o a un rechazo del pulpado al sulfito.

Es posible percibir, en concordancia con los trabajos citados, que existe una relación directa entre el contenido de lignina y la digestibilidad del material. 
Tabla 14. Comparación entre coníferas sometidas a deslignificación con oxígeno.

\begin{tabular}{|c|c|c|c|c|c|}
\hline $\begin{array}{c}\text { Materia } \\
\text { prima }\end{array}$ & Origen & Condiciones pretratamiento & $\begin{array}{c}\text { Condiciones } \\
\text { HE }\end{array}$ & $\begin{array}{l}\text { Máximo } \\
\text { RHE (\%) }\end{array}$ & Referencia \\
\hline $\begin{array}{l}\text { Douglas } \\
\text { fir }\end{array}$ & Canadá & $\mathrm{Kraft}+\mathrm{O}_{2}$ & $\begin{array}{c}50{ }^{\circ} \mathrm{C}, 2 \mathrm{FPU} / \mathrm{g} \\
\mathrm{y} 20 \mathrm{IU} / \mathrm{g}, \mathrm{pH} \\
4,8\end{array}$ & $\begin{array}{c}\text { a) } 18,2 \\
\text { (Kraft) a } \\
31,8 \%\end{array}$ & $\begin{array}{c}\text { (Draude } e t \\
a l, 2001)\end{array}$ \\
\hline Coníferas & Canadá & $\begin{array}{c}\text { a) } \mathrm{Kraft}+\mathrm{O}_{2} \text { en } 2 \text { etapas } \\
\text { b) rechazos pulpa al sulfito }+ \\
\mathrm{O}_{2}\left(10-100 \mathrm{psig}, 90-165^{\circ} \mathrm{C}, 1-\right. \\
3 \% \mathrm{NaOH}, 0,1 \% \\
\left.\mathrm{MgSO}_{4} .7 \mathrm{H}_{2} \mathrm{O}\right) \\
\text { c) ídem "b" pero refinadas } \\
\text { antes de la } \mathrm{HE} \\
\end{array}$ & $\begin{array}{c}45^{\circ} \mathrm{C}, 5 \\
\text { FPU/g pulpa } \\
\text { y50 CBU/g } \\
\text { pulpa, pH } 4,8 \\
\quad 48 \mathrm{~h}\end{array}$ & $\begin{array}{l}\text { a) } 51 \text { a } 89 \% \\
\text { b) } 43 \text { a } 51 \% \\
\text { c) } 51 \text { a } 67 \%\end{array}$ & $\begin{array}{c}\text { (Charles, } \\
\text { 2002) }\end{array}$ \\
\hline $\begin{array}{l}\text { Pinus } \\
\text { elliottii }\end{array}$ & Argentina & $\begin{array}{l}\text { a) } 25 \mathrm{~g} / \mathrm{L} \mathrm{NaOH}, 170 \mathrm{~min}, 170 \\
{ }^{\circ} \mathrm{C}, \mathrm{RLM}: 10 / 1 \\
\text { b) } 120^{\circ} \mathrm{C}, 60 \mathrm{~min}, \text { consistencia } \\
10 \% \mathrm{~m} / \mathrm{m}, 5 \% \mathrm{smpNaOH}, 6 \\
\text { kg O } \mathrm{Om}_{2} / \mathrm{cm}^{2}\end{array}$ & $\begin{array}{c}50^{\circ} \mathrm{C} \\
20 \mathrm{FPU} / \mathrm{g} \\
\text { glucanos y } 40 \\
\text { IU/g glucanos, } \\
\mathrm{pH} 4,8,72 \mathrm{~h}\end{array}$ & $\begin{array}{c}\text { a) } 68,3 \% \\
\text { a+b) } 72,0 \%\end{array}$ & Este trabajo \\
\hline
\end{tabular}

\section{h) Deslignificación soda-etanol}

Los tratamientos con etanol, soda o combinación de ambos (variando niveles) generaron materiales de diversa composición química y distintas susceptibilidades a las celulasas.

Los rendimientos correspondientes a los materiales sólidos de los pretratamientos en los que se empleó $25 \% \mathrm{NaOH}$ fueron menores a $50 \%$, debido principalmente a una alta deslignificación. Sin embargo, no hubo un cambio significativo con respecto a los glucanos.

De los dos factores estudiados (tiempo y carga alcalina), el ANOVA determinó que el efecto del tiempo (en el rango estudiado) no fue significativo (p-valor $>0,05$ ), por lo tanto, 60 minutos es suficiente para alcanzar los resultados deseados. Por el contrario, la carga alcalina afectó significativamente al rendimiento de la hidrólisis enzimática ( $\mathrm{p}$-valor $<<0,05$ ).

En la Figura 22 se observa claramente que los químicos aplicados presentan un efecto sinérgico, dado que los rendimientos de las hidrólisis cuando se empleó un solo reactivo (etanol o $\mathrm{NaOH}$ ) son mucho menores que los de los materiales que fueron sometidos simultáneamente a ambos reactivos. 
Este resultado coincide con el de Von Schenck et al (2013), quienes observaron que al agregar etanol a un pretratamiento con álcali mejora la deslignificación.

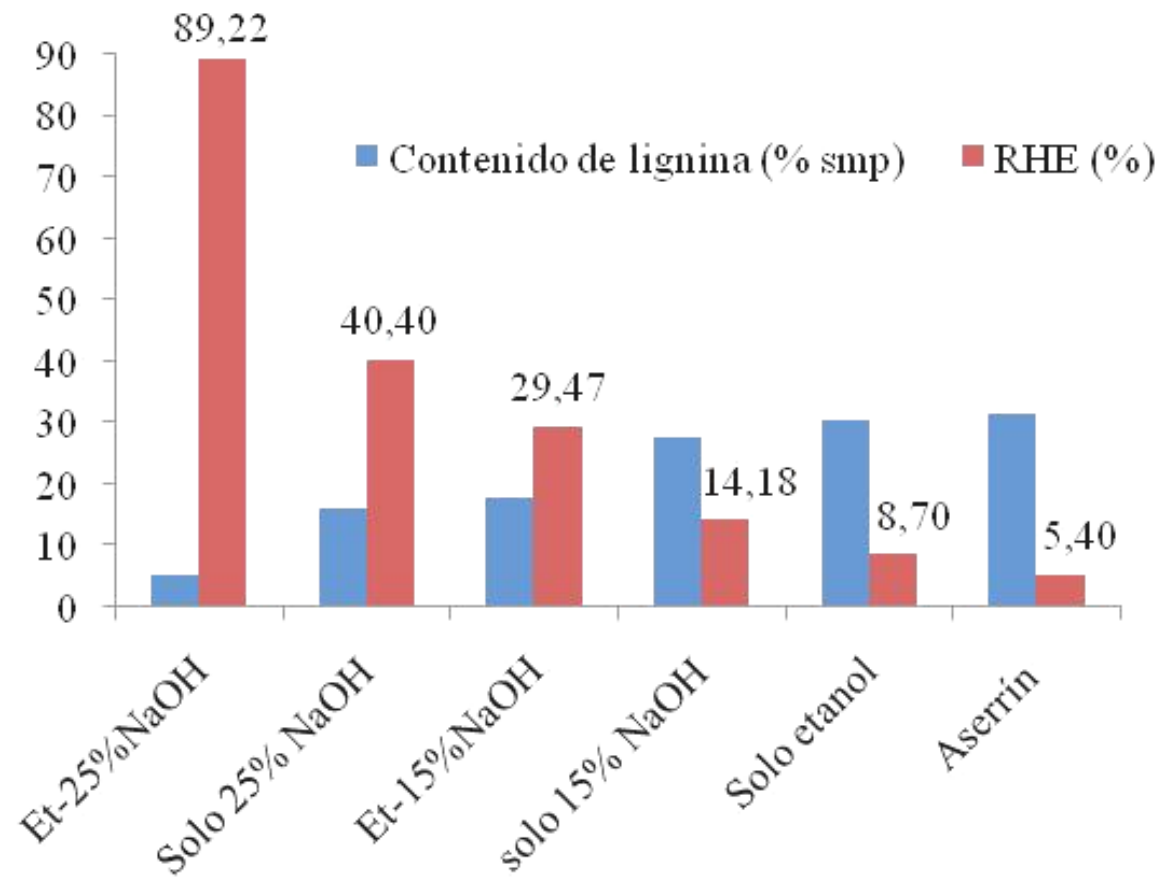

Figura 22. Digestibilidad (72h) y contenido de lignina, todas las experiencias a los 90 minutos.

El aumento de la digestibilidad después de la deslignificación fue confirmado por este estudio. Hay una correlación negativa entre el contenido de lignina y el rendimiento de la hidrólisis enzimática $(\mathrm{r}=$ -0,96; p- valor $<<0,05)$. La explicación puede ser que la lignina se una irreversiblemente a las enzimas a través de interacciones hidrofóbicas causando una pérdida en la actividad de las celulasas (Araya et al, 2015).

La comparación con resultados obtenidos por otros autores que trabajan con similares materias primas (pino) se observa en la Tabla 15. Los resultados pueden variar apreciablemente si se emplea una materia prima diferente, debido a diferencias en la reactividad, estructura y distribución de la lignina. 
Tabla 15. Comparación de coníferas sometidas a un pretratamiento organosolv.

\begin{tabular}{|c|c|c|c|c|c|}
\hline $\begin{array}{c}\text { Materia } \\
\text { prima }\end{array}$ & Origen & $\begin{array}{l}\text { Condiciones } \\
\text { pretratamiento }\end{array}$ & Condiciones HE & $\begin{array}{c}\text { Máximo } \\
\text { RHE (\%) }\end{array}$ & Referencia \\
\hline $\begin{array}{l}\text { Pinus } \\
\text { taeda }\end{array}$ & $\begin{array}{l}\text { Estados } \\
\text { Unidos }\end{array}$ & $\begin{array}{c}170^{\circ} \mathrm{C} \text {, etanol/agua: } 65 / 35 \\
1,1 \% \text { (sobre material seco) } \\
\mathrm{H}_{2} \mathrm{SO}_{4}, 60 \mathrm{~min}\end{array}$ & $\begin{array}{c}50^{\circ} \mathrm{C}, 8 \mathrm{FPU} / \mathrm{g} \\
\text { celulosa y } 16 \mathrm{IU} / \mathrm{g} \\
\text { celulosa, } 80 \mathrm{~h} \\
\end{array}$ & $\approx 70 \%$ & $\begin{array}{l}\text { (Sannigrahi } \\
\text { et al, 2010) }\end{array}$ \\
\hline $\begin{array}{l}\text { Pinus } \\
\text { rigida }\end{array}$ & $\begin{array}{l}\text { Corea del } \\
\text { Sur }\end{array}$ & $\begin{array}{c}\text { Previamente molido (pasa } \\
\text { 40mesh) } \\
\text { a) } 190^{\circ} \mathrm{C} \text {, etanol/agua: } \\
50 / 50,20 \mathrm{~min}, 2 \%(\mathrm{~m} / \mathrm{v}) \\
\mathrm{NaOH} . \\
\text { b) } 210^{\circ} \mathrm{C} \text {, etanol/agua: } \\
50 / 50,2 \%(\mathrm{~m} / \mathrm{v}) \mathrm{NaOH}, 20 \\
\mathrm{~min}\end{array}$ & $\begin{array}{c}50{ }^{\circ} \mathrm{C}, 60 \mathrm{FPU} / \mathrm{g} \\
\text { celulosa y } \\
64 \mathrm{pNPGU} / \mathrm{g} \\
\text { celulosa, } 72 \mathrm{~h}\end{array}$ & $\begin{array}{l}\text { a) } 58 \% \\
\text { b) } 85,4 \%\end{array}$ & $\begin{array}{l}\text { (Park et al, } \\
\text { 2010) }\end{array}$ \\
\hline $\begin{array}{l}\text { Pinus } \\
\text { taeda }\end{array}$ & $\begin{array}{l}\text { Estados } \\
\text { Unidos }\end{array}$ & $\begin{array}{c}170^{\circ} \mathrm{C}, 75 \% \text { etanol, } 1 \% \\
(\mathrm{~m} / \mathrm{m}) \text { ácido sulfúrico } \\
\text { durante la noche, } 60 \mathrm{~min}, \\
\text { RLM } 7: 1\end{array}$ & $\begin{array}{c}50^{\circ} \mathrm{C}, 10 \mathrm{FPU} / \mathrm{g} \\
\text { glucanos, } 72 \mathrm{~h}\end{array}$ & $41,20 \%$ & $\begin{array}{l}\text { (Lai et al, } \\
\text { 2014) }\end{array}$ \\
\hline $\begin{array}{c}\text { Pinus } \\
\text { taeda L. }\end{array}$ & $\begin{array}{l}\text { Estados } \\
\text { Unidos }\end{array}$ & $\begin{array}{l}\text { Previamente molida } \\
\text { (20mesh). } 170^{\circ} \mathrm{C} ; \\
\text { concentración de etanol } \\
55 \%, 60 \mathrm{~min} ; 1 \% \text { ácido } \\
\quad \text { sulfúrico diluido }\end{array}$ & $\begin{array}{c}55^{\circ} \mathrm{C}, 60 \mathrm{FPU} / \mathrm{g} \\
\text { glucanos, } 48 \mathrm{~h}\end{array}$ & $75 \%$ & $\begin{array}{l}\text { (Heringer, } \\
\text { 2016) }\end{array}$ \\
\hline $\begin{array}{l}\text { Pinus } \\
\text { radiata } \\
\text { chips }\end{array}$ & Chile & $\begin{array}{l}189^{\circ} \mathrm{C} \text {, etanol/ agua }(\mathrm{v} / \mathrm{v}): \\
\text { 50/50; RLM } 6 / 1 ; 1,1 \% \mathrm{~m} / \mathrm{m} \\
\text { ácido sulfúrico y } 8 \mathrm{~min}\end{array}$ & $\begin{array}{l}50^{\circ} \mathrm{C} ; 0,044 \mathrm{~g} \mathrm{de} \\
\text { enzimas por gramo } \\
\text { de material seco } \\
\text { pretratado, } 72 \mathrm{~h}\end{array}$ & $94 \%$ & $\begin{array}{c}\text { (Valenzuela, } \\
\text { et al, 2016) }\end{array}$ \\
\hline $\begin{array}{l}\text { Pinus } \\
\text { elliottii }\end{array}$ & Argentina & $\begin{array}{c}170^{\circ} \mathrm{C}, \text { etanol/agua: } 35 / 65 \\
25 \% \text { smiNaOH, } 60 \mathrm{~min}, \\
\text { RLM 5/1 }\end{array}$ & $\begin{array}{c}50^{\circ} \mathrm{C}, 20 \mathrm{FPU} / \mathrm{g} \\
\text { glucanos and } 40 \\
\text { IU/g glucanos, } 72 \mathrm{~h}\end{array}$ & $91 \%$ & Este trabajo \\
\hline
\end{tabular}

Como se observa en la Tabla 15, la relación etanol/ agua más frecuentemente utilizada es 50/50, pese a que se ha reportado que el uso de bajas concentraciones de etanol $(\approx 30 \% \mathrm{v} / \mathrm{v})$ es favorable en este proceso organosolv (Mesa et al, 2011).

Comparando con Park et al (2010), quien trabajó también con coníferas y un proceso organosolv alcalino, en este trabajo se obtuvieron mayores rendimientos a menores temperaturas y menores cargas enzimáticas, posiblemente debido a la diferencia en la relación etanol/ soda y/o en el tiempo a temperatura máxima. Es posible llegar a la misma conclusión al comparar con la mayoría de los tratamientos organosolv catalizados con ácido. 
El pretratamiento soda-etanol ha demostrado proveer una alta digestibilidad a moderada temperatura.

El proceso con etanol catalizado con ácido sulfúrico ha sido el proceso organosolv más aplicado pese al hecho de que el álcali ha sido reconocido como uno de los agentes más efectivos en el hinchamiento de la biomasa, y el grado de hinchamiento es una propiedad importante que afecta a la digestibilidad (Koo et al, 2011).

\section{i) Deslignificación con peróxido de hidrógeno en medio alcalino de materiales pretratados con ácido}

En la Tabla 16 se observa el mejor resultado de la hidrólisis enzimática del material sometido a deslignificación con peróxido de hidrógeno (sobre el material desresinado y sometido a explosión de vapor) frente a otros materiales similares.

Tabla 16. Comparación de coníferas sometidas a explosión de vapor y deslignificación con peróxido de hidrógeno en medio alcalino.

\begin{tabular}{|c|c|c|c|c|c|}
\hline $\begin{array}{c}\text { Materia } \\
\text { prima }\end{array}$ & Origen & Condiciones pretratamiento & Condiciones HE & $\begin{array}{c}\text { Máximo } \\
\text { RHE (\%) }\end{array}$ & Referencia \\
\hline $\begin{array}{l}\text { Douglas fir } \\
\text { chips }\end{array}$ & Canadá & $\begin{array}{c}\text { a) } \mathrm{EV}: 195^{\circ} \mathrm{C}, 4,5 \min , 4,5 \% \\
\mathrm{~m} / \mathrm{m} \mathrm{SO}_{2} \\
\text { b) } 1 \% \mathrm{H}_{2} \mathrm{O}_{2}, \mathrm{pH} 11,5 \\
\text { (ajustado con } \mathrm{NaOH} \text { ), } 80^{\circ} \mathrm{C}, \\
45 \text { minutos }\end{array}$ & $\begin{array}{c}45^{\circ} \mathrm{C}, 20 \mathrm{FPU} / \mathrm{g} \\
\text { celulosa y } 35 \\
\mathrm{IU} / \mathrm{g} \text { glucanos, } \\
\mathrm{pH} 4,8,48 \mathrm{~h}\end{array}$ & $\begin{array}{l}\text { a) } 45 \% \\
\text { a+b) } 100 \% \\
\text { (24h) }\end{array}$ & $\begin{array}{l}\text { (Yang et } \\
a l, 2002)\end{array}$ \\
\hline $\begin{array}{l}\text { Picea albis } \\
\text { (Spruce) } \\
\text { chips }\end{array}$ & Canadá & $\begin{array}{c}\mathrm{EV}\left(210^{\circ} \mathrm{C}, 2,5 \mathrm{~min}, 2,5 \%\right. \\
\left.\mathrm{m} / \mathrm{m} \mathrm{SO}_{2}\right)+ \text { lavado alcalino } \\
(0,4 \% \mathrm{~m} / \mathrm{v} \mathrm{NaOH})+\mathrm{H}_{2} \mathrm{O}_{2} \\
\text { alcalino }\left(1 \% \mathrm{H}_{2} \mathrm{O}_{2}, \mathrm{pH} 11,5,\right. \\
12 \mathrm{~h})\end{array}$ & $\begin{array}{c}45^{\circ} \mathrm{C}, 10 \mathrm{FPU} / \mathrm{g} \\
\text { celulosa, } \mathrm{pH} 4,8, \\
48 \mathrm{~h}\end{array}$ & $100 \%$ & $\begin{array}{c}\text { (Ramos et } \\
\text { al, 1992) }\end{array}$ \\
\hline Douglas fir & Canadá & $\begin{array}{c}\mathrm{EV}\left(195^{\circ} \mathrm{C}, 4,5 \mathrm{~min}, 4,5 \%\right. \\
\left.\mathrm{SO}_{2}\right)+0,5 \% \mathrm{H}_{2} \mathrm{O}_{2}, 0,18 \% \\
\mathrm{DTMPA} 95^{\circ} \mathrm{C}, 1 \mathrm{~h}, \mathrm{pH} 11,5 \\
\quad \text { (ajustado con } \mathrm{NaOH})\end{array}$ & $\begin{array}{c}45^{\circ} \mathrm{C}, 20 \mathrm{FPU} / \mathrm{g} \\
\text { celulosa y } 40 \\
\mathrm{CBU} / \mathrm{g} \text { celulosa, } \\
\mathrm{pH} 4,8,48 \mathrm{~h}\end{array}$ & $90 \%$ & $\begin{array}{l}\text { (Cullis, } \\
\text { 2003) }\end{array}$ \\
\hline $\begin{array}{l}\text { Pinus } \\
\text { elliottii }\end{array}$ & Argentina & $\begin{array}{c}\text { a) desresinación alcalina }+\mathrm{EV} \\
\left(20{ }^{\circ} \mathrm{C}, 5 \mathrm{~min}, 3 \% \mathrm{H}_{2} \mathrm{SO}_{4}\right) \\
\text { b) } 10 \% \mathrm{H}_{2} \mathrm{O}_{2}, 120 \mathrm{~min}, \mathrm{pH} \\
11,5(\text { ajustado con } \mathrm{NaOH}) \\
0,1 \% \text { DTMPA, } 90^{\circ} \mathrm{C}\end{array}$ & $\begin{array}{c}50^{\circ} \mathrm{C}, 20 \mathrm{FPU} / \mathrm{g} \\
\text { glucanos y } 40 \\
\mathrm{IU} / \mathrm{g} \text { glucanos, } \\
\mathrm{pH} 4,8,72 \mathrm{~h}\end{array}$ & a) $\begin{array}{l}20,3 \% \text { b) } \\
27,5 \%\end{array}$ & $\begin{array}{c}\text { (Stoffel R. } \\
\text { B., 2016) }\end{array}$ \\
\hline
\end{tabular}


Pese a que las cargas enzimáticas son similares, y el porcentaje de peróxido utilizado es mucho mayor en este trabajo (Stoffel R. B., 2016), los mayores rendimientos de hidrólisis enzimática obtenidos por los trabajos de la Tabla 16 son debidos al mayor grado de deslignificación producido por la sulfonación de las unidades de tipo guayacilo (presentes en gran proporción en las coníferas) en la lignina durante la etapa de explosión de vapor.

La sulfonación disminuye la temperatura de transición vítrea de la lignina e incrementa su carácter hidrofílico promoviendo a su vez el ablandamiento de la lámina media y mejorando la separación de las fibras (Fardim et al, 2012). Los contenidos de lignina de los trabajos que se muestran en la Tabla 16 varían entre $8-15 \%$, mientras que en las experiencias de peróxido alcalino reportadas por Stoffel (2016) los contenidos de lignina son mayores a 40\% smp (se obtiene 15\% de deslignificación en las diferentes condiciones experimentadas).

\section{j) Deslignificación con oxígeno alcalino de materiales pretratados con ácido}

Se observa en la Tabla 17 una comparación de materiales en una secuencia similar (explosión de vapor seguido de deslignificación con oxígeno).

Tabla 17. Comparación de los RHE de coníferas pretratadas con ácido y luego deslignificadas con oxígeno alcalino.

\begin{tabular}{|c|c|c|c|c|c|}
\hline $\begin{array}{c}\text { Materia } \\
\text { prima }\end{array}$ & Origen & Condiciones pretratamiento & Condiciones HE & $\begin{array}{l}\text { Máximo } \\
\text { RHE (\%) }\end{array}$ & Referencia \\
\hline $\begin{array}{l}\text { Douglas } \\
\text { fir chips }\end{array}$ & Canadá & $\begin{array}{c}\text { a) } \mathrm{EV}: 4,5 \% \mathrm{~m} / \mathrm{m} \mathrm{SO}_{2}, 195^{\circ} \mathrm{C} \\
\text { y } 4,5 \mathrm{minutos} \\
\text { b) } \mathrm{O}_{2}: 500 \mathrm{kPa}, 110^{\circ} \mathrm{C}, 5 \% \\
\text { consistencia, } 15 \% \mathrm{NaOH}, \\
0,5 \% \mathrm{MgSO}_{4}, 3 \mathrm{~h}\end{array}$ & $\begin{array}{c}45^{\circ} \mathrm{C}, 20 \mathrm{FPU} / \mathrm{g} \\
\text { celulosa, } 40 \\
\mathrm{CBU} / \mathrm{g} \text { celulosa, } \\
\mathrm{pH} 4,8,72 \mathrm{~h}\end{array}$ & $\begin{array}{c}\text { a) } 35 \% \\
\text { a+b) } 90 \%\end{array}$ & $\begin{array}{c}\text { (Pan et al } \\
\text { 2004) }\end{array}$ \\
\hline $\begin{array}{l}\text { Pinus } \\
\text { elliottii }\end{array}$ & Argentina & $\begin{array}{c}\text { a) Desresinación alcalina }+ \\
\mathrm{EV}\left(200^{\circ} \mathrm{C}, 5 \mathrm{~min} \text { y } 3 \% \text { ácido }\right. \\
\left.\mathrm{H}_{2} \mathrm{SO}_{4}\right) \text { b) } \mathrm{O}_{2}, 10 \% \\
\text { consistencia, } 15 \% \mathrm{smiNaOH} \text {, } \\
120 \mathrm{~min}, 100^{\circ} \mathrm{C}, 6 \mathrm{~kg} \mathrm{O}_{2} / \mathrm{cm}^{2}\end{array}$ & $\begin{array}{l}50{ }^{\circ} \mathrm{C}, 20 \mathrm{FPU} / \mathrm{g} \\
\text { glucanos y } 40 \\
\mathrm{IU} / \mathrm{g} \text { glucanos, } \\
\mathrm{pH} 4,8,72 \mathrm{~h}\end{array}$ & $\begin{array}{l}\text { a) } 20,3 \% \\
\text { a+b) } 36 \%\end{array}$ & $\begin{array}{l}\text { (Stoffel R. } \\
\text { B., 2016) }\end{array}$ \\
\hline
\end{tabular}


En ambos casos la deslignificación con oxígeno mejora los rendimientos de la hidrólisis enzimática del material sometido previamente a explosión de vapor. Es un tratamiento deslignificante, ya que como se denota en el trabajo de Pan et al, la lignina disminuye de 42,8 a $12 \%$.

Análogamente al resultado de la deslignificación con peróxido alcalino, con la deslignificación empleando oxígeno alcalino el contenido de lignina residual es alto (44,18\% smp o 30,33\%smi). Es posible explicar esto dada la mayor sulfonación cuando se emplea dióxido de azufre en el tratamiento de explosión de vapor, lo que facilita remoción lignina y digestibilidad.

Es notable la existencia de una relación directa entre el contenido de lignina y la digestibilidad del material.

\section{k) Deslignificación con $\mathrm{NaOH}$ - etanol de los materiales pretratados con ácido}

Pese a que se trata de un tratamiento organosolv alcalino, se expone separadamente ya que en lugar de someter al aserrín original directamente al tratamiento deslignificante, se emplea esta etapa sobre un material proveniente de una secuencia desresinación seguida de explosión de vapor $\left(200^{\circ} \mathrm{C}\right.$, 5minutos y $3 \%$ ácido sulfúrico). Si bien el material se encuentra parcialmente deslignificado $(9,71 \%$ de lignina smi), el rendimiento de la hidrólisis enzimática es prácticamente el mismo que se obtiene solo con el material sin deslignificar $(24,1$ a $25,4 \%)$. Es posible, que la lignina presente se encuentre muy condensada debido al tratamiento ácido previo (explosión de vapor catalizada con ácido sulfúrico), lo cual obstaculiza ataque enzimático. Amiri y Karimi (2016), también trabajando con pino, probaron la deslignificación organosolv en dos etapas (1ra: $75 \%$ v/v etanol $+1 \%$ ácido sulfúrico, $10-15 \mathrm{~min}$ y $2 \mathrm{da}: 180^{\circ} \mathrm{C} 60 \mathrm{~min}$ ) sobre un material previamente sometido a autohidrólisis $\left(180^{\circ} \mathrm{C}\right.$ y $\left.60 \mathrm{~min}\right)$. Obtuvieron bajos rendimientos de hidrólisis enzimática $\left(45^{\circ} \mathrm{C}, 72 \mathrm{~h}\right.$ y $5 \mathrm{FPU} / \mathrm{g}$ material pretratado), menor a $10 \%$ solo con el pretratamiento de autohidrólisis y $23 \%$ con el material sometido a deslignificación organosolv (con un contenido de lignina de 24,8\%). 


\section{Efectos de la molienda}

En muchos casos los autores optan por someter el material pretratado a una etapa intermedia previa a la hidrólisis enzimática, específicamente a una molienda, para aumentar el área superficial y la digestibilidad. Si la molienda se realizó previo al pretratamiento, no se emplea este paso adicional. Como se observó en los rendimientos de los materiales provenientes de la explosión de vapor, fue muy difícil aumentar su digestibilidad aún empleando una etapa adicional de deslignificación.

Por las razones previamente expuestas, se probó someter el material pretratado a una molienda empleando un molino de granos. Se realizaron 3 pasadas del material por el mismo con agua y luego se filtró dicho material en un tamiz de 200mesh (tamaño abertura 0,074 mm). Luego se realizó la hidrólisis enzimática del material en las condiciones mencionadas en materiales y métodos.

Los resultados obtenidos se encuentran en la Tabla 18 (el porcentaje se calculó sobre la digestibilidad original, sin molienda). En concordancia con los resultados de otros autores previamente expuestos, en la mayoría de las muestras se produjeron aumentos del 8-9\% (que representan 30-40\% del rendimiento inicial), sin embargo los rendimientos siguen siendo bajos. En el caso del último material (38) la digestibilidad de ese material no se modificó dado que el desvío estándar de la hidrólisis es +/- 3-4\%.

Tabla 18. Digestibilidad de los materiales con y sin molienda.

\begin{tabular}{|c|c|c|c|c|c|}
\hline $\begin{array}{c}\mathbf{N} \\
\circ\end{array}$ & Condición pretratamiento & Sin & Con & $\Delta$ & $\%$ \\
\hline 8 & $\begin{array}{l}\text { Desresinación }+\mathrm{EV}\left(200^{\circ} \mathrm{C}, 5 \mathrm{~min}, 3 \% \mathrm{H}_{2} \mathrm{SO}_{4}(\mathrm{se} \text { emplea }\right. \\
\text { material húmedo) }\end{array}$ & 20,30 & 28,65 & 8,35 & 41,1 \\
\hline 34 & $\begin{array}{c}\text { Desresinación }+\mathrm{EV}\left(200^{\circ} \mathrm{C}, 5 \mathrm{~min}, 3 \% \mathrm{H}_{2} \mathrm{SO}_{4}\right)+5 \% \mathrm{H}_{2} \mathrm{O}_{2} ; 120 \\
\text { minutos, } \mathrm{pH} 11,5\end{array}$ & 22,45 & 31,59 & 9,14 & 41,7 \\
\hline 35 & $\begin{array}{c}\text { Desresinación }+\mathrm{EV}\left(200^{\circ} \mathrm{C}, 5 \mathrm{minutos}, 3 \% \mathrm{H}_{2} \mathrm{SO}_{4}\right)+10 \% \\
\mathrm{H}_{2} \mathrm{O}_{2} ; 120 \mathrm{minutos}, \mathrm{pH} 11,5,90{ }^{\circ} \mathrm{C}\end{array}$ & 27,49 & 35,58 & 8,09 & 29,4 \\
\hline 38 & $\begin{array}{c}\text { Desresinación alcalina }+\mathrm{EV}\left(200^{\circ} \mathrm{C}, 5 \mathrm{~min} \mathrm{y} \mathrm{3 \%} \text { ácido } \mathrm{H}_{2} \mathrm{SO}_{4}\right. \\
+ \text { deslignificación con } \mathrm{O}_{2}(10 \% \text { consistencia, } 15 \% \text { smi } \mathrm{NaOH}, \\
\left.120 \mathrm{~min}, 100{ }^{\circ} \mathrm{C}, 6 \mathrm{~kg} \mathrm{O}_{2} / \mathrm{cm}^{2}\right)\end{array}$ & 35,97 & 35,55 & $-0,42$ & 1,2 \\
\hline
\end{tabular}




\section{Análisis del efecto de la composición química del material sobre la hidrólisis enzimática}

El RHE como una función de los carbohidratos y del contenido de lignina se observa en la Figura 23 y en la Figura 24 respectivamente, para el material fibroso obtenido de la aplicación de los diferentes pretratamientos al pino.

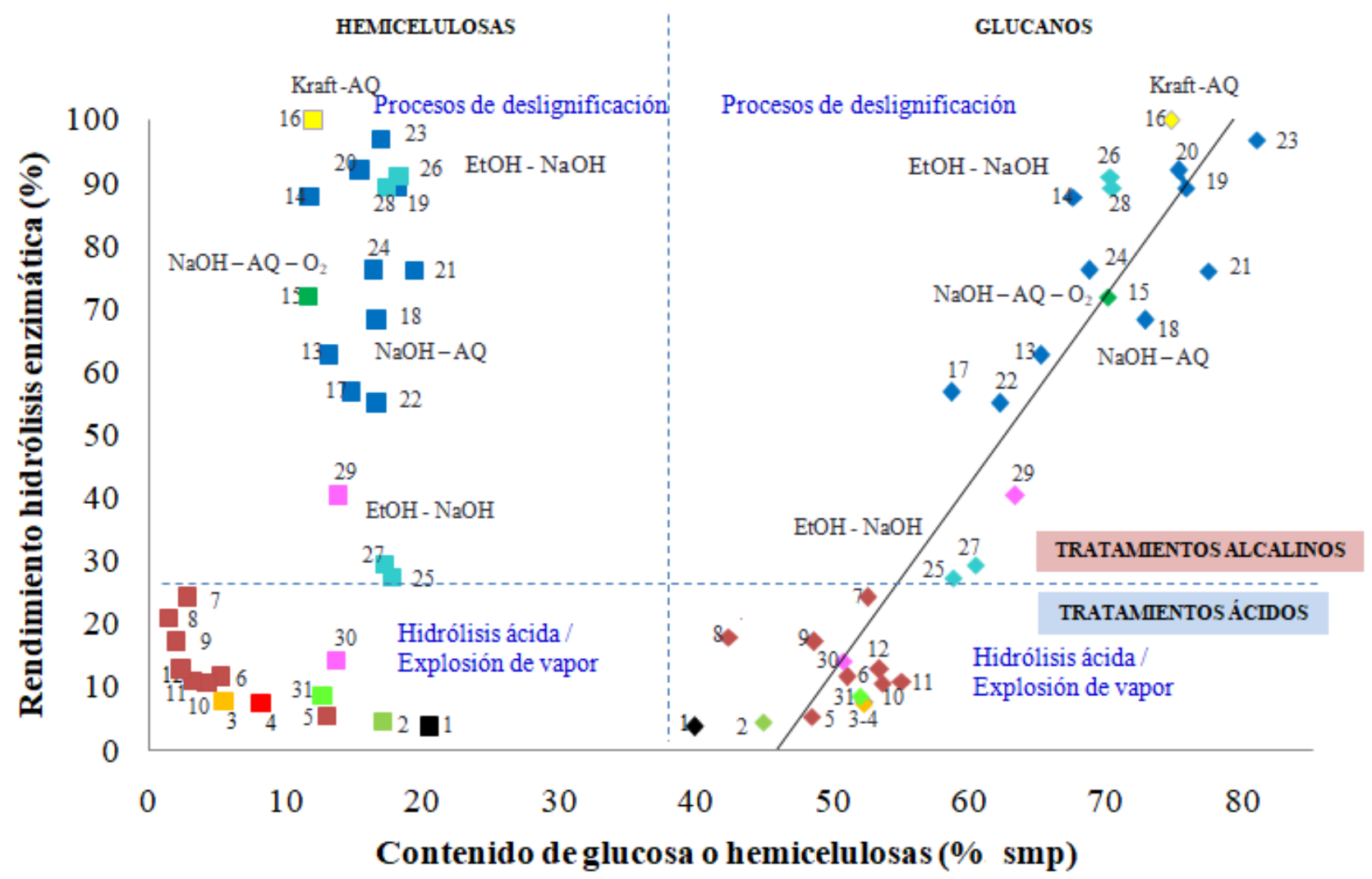

Figura 23. Digestibilidades enzimáticas (72h) en función del contenido de hemicelulosas o glucanos, especificando los tipos de tratamiento. 


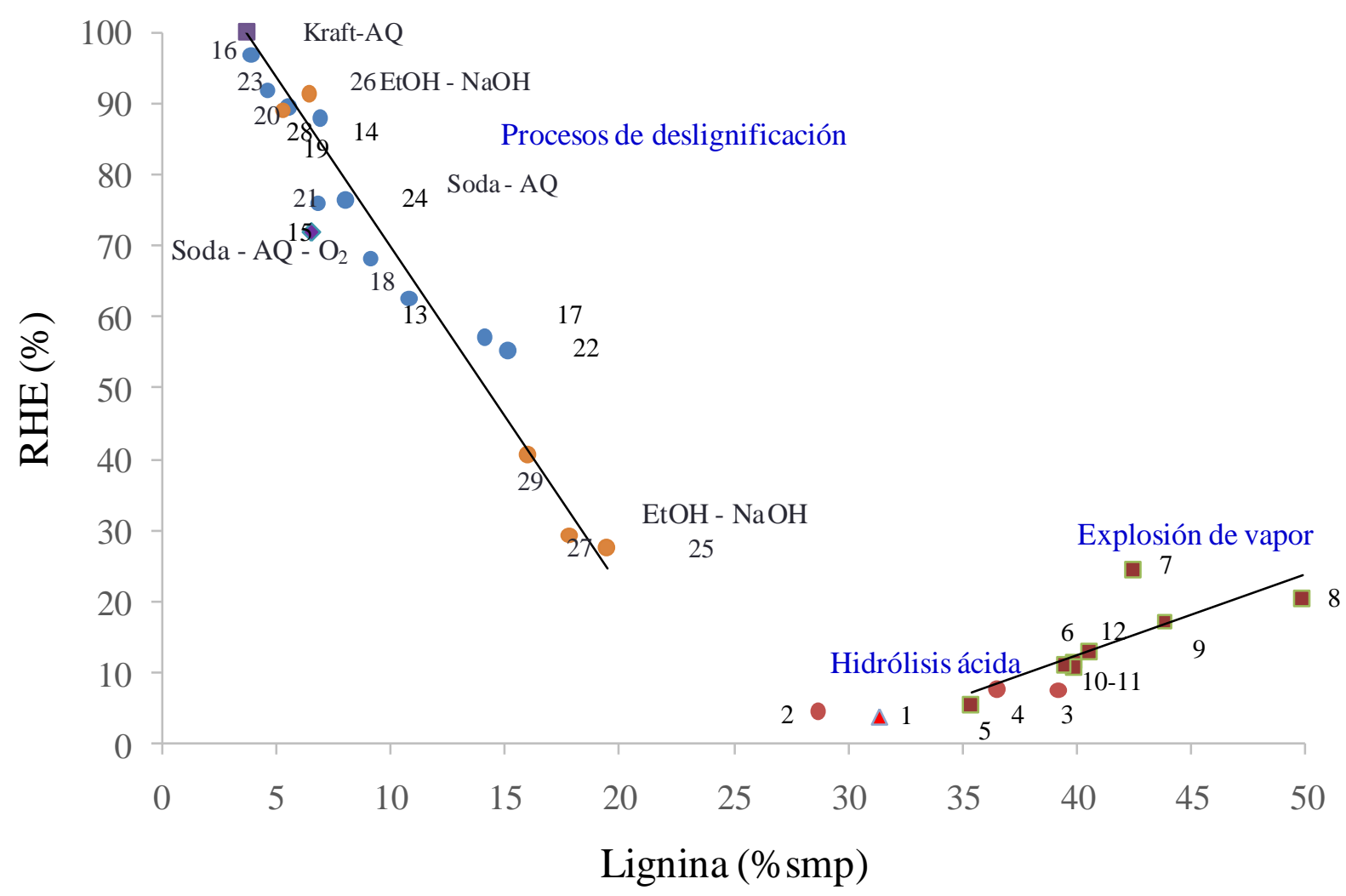

Figura 24. Digestibilidades enzimáticas (72h) en función del contenido de lignina, especificando los tipos de tratamiento.

Todos los pretratamientos causaron una reducción del contenido de hemicelulosas en el material fibroso, lo cual debería mejorar la accesibilidad de las enzimas (Zhu et al, 2010). El efecto de la explosión de vapor fue el más significativo, seguido de la hidrólisis ácida diluida. Los tratamientos alcalinos de deslignificación aplicados sobre el aserrín original preservaron parcialmente las hemicelulosas. Sin embargo, no se observó correlación entre el nivel de extracción de las hemicelulosas y el RHE (Figura 23). El tratamiento con ácido diluido prácticamente no afecta el $\operatorname{RHE}(7,7$ y 7,5\% en los ensayos 3 y 4 respectivamente) con respecto al material sin pretratar $(5,40 \%)$, mientras que el aserrín tratado con explosión de vapor alcanza valores más altos. Por otra parte, los tratamientos que se aplicaron al aserrín tal cual con alta carga alcalina $(14,16,19,21,23$, 24, 26 y 28) llevan a un RHE mucho mayor ( $88 \%$ y superiores).

Debido a la elevada extracción de hemicelulosas, la explosión de vapor lleva a un ficticio aumento del contenido de lignina en el balance de masa, como se ve en la Figura 24. Por el contrario, los 
tratamientos $\mathrm{NaOH}$-etanol, $\mathrm{NaOH}-\mathrm{AQ}, \mathrm{NaOH}-\mathrm{AQ}-\mathrm{O}_{2}$ y kraft-AQ remueven la lignina preservando parcialmente las hemicelulosas y aumentando el contenido de glucanos en el balance de masa (Figura 23). Por lo tanto, los tratamientos de deslignificación alcalina aplicados sobre el aserrín original son los que producen un material fibroso con el menor contenido de lignina y el mayor contenido de glucanos. No hay diferencia significativa ( $p$-valor $>0,05$ ) en el contenido final de glucanos de los materiales tratados con los procesos $\mathrm{NaOH}$-AQ y kraft-AQ (ambos sobre aserrín).

Contrariamente a las hemicelulosas, existe una correlación entre el rendimiento de la hidrólisis enzimática y el contenido de glucanos del material, como se muestra en el modelo empírico de la ecuación 9, donde $\mathrm{R}_{1}$ representa RHE en función del contenido de glucanos, considerando los aserrines sin pretratar y los materiales tratados (2-31).

\section{$R_{1}=-128,3+2,86 x$ contenido de glucanos $R^{2}=0,864$ Ecuación 9}

No se incluyen en la figura ni en la ecuación los materiales sometidos a un tratamiento ácido (HAD o EV) con posterior deslignificación. Como se analizó en detalle previamente, dichos materiales son refractarios a la deslignificación, por lo cual los contenidos de lignina residual continúan siendo elevados para obtener una buena digestibilidad. Además del contenido, influye la distribución de la lignina. Pielholp et al (2015) encontraron que las reacciones de repolimerización, especialmente en ligninas de coníferas, modifican la nanoestructura de la lignina de una forma que se incrementa significativamente su área específica, lo cual suponen aumenta la unión improductiva con las enzimas. McDonough (1992) plantean que las estructuras guayacil- propano (predominantes en coníferas) son más susceptibles a las reacciones de condensación que las unidades siringil - propano (predominantes en latifoliadas). 
Los modelos desarrollados para celulosa pura no pueden ser aplicados a materiales lignocelulósicos con altos contenidos de lignina (Bansal et al, 2009). Pueden encontrarse dos tendencias diferentes con respecto al impacto en el RHE (Figura 24) considerando el contenido de lignina, por lo cual pueden diferenciarse dos modelos (i) uno basado en los tratamientos de remoción de lignina $\left(R_{2}\right.$, tratamientos alcalinos del 13 al 29) y (ii) otro basado en los tratamientos de remoción de hemicelulosas $\left(R_{3}\right.$, tratamientos de EV de 5 al 12; exceptuando experiencia 7), ecuación 10 y ecuación 11:

\section{$R_{2}=112,3-4,34 x$ contenido de lignina $\quad R^{2} \approx 0,95 \quad$ Ecuación 10}

\section{$R_{3}=-30,05+1,04 x$ contenido de lignina $R^{2} \approx 0,94 \quad$ Ecuación 11}

Draude et al (2001), trabajaron con deslignificación con oxígeno, encontrando una relación lineal entre la fracción del incremento en la conversión de los carbohidratos frente a la fracción de lignina removida.

Además de los beneficios de la remoción de la lignina, que funciona como un inhibidor de la hidrólisis enzimática, los tratamientos alcalinos producen un hinchamiento del material lignocelulósico y por lo tanto incrementa el área superficial interna (Singha et al, 2015). Adicionalmente, este tratamiento también rompe el enlace entre la lignina y la fracción de carbohidratos, haciendo que el material sea más accesible a las enzimas (Yu et al, 2011) y como consecuencia, que mejore el RHE. Esto está en concordancia con el hecho de que el álcali es uno de los agentes de hinchamiento más efectivos y el grado de hinchamiento afecta la hidrólisis enzimática (Aditiya et al, 2016; Wingren et al, 2008).

La pendiente hallada para las experiencias de explosión de vapor (sin deslignificar) es positiva, aparentando un aumento del RHE con el incremento relativo del contenido de lignina. Sin embargo, 
el contenido real de lignina es apenas afectado en el proceso y lo que aparenta ser un aumento relativo de lignina en porcentaje es en realidad debido a la extracción de hemicelulosas, como se mencionó previamente. De hecho, es la remoción de las hemicelulosas (Figura 23), así como el disturbio concomitante del complejo carbohidrato-lignina, lo que mejora la porosidad de las fibras y el área disponible para la hidrólisis enzimática. Por otra parte, es probable que la estructura de la lignina haya sido modificada por el pretratamiento ácido (Stoffel R. B., 2016), ya que el RHE casi no se vió afetado a pesar de la extracción de hemicelulosas (Figura 23) y la leve deslignificación.

Se aplicó un modelo de regresión múltiple a los valores obtenidos de HE en función de los contenidos de lignina y hemicelulosasconsiderando todas las experiencias (1 a 31). El mejor modelo obtenido se muestra en la ecuación 12 .

\section{$R_{4}=102,171-1,806 x c o n t$. lignina $-0,088$ cont. de lignina $x$ cont. hemicelulosas \\ $\mathbf{R}^{2} \approx 0,95$ Ecuación 12}

El rango de aplicación de este modelo es de 4 a 49,86\% contenido de lignina y de 1,3 a 20,85\% contenido de hemicelulosas. El modelo plantea que tanto el contenido de lignina como la interacción entre la lignina y las hemicelulosas actúan en detrimento del rendimiento de la hidrólisis enzimática.

Wong et al (1988) reportaron la influencia de la porosidad de la fibra en la digestión de la celulosa en Pinus radiata tratado con explosión de vapor. Ellos observaron que el aumento del volumen de poro y el área superficial mejoraban la hidrólisis enzimática, alcanzando 24,1\% de RHE (para $24 \mathrm{~h}$ con un pretratamiento de $\mathrm{EV}$ sin catalizador a $215^{\circ} \mathrm{C}$ durante 3 minutos). Este valor es similar al RHE obtenido con el material de la experiencia 7. 


\section{Cristalinidad}

Para entender mejor el efecto de la extracción de hemicelulosas y/o lignina en el RHE, ocho muestras de aserrín de pino (sin pratratar y pretratado) fueron seleccionadas para analizar su cristalinidad y porosidad. La selección se realizó empleando muestras pretratadas de diferente contenido de lignina y similar digestibilidad o inversamente, similar digestibilidad y diferente contenido de lignina, también considerando materiales provenientes de fraccionamientos distintos pero con similar digestibilidad y contenido de lignina, además del aserrín sin pretratar.

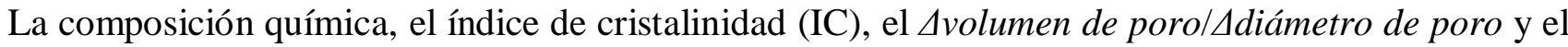
rendimiento de la hidrólisis enzimática de los pretratamientos seleccionados se observan en la tabla 19. El IC fue calculado acorde al método de Segal, empleado para determinar la cristalinidad en materiales lignocelulósicos.

Tabla 19. Compendio de la caracterización de los pretratamientos seleccionados.

\begin{tabular}{|c|c|c|c|c|c|c|c|}
\hline $\mathbf{N}^{\mathbf{o}}$ & Pretratamiento & $\begin{array}{c}\text { Glucanos } \\
(\%)\end{array}$ & $\begin{array}{c}\text { Hemicelulosas } \\
(\%)\end{array}$ & $\begin{array}{c}\text { Lignina } \\
(\%)\end{array}$ & $\begin{array}{l}\text { IC } \\
(\%)\end{array}$ & $\begin{array}{c}\Delta \text { Poro } / \Delta D * 100 \\
(D=0,792 n m)\end{array}$ & $\begin{array}{l}\text { RHE } \\
(\%)\end{array}$ \\
\hline 1 & Sin pretratar & 39,9 & 20,5 & 31,4 & 56,4 & 2,084 & 5,4 \\
\hline 7 & EV & 52,5 & 2,8 & 42,5 & 65,7 & 6,791 & 24,1 \\
\hline 12 & EV & 53,4 & 2,3 & 40,6 & 67,2 & 6,788 & 12,9 \\
\hline 15 & $\mathrm{NaOH}-\mathrm{AQ}-\mathrm{O}_{2}$ & 70,1 & 11,7 & 6,5 & 76,1 & 26,850 & 72,0 \\
\hline 16 & Kraft-AQ & 74,7 & 12,0 & 3,8 & 76,3 & 4,899 & 100,0 \\
\hline 23 & $\mathrm{NaOH}-\mathrm{AQ}$ & 81,0 & 16,9 & 4,0 & 75,5 & 8,190 & 96,9 \\
\hline 25 & $\mathrm{NaOH}-\mathrm{EtOH}$ & 58,8 & 17,8 & 19,5 & 65,0 & 15,805 & 27,4 \\
\hline 26 & $\mathrm{NaOH}-\mathrm{EtOH}$ & 70,2 & 18,2 & 6,4 & 70,4 & 13,068 & 91,1 \\
\hline
\end{tabular}

Los diagramas de rayos X de las muestras seleccionadas se observan en la Figura 25. 


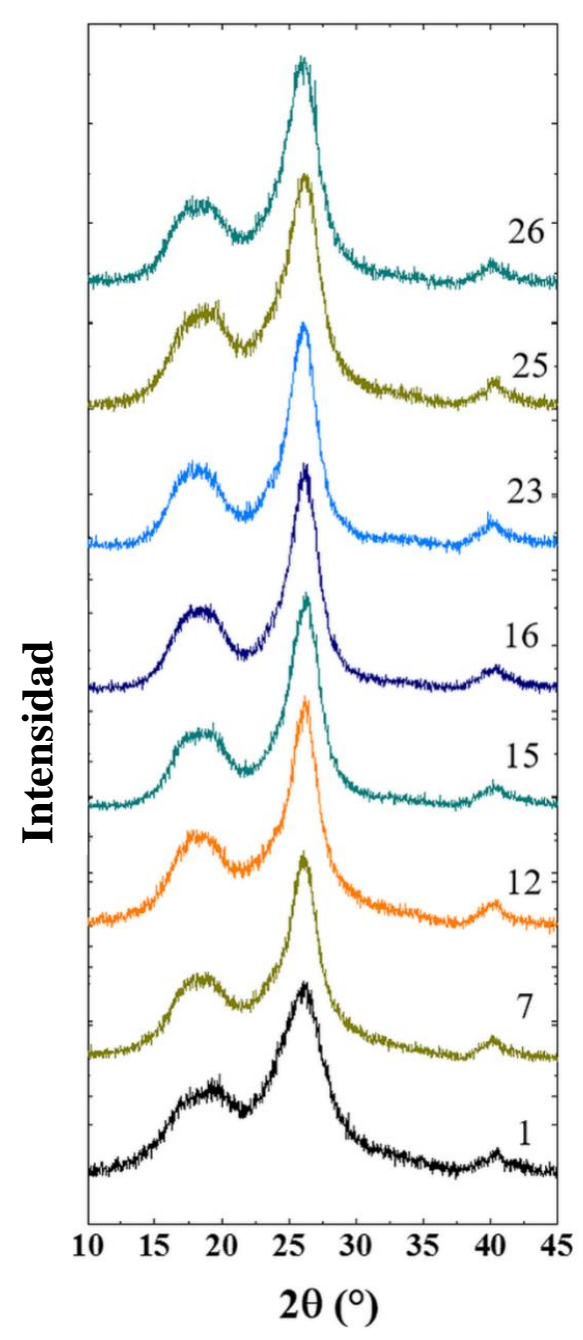

Figura 25. Diagrama rayos $X$ de las muestras seleccionadas.

El IC del aserrín sin pretratamiento fue $56,4 \%$, similar a lo encontrado por otros autores para pino (Andersson et al, 2004). Los tratamientos $\mathrm{NaOH}-\mathrm{AQ}-\mathrm{O}_{2}$, Kraft y NaOH-AQ, experiencias 15, 16 y 23 produjeron los materiales más deslignificados (lignina $<7 \% \mathrm{smp}$ ) y los valores de IC más altos $(\approx 76 \%)$, mientras que el IC de los materiales provenientes de explosión de vapor y $\mathrm{NaOH}$-etanol fueron menores $(\approx 66 \%$ en los tratamientos 7,12 y 25$)$. Una fuerte y significativa correlación positiva $(\mathrm{r}=0,94, \mathrm{p}<0,05)$ se encontró entre el IC (que varió desde 56,4 a 76\%) y el contenido de glucanos (con variación entre 40 a $81 \%$ smp). Por el contrario, una débil pero significativa correlación negativa se encontró con la lignina $(\mathrm{r}=-0,73, \mathrm{p}<0,05)$, similar a lo encontrado por Yu et al (2011). El aumento de cristalinidad con los tratamientos de deslignificación es debido a la remoción del 
material amorfo, como la lignina, hemicelulosas y celulosa amorfa, y fue detectado previamente por otros autores (Kumar et al, 2013; Park et al, 2010; Yoshida et al, 2008). El RHE del material se correlaciona positivamente con el IC $(r=0,86, p<0,05)$, ese es un resultado esperado ya que tanto el RHE y el IC correlacionan con el contenido de glucanos como se mencionó previamente (el material puro genera altos rendimientos de sacarificación), esto muestra la dificultad de desacoplar el IC de cambios en otras propiedades (Park et al, 2006). En la Figura 26 se observan las correlaciones mencionadas.
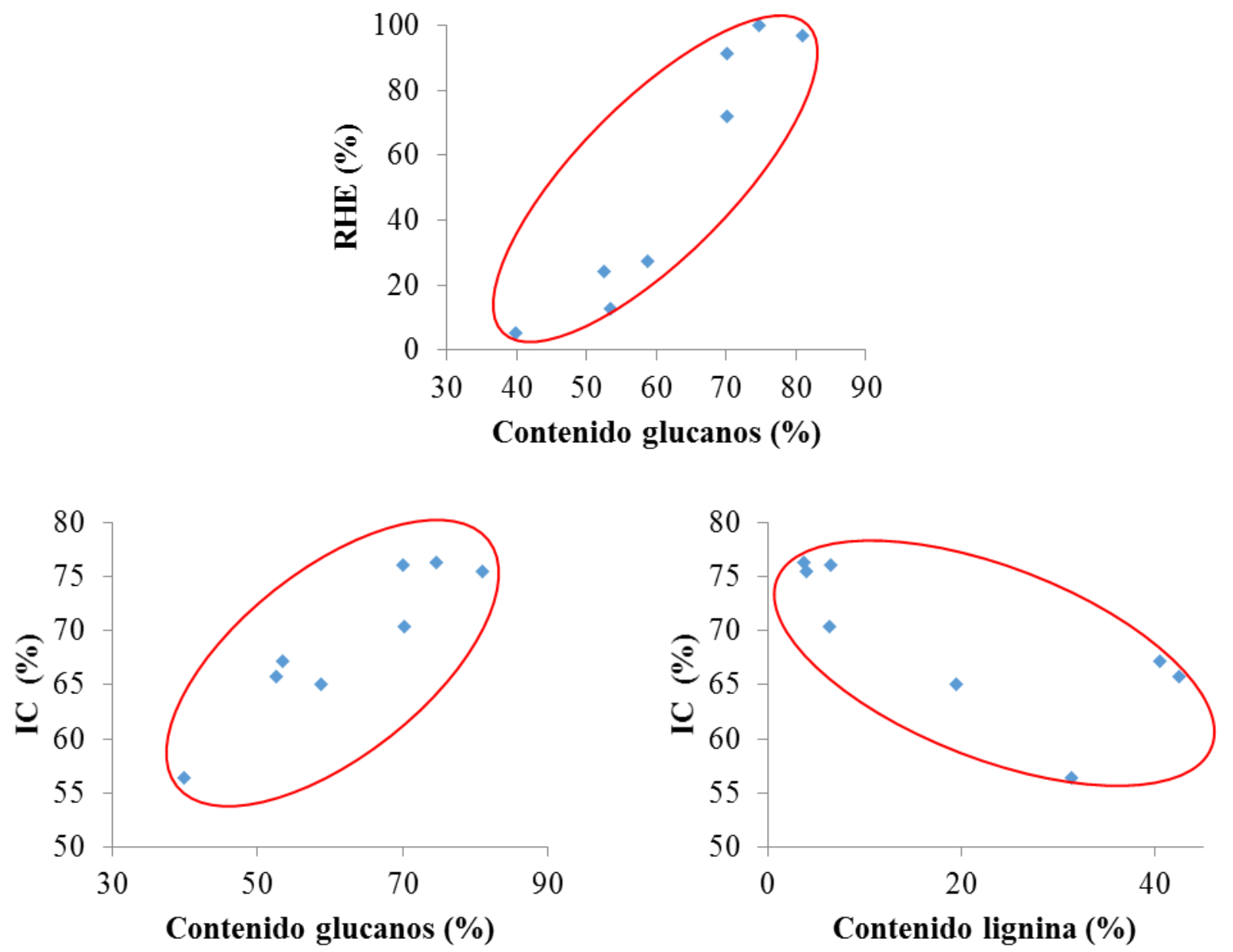

Figura 26. Gráfico de correlaciones significativas entre las variables estudiadas. 


\section{Porosidad}

El método seleccionado (DSC) para medir la porosidad del material es el método más adecuado cuando se trabaja con muestras húmedas (Hill \& Papadopolus, 2001).

El gráfico resultante de porosidad acumulamulativa se observa en la Figura 27 y el correspondiente a la distribución de poros se presenta en la Figura 28.

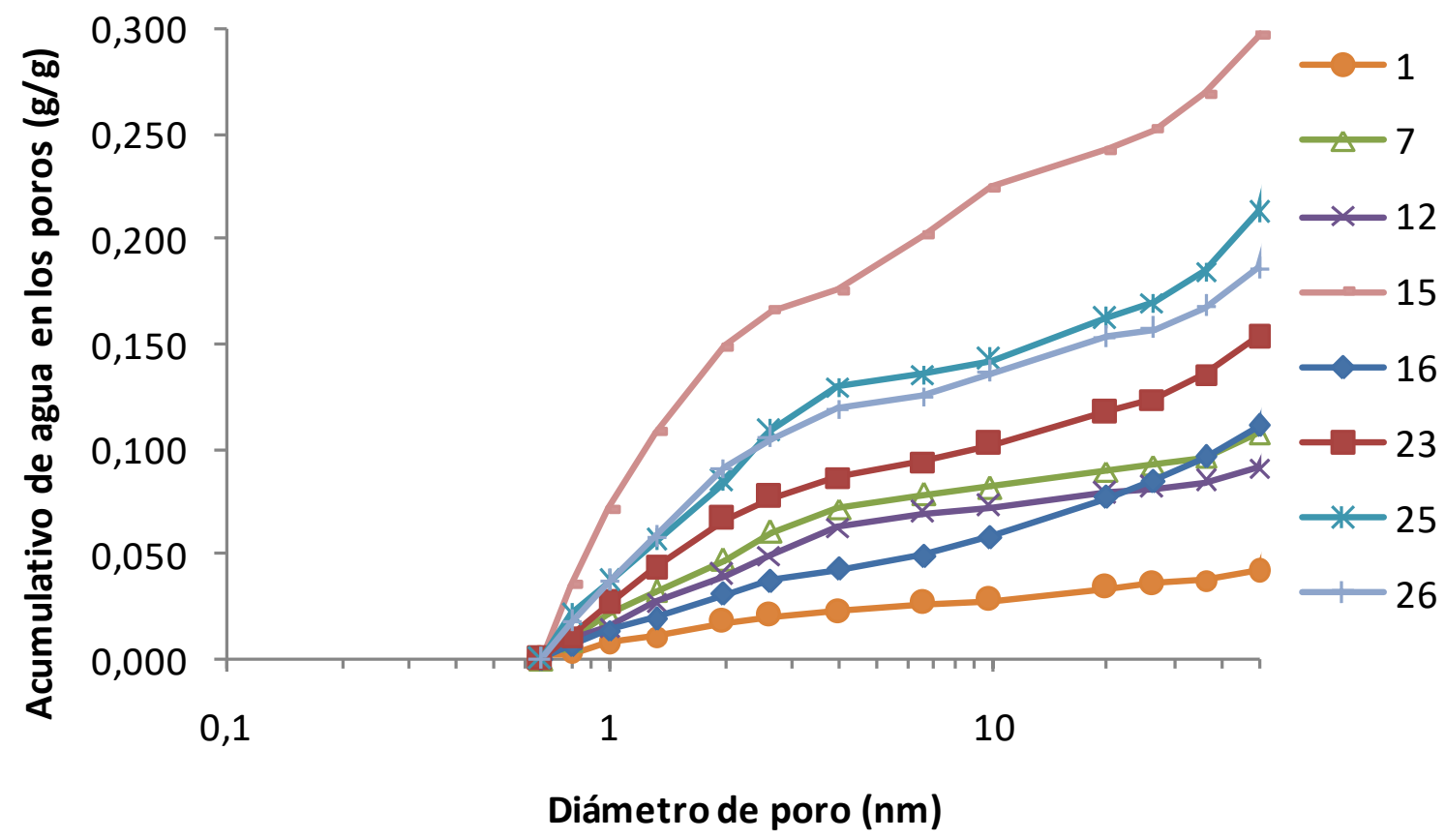

Figura 27. Gráfico de porosidad acumulada de las muestras seleccionadas. 


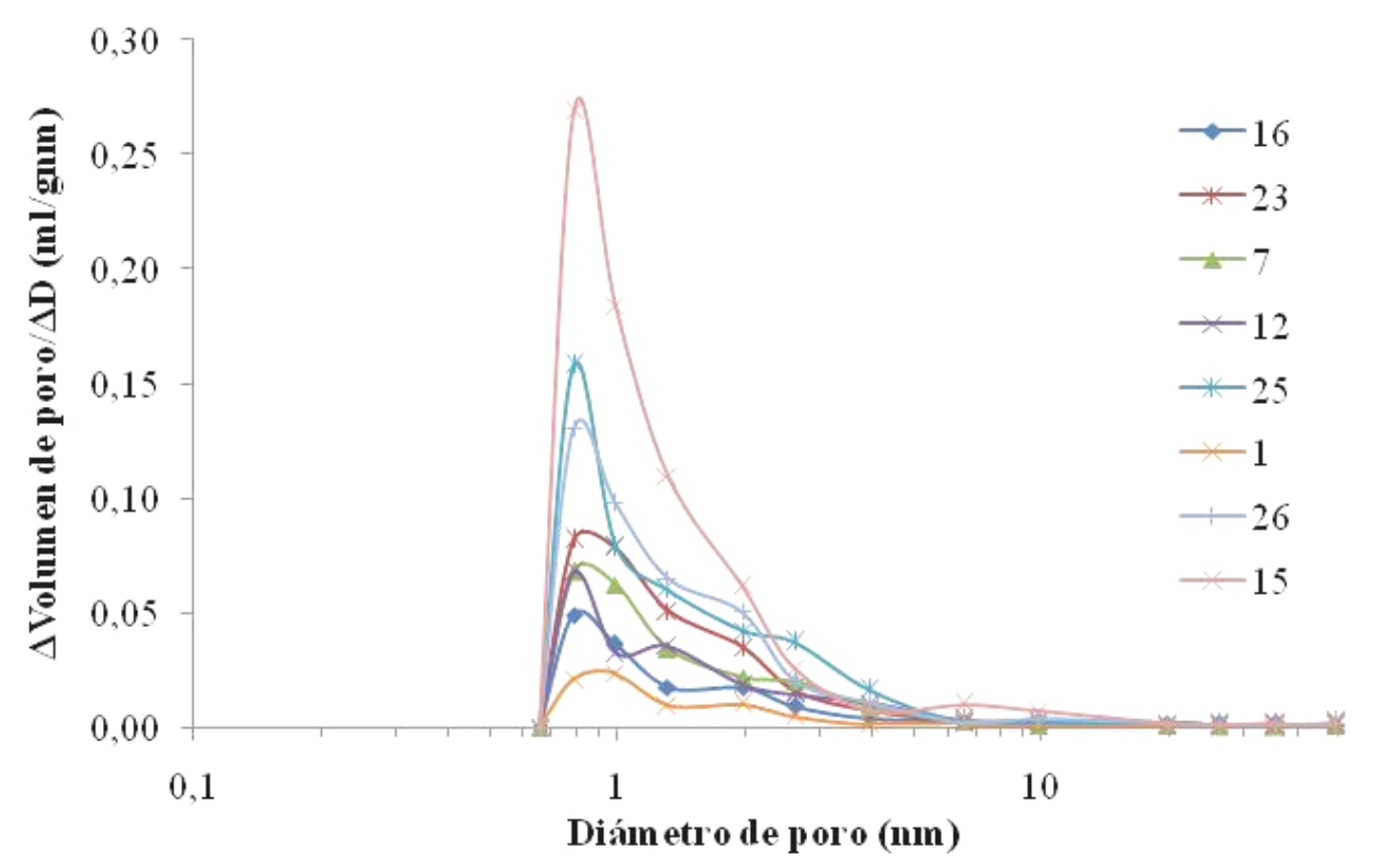

Figura 28. Gráfico de la distribución de poros de las muestras seleccionadas.

Los resultados revelan que, independientemente del tratamiento, todas las distribucionestienen una moda definida en el rango de 0,66 a 1,32 nm, y haciendo la comparación con el aserrín original, es posible concluir que hay un incremento del número de poros pero no en su diámetro. Este efecto ha sido descripto por otros autores. Por ejemplo, en el estudio de decaimiento por hongos de pudrición parda del liquidámbar, se observó que los volúmenes de microporo de la pared celular aumentaban durante la pudrición pero no había aumento de las dimensiones de los microporos (Flournoy et al, 1991). El aumento de número de poros en el rango de 0,66-1,32 nm es consistente con los hallazgos de Frey-Wyssling (1938), quien concluyó que las regiones ocupadas por componentes no-celulósicos en lasmicrofibrilas de la pared celular eran de $1 \mathrm{~nm}$ de ancho.

Como se observa en la Figura 28, la remoción de la lignina en general produce mayor número de poros que la remoción de hemicelulosas de los tratamientos de explosión de vapor, lo cual puede tener una relación con el modelo propuesto del arreglo ultraestructural de los polímeros de la madera en la pared celular de la Figura 6, en el cual se nota que los xilanos están atrapados en una matriz de 
lignina y los glucomamanos están unidos a la celulosa. Por lo cual, removiendo lignina, se abre más la estructura que si solo se extraen las hemicelulosas.

Los procesos como el pulpado y el blanqueo aumentan la porosidad mediante remoción de lignina y hemicelulosas de las fibras (Park et al, 2006). El impacto de los tratamientos en la porosidad (sin pretratar $<$ Kraft-AQ $\quad<\mathrm{EV}<\mathrm{NaOH}-\mathrm{AQ}<<\mathrm{NaOH}-\mathrm{EtOH}<<\mathrm{NaOH}-\mathrm{AQ}-\mathrm{O}_{2}$ ), revelan que la deslignificación con oxígeno aumenta notablemente el número de poros.

Stone et al (1969) empleando la técnica de exclusión de soluto, encuentran una correlación entre la digestibilidad con la accesibilidad de moléculas de $30 \AA$ (3nm), sugiriendo que el diámetro de la molécula de la enzima sería de 30 Å. Grethlein y Converse (1991) también empleando exclusión de soluto, plantean como primera aproximación un tamaño para las celulasas de T. reesei de $51 \AA$ (5,1nm). Comparando con el rango de máxima porosidad encontrado para los materiales estudiados (0,66-1,32nm), podemos suponerque no se observa una relación directa entre la distribución de poros obtenida y la digestibilidad de los pretratamientos, ya que el diámetro de la enzima sería entre 3 a 5 veces mayor al diámetro del poro del material. Sin embargo, teniendo en cuenta que se emplean técnicas diferentes para realizar las mediciones, es posible que las cifras no sean coincidentes.

\section{Resumen del análisis de las muestras seleccionadas}

La influencia de los glucanos, hemicelulosas, lignina, índice de cristalinidad y $\Delta$ Poro/ $\Delta \mathrm{Dx} 100$ (para $\mathrm{D}=0,792 \mathrm{~nm}$ ) en la hidrólisis enzimática se resume en la Figura 29. 


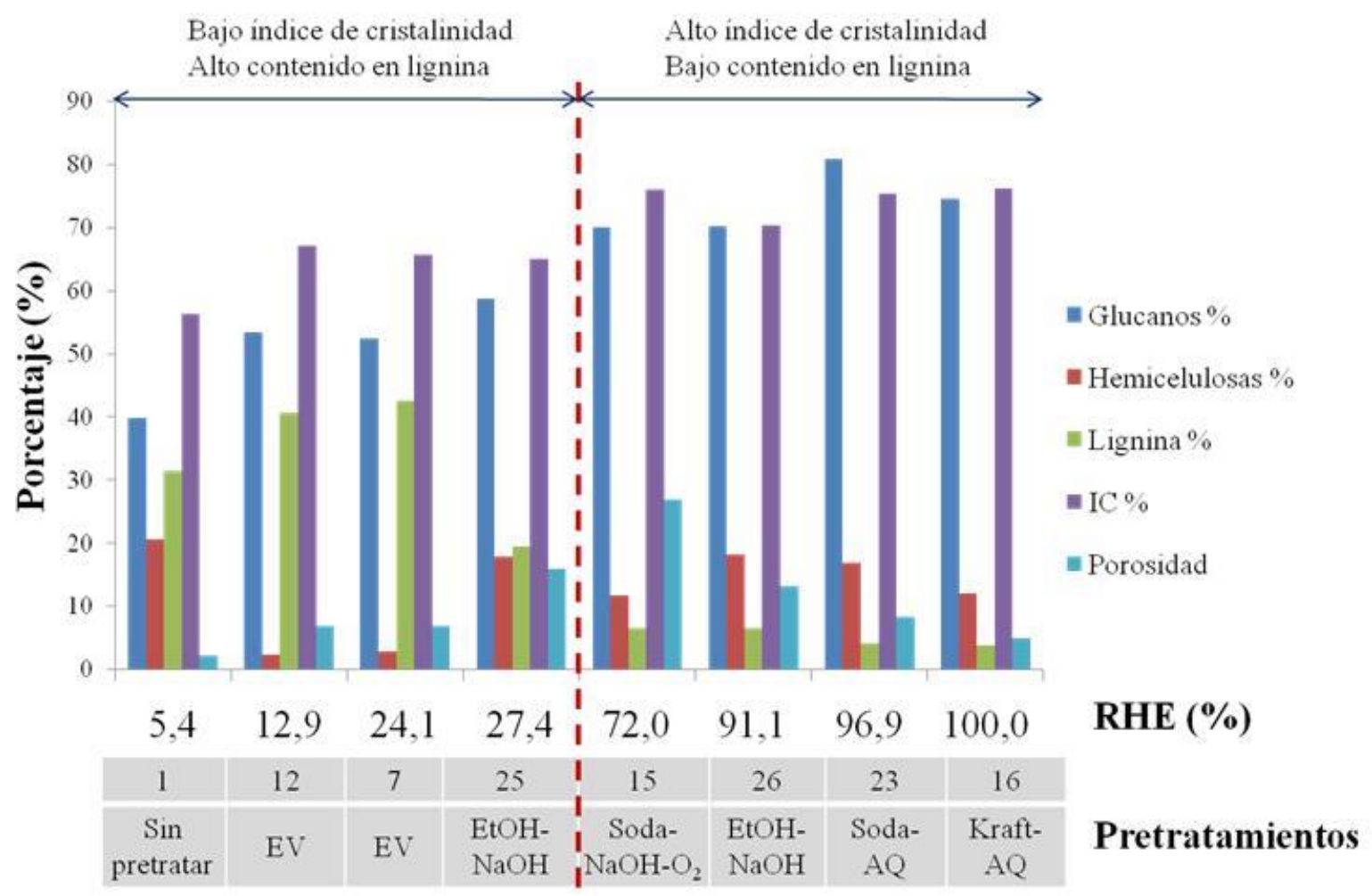

Figura 29. Resumen de la composición química, digestibilidad (72h), cristalinidad y porosidad de las ocho muestras seleccionadas.

En la Figura 29 es posible distinguir dos grupos de RHE marcadamente diferentes, cuya diferencia principal es el contenido de lignina. Los materiales con RHE mayor a 70\% presentan contenidos de lignina menores a 7\% (smp) y debido a la deslignificación también presentan a su vez contenidos de glucanos mayores a 70\%. Sin embargo, no es posible reconocer una tendencia clara entre el RHE y el contenido de hemicelulosas. Observando detalladamente la experiencia 25, el contenido de lignina es cercano al $20 \%$ y por su digestibilidad se observa que sigue siendo un contenido elevado que obstaculiza el ataque enzimático. Yu et al (2001) encontraron que a partir de un contenido de lignina de $15 \%$, los efectos de mayor deslignificación (con clorito de sodio) muestran efectos marginales en el aumento de la digestibilidad. Estos autores exponen que la lignina puede actuar de tres formas: como barrera física, uniéndose improductivamente a las enzimas (60-70 \% de las enzimas se unen en 
materiales no deslignificados) y el complejo lignina carbohidratos posiblemente limita también el ataque enzimático (Yu et al, 2001).

El aumento de IC producido por la EV es debido a la extracción de hemicelulosas, como muestran los datos en la Figura 29, pero está claro que la digestibilidad no aumentó significativamente. Análogamente, a pesar del efecto positivo de la explosión de vapor en la porosidad, no hay un aumento relevante en la digestibilidad. La razón de este comportamiento incluye que la estructura lignificada sumada a la naturaleza de la lignina de estos pinos (por ejemplo, la lignina de las coníferas posee más unidades guayacilo), limitarían el hinchamiento del material. Yu et al (2011) encontraron, para un mismo contenido de lignina, mayor digestibilidad para latifoliadas que para coníferas, confirmando nuevamente que las coníferas son más recalcitrantes.

\section{Fermentación}

Los rendimientos están usualmente expresados frente al rendimiento teórico, es decir 0,511 g de etanol/ g hexosa. Análogamente a la hidrólisis enzimática, los rendimientos de etanol están influenciados por la materia prima, el pretratamiento y el proceso de fermentación. En varios casos es necesario aplicar un proceso de detoxificación para eliminar inhibidores de la fermentación como el HMF, furfural y ácido acético, entre otros (Hahn-Hägerdal et al, 2006).

Los hidrolizados de la hidrólisis enzimática sobre los cuales se realizó la etapa de fermentación se observan en la Tabla 20. La tasa de crecimiento del inóculo fue de 2,2 x $10^{8}$ células $/ \mathrm{mL}$. 
Tabla 20. Materiales sobre los cuales se realizó la fermentación empleando el hidrolizado de la HE.

\begin{tabular}{|c|c|c|c|}
\hline $\begin{array}{c}\text { Fermentación } \\
\mathbf{N}^{\circ}\end{array}$ & $\begin{array}{c}\text { Experiencia } \\
\mathbf{N}^{\circ}\end{array}$ & Pretratamiento & Condiciones \\
\hline$(1)$ & 7 & $\begin{array}{c}\text { Desresinación alcalina } \\
\text { + explosión de vapor }\end{array}$ & $\begin{array}{c}90^{\circ} \mathrm{C}, 60 \text { minutos, } 5 \% \mathrm{smiNaOH}+200^{\circ} \mathrm{C}, \\
5 \text { minutos, } 3 \% \mathrm{smp} \mathrm{H}_{2} \mathrm{SO}_{4}\end{array}$ \\
\hline$(2)$ & 12 & $\begin{array}{c}\text { Explosión de vapor }+ \\
\text { lavado alcalino }\end{array}$ & $\begin{array}{c}190^{\circ} \mathrm{C}, 7,5 \text { minutos, } 0,75 \% \mathrm{smi}_{2} \mathrm{SO}_{4}+ \\
60^{\circ} \mathrm{C}, 60 \text { minutos, } 0,4 \% \mathrm{smpNaOH}\end{array}$ \\
\hline$(3)$ & 15 & soda-AQ-oxígeno & $\begin{array}{c}170^{\circ} \mathrm{C}, 170 \text { minutos, } 25 \mathrm{~g} / \mathrm{L} \mathrm{NaOH}, \mathrm{RLM} \\
10 / 1+120^{\circ} \mathrm{C}, 60 \mathrm{minutos}, 10 \% \\
\text { consistencia, } 6 \mathrm{~kg} / \mathrm{cm}^{2}\end{array}$ \\
\hline$(4)$ & 16 & Kraft-AQ & $\begin{array}{c}170^{\circ} \mathrm{C}, 170 \text { minutos, } 25 \mathrm{~g} / \mathrm{L} \mathrm{NaOH}, 0,11 \% \\
\mathrm{AQ}, \mathrm{RLM} 10 / 1\end{array}$ \\
\hline$(5)$ & 23 & Soda-AQ & $\begin{array}{c}170^{\circ} \mathrm{C}, 140 \text { minutos, 55, } 17 \mathrm{~g} / \mathrm{L} \mathrm{NaOH}, \\
0,11 \% \mathrm{AQ}, \mathrm{RLM} 5 / 1\end{array}$ \\
\hline
\end{tabular}

En la Figura 30 se observa claramente el descenso del contenido de glucosa y el incremento en el contenido de bioetanol. En 30 horas, la mayoría de las muestras alcanzaron la concentración máxima.

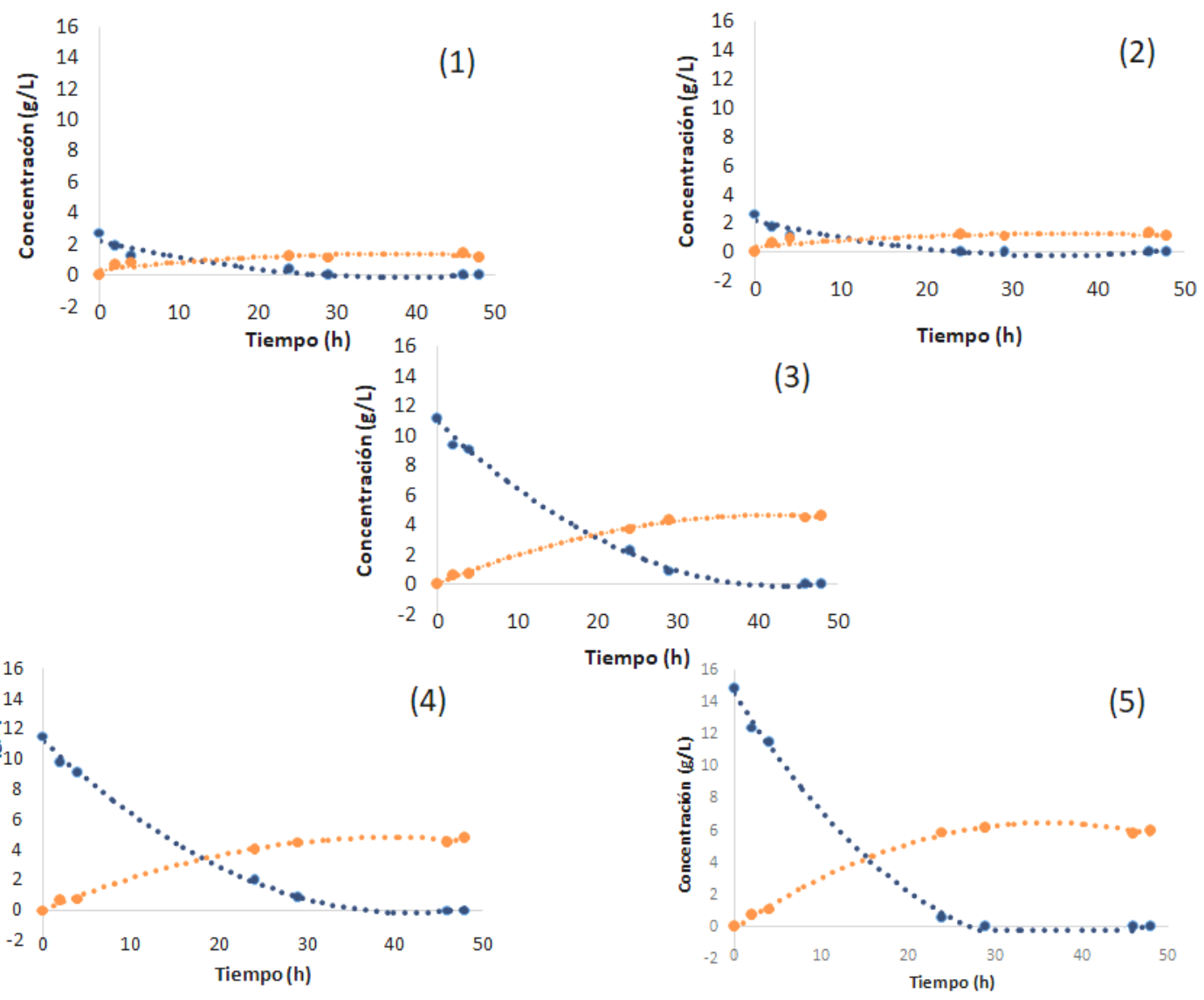

Figura 30. Concentración (g/L) de glucosa (azul) y de etanol (naranja) en función del tiempo (horas). Los números corresponden a las experiencias de la Tabla 20. 
Empleando HPLC no se detectaron inhibidores en los hidrolizados, como ser HMF, furfural u ácidos carboxílicos. El rendimiento al final de la fermentación varió entre 88 y $93 \%$, estos máximos se alcanzaron en general a las 30 horas (Figura 31). Las muestras 1 y 2 alcanzan el máximo más rápido. Es posible concluir que los hidrolizados son viables para el proceso de fermentación empleado.

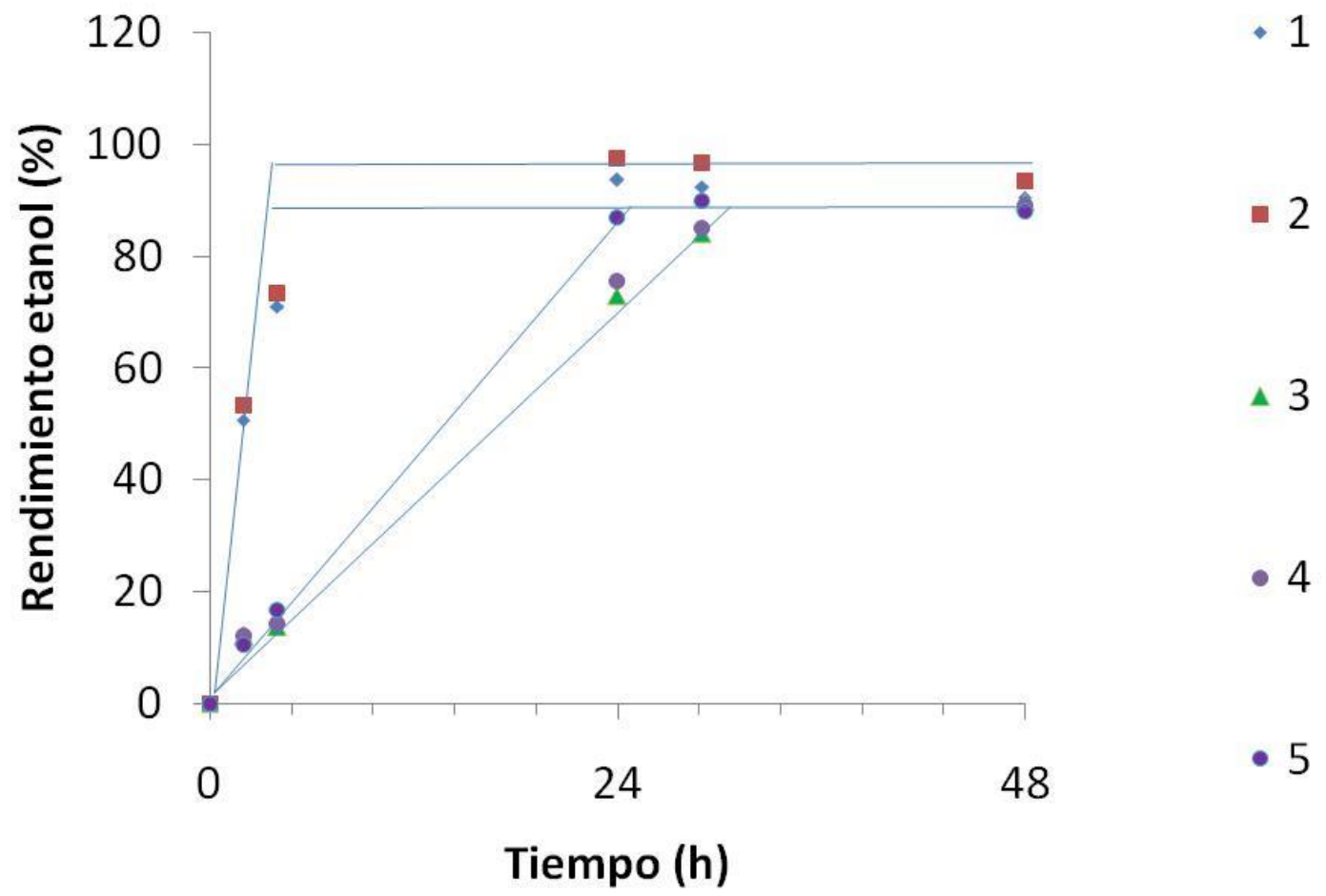

Figura 31. Rendimiento de etanol (\% sobre el máximo) en función del tiempo.

Los rendimientos de etanol reportados obtenidos a partir de los hidrolizados enzimáticos de aserrín de pino que proceden de pretratamientos con bajos o medios rendimientos de sacarificación, son generalmente bajos, en el rango de $28 \%$ a 46,6\%, empleando un proceso de sacarificación e hidrólisis separadas. Por el contrario, los materiales deslignificados presentan altos rendimientos de etanol, en coincidencia con lo planteado por otros autores ya sea empleando procesos SHF o SSF, por ejemplo, $80,42 \%$ con un proceso SSF y $88 \%$ con SHF (Vallejos et al, 2017). 


\section{CAPÍTULO V. CONCLUSIONES}

Este trabajo se realizó con el objetivo de encontrar los requisitos de calidad que debe poseer el material celulósico pretratado para su conversión a bioetanol. Al mismo tiempo estudiar a influencia del pretratamiento en las etapas siguientes (hidrólisis y fermentación). Las conclusiones obtenidas se detallan a continuación.

Todos los pretratamientos aplicados al aserrín de pino aumentaron el rendimiento de la hidrólisis enzimática pero el contenido de lignina y su distribución han demostrado tener un efecto dominante en el carácter recalcitrante de la biomasa a la digestibilidad enzimática.

La extracción de las hemicelulosas hasta $89 \%$ smi, juega un rol menor, siendo menor a $25 \%$ el máximo rendimiento obtenido con los tratamientos ácidos (EV y HAD).

Los tratamientos Kraft y NaOH-AQ produjeron el mayor índice de cristalinidad (de 75-76\%) y también el mayor rendimiento de hidrólisis enzimática, sin embargo el efecto de la cristalinidad puede ser confundido con el aumento del contenido de glucanos. Debieran ampliarse los estudios de cristalinidad de materiales de diferentes calidades para verificar si es posible desdoblar estas variables.

El análisis de termoporosimetría por DSC dio como resultado que en todos los tratamientos evaluados mediante esta técnica aumentó el número de poros pero no su diámetro. El orden referente a la porosidad encontrado fue aserrín sin pretratamiento $<$ Kraft-AQ $<$ EV $<\mathrm{NaOH}-\mathrm{AQ}<<\mathrm{NaOH}-$ EtOH $<<\mathrm{NaOH}-\mathrm{AQ}-\mathrm{O}_{2}$. La porosidad aumenta con la extracción tanto de hemicelulosas como de lignina. No queda clara la relación entre el tamaño del poro y el tamaño de las enzimas, y su relación con la eficiencia del proceso de HE.

Se pueden encontrar dos modelos de regresión lineal con respecto a la digestibilidad del material pretratado en función del contenido de lignina, I) negativa, basada en la remoción de lignina $\left(\mathrm{R}^{2} \approx 0,95\right)$ y II) positiva, basado en la extracción de hemicelulosas mediante explosión de vapor 
$\left(\mathrm{R}^{2} \approx 0,94\right)$. También existe un modelo de regresión lineal positiva que vincula la digestibilidad con el contenido de glucanos $\left(\mathrm{R}^{2} \approx 0,86\right)$. Considerando una regresión múltiple, el modelo resultante considera tanto el contenido de lignina como la interacción entre lignina y hemicelulosas, ambos con influencia negativa sobre la constante, es decir en detrimento de la digestibilidad $\left(\mathrm{R}^{2} \approx 0,95\right)$.

En los hidrolizados seleccionados, analizando con HPLC, no se detectaron inhibidores del proceso fermentativo (HMF, furfural y ácidos carboxílicos). El rendimiento al final de la fermentación (con Saccharomyces cerevisiae) varió entre 88 y 93\%. En la mayoría de los casos, estos valores se alcanzaron las 30h, mostrando que los hidrolizados son viables para el proceso de fermentación empleado.

El requisito de calidad de un material celulósico pretratado para maximizar su rendimiento de hidrólisis enzimática es, fundamentalmente, presentar un bajo contenido de lignina. El contenido de hemicelulosas por sí solo no es un factor significativo, tornándose importante solamente cuando existe una simultánea extracción de lignina (interacción). Considerando los resultados observados, la mejor opción es aplicar directamente un tratamiento alcalino deslignificante sobre el aserrín para luego sacarificarlo. 


\section{REFERENCIAS BIBLIOGRÁFICAS}

Achinas, S., \& Euverink, G. (2016). Consolidated briefing of biochemil ethanol production from lignocelulosic biomass.Electron. J. Biotechnol., 23, 44-53.

Aditiya, H., Mahlia, T., Chong, W., \& Nur, H. (2016). Second generation bioethanol production: A critical review. Renew. Sustain. Energy Rev., 66, 631-653.

Álvarez Godoy, E. (2017). ecoportal.net. Recuperado el 19 de 11 de 2017, de https://www.ecoportal.net/temas-especiales/educacion-ambiental/extractivos_del_arbol/

Alvarez-Vasco, C., Guo, M., \& Zhang, X. (2015). Dilute Acid Pretreatment of Douglas Fir Forest Residues: Pretreatment Yield, Hemicellulose Degradation, and Enzymatic Hydrolysability. Bioenerg. Res., 8, 42-45.

Alvarez-Vasco, C., \& Zhang, X. (2017). Alkaline hydrogen peroxide (AHP) pretreatment of softwood: Enhanced enzymatic hydrolysability at low peroxide loadings. Biomass and Bioenergy, 96, 96-102.

Alvira, P., Tomás-Pejó, E., Ballesteros, M., \& Negro, M. (2010). Pretreatment technologies for an efficient bioethanol production process based on enzymatic hydrolysis: A review. Bioresourse Technology, 101 (13), 4851-4861.

Amiri, H., \& Karimi, K. (2016).Integration of Autohydrolysis and Organosolv Delignification for Efficient Acetone, Butanol, and Ethanol Production and Lignin Recovery.Ind. Eng. Chem. Res., 55 (17), 4836-4845.

Andersson, S., Wikberg, H., Pesonen, E., Maunu, S. L., \& Serimaa, R. (2004). Studies of crystallinity of Scots pine and Norway spruce cellulose. Trees- Struct. Funt., 18 (3), 346-353.

Araújo, W. (2016). Ethanol Industry: surpassing Uncertainties and Looking Foward. En S. Monteiro Salles-Filho, L. Barbosa Cortez, J. Ferreira Jardim da Silva, \& S. Trinidade (Edits.), Global Bioethanol. Evolution, Risks, and Uncertaities (págs. 1-33). Academic Press.

Araya, F., Troncoso, E., Mendonça, R., Freer, J., Rencoret, J., \& Del Rio, J. (2015). Structural characteristics and distribution of lignin in eucalytus globulus pulps obtained by a combined autohydrolysis /alcaline extraction for enzymatic saccarificarification of cellulose. J. Chil. Chem. Soc., 60 (2), 2954-2960.

Area, M. C. (2012). Apunte curso de postgrado: Metodología de la investigación, módulo II estadística. Posadas, Misiones, Argentina.

Arora, A., Martin, E., Pelkki, M., \& Carrier, D. (2013). Effect of formic acid and furfural on the enzymatic hydrolysis of cellulose powder and dilute acid-pretreated Poplar hydrolysates. ACS sustainable Chem. Eng., 1 (1), 23-28. 
Asada, C., Sasaki, C., Hirano, T., \& Nakamura, Y. (2015).Chemical characteristics and enzymatic saccharification of lignocellulosic biomass treated using high-temperature saturated steam: Comparison of softwood and hardwood. Bioresource Technology, 182, 245-250.

Balat, M. (2011). Production of bioethanol from lignocellulosic materials via the biochemical pathway: A review. Energy Conversion and Management, 52 (2), 858-875.

Bansal, P., Hall, M., Realff, M., Lee, J., \& Bommarius, A. (2009).Modeling cellulase kinetics on lignocellulosic substrates.Biotechnology Advances (27), 833-848.

Bengoechea, D., Stoffel, R., \& Area, M. (2012). Pretratamientos o fraccionamientos. En M. Area, \& M. Vallejos (Edits.), Biorefinería a partir de residuos lignocelulósicos. Conversión de Residuos a Productos de Alto Valor. (págs. 109-150). Saarbrücken, Alemania: Editorial Académica Española.

BioRefineries blog. (s.f.). Recuperado el 10 de 04 de 18 de https://biorrefineria.blogspot.com.ar/p/listado-de-biorrefiern.html

Cámara de representantes. Provincia de Misiones. República Argentina. (2017). Recuperado el 29 de 10 de 2017, de http://www.diputadosmisiones.gov.ar/web_camara/home.php?secretaria=4\&pagina=ramas\&rama=1 $\underline{6 \# \text { menu }}$

Carriquiry, M., Du, X., \& Timilsina, G. (2011). Second generation biofuels: Economics and policies. Energy Policy, 39 (7), 4222-4234.

Charles, N. (2002). Master thesis. Oxigen delignification for the enzymatic hydrolysis of lignocellulosic material .University of British Columbia.

Cullis, F. (2003).Master thesis. The effect of steam explosion pretreatment parameters of softwood delignification efficiency .University of British Columbia.

Dagnino, E. (2012). En M. Area, \& M. Vallejos (Edits.), Biorrefinería a Partir de Residuos Lignocelulósicos. Conversión de Residuos a Productos de Alto Valor. (págs. 151-170). Saarbrücken: Editorial Académica Española.

Diario ámbito financiero. (01 de 04 de 2016). Recuperado el 22 de 05 de 2018, de http://www.ambito.com/833547-incrementan-de-10-a-12-el-corte-de-bioetanol-en-los-combustibles

Di Paola, M. M. (2013). La producción de biocombustibles en Argentina. Buenos Aires: Fundación Ambiente y Recursos Naturales (FARN).

Donaldson, L., Wong, K., \& Mackie, K. (1988). Ultrastructure of steam-exploded wood. Wood Sci. Technol., 22, 103-114.

Draude, K., Kurniawan, C., \& Duff, S. (2001). Effect of oxigen delignification on the rate and extend of enzymatic hydrolysis of lignocellulosic material. Bioresource technology (79), 113-120.

Driemeier, C., Mendes, F. M., \& Oliveira, M. M. (2012).Dynamic vapor sorption and thermoporometry to probe water in celluloses.Cellulose, 19 (4), 1051-1063. 
Duque, A., Manzanares, P., Ballesteros, I., \& Ballesteros, M. (2016).Steam Explosion as Lignocellulosic biomass pretreatment. En Biomass Fractionation Technologies for a Lignocellulosic Feedstock Based (págs. 349-368). Madrid: Elsevier Inc.

Energías renovables. El periodismo de las energías limpias. (2017). Recuperado el 2017 de 08 de 22, de https://www.energias-renovables.com/biomasa/la-convivencia-entre-tres-generaciones-debiorrefinerias-20130924

Fardim, P., Liebert, T., \& Heinze, T. (2012).Pulp Fibers for Papermaking and Cellulose Dissolution. The European Polysaccharide Network of Excellence (EPNEO), 253-282.

Fengel, D., \& Wegener, G. (1984).Wood, Chemistry - Ultrastructure - Reactions.Alemania.

Flournoy, D., Kirk, T., \& Highley, T. (1991). Wood Decay by Brown-Rot Fungi: Changes in Pore Structure and Cell Wall Volume. Holzforshung, 45 (5), 383-388.

French, A., \& Cintrón, M. (2013). Cellulose polymorphy, crystallite size, and the Segal Cristallinity Index. Cellulose, 20 (1), 583-588.

Frey-Wyssling A. (1938), Submicroscopic structure and maceration pictures of native cellulose fibers, Pap. Fabr., 36, 212-217.

Ghose, T. (1987).Measurement of cellulase activities. Pure \& Applied Chemistry, 59 (2), 257-268.

Glasser W.G., N. R. (2000). Lignin: Historical, Biological and Materials Perspectives. American Chemical Society.

Glasser, W. (2000). Lignin: Historical, Biological and Materials Perspectives. American Chemical Society.

González, J., \& García, A. (2015).Availability of forest biomass in Chile for second generation biodiesel production.6th International Congress of Energy and Environment Engineering and Management.París.

Gonzalez, R., Treasure, T., Phillips, R., Jameel, H., \& Saloni, D. (2011). Economics of cellulosic ethanol production: green liquor pretreatment for softwood and hardwood, greenfield and repurpose scenarios. BioResources, 6 (3), 2551-2567.

Grace, T. M., Malcom, E. W., \& Kocurek, M. J. (Edits.). (1989). Alkaline pulping (pulp and paper manufacture series, volume 5) (Tercera ed.). U.S.A.: TAPPI Press.

Grethlein, H. E., \& Converse, A. O. (1991).Common aspects of acid prehydrolysis and steam explosion for pretreating wood.Bioresource Technology, 36, 77-82.

Hahn-Hägerdal, B., Galbe, M., Gorwa-Grauslund, M., Lidén, G., \& Zacchi, G. (2006).Bio-ethanolthe fuel of tomorrow from the residues of today.Trends Biotechnol., 24 (12), 549-556. 
Heringer, N. (2016). Minimizing Ethanol Concentration in Organosolv Pretreatment for the Saccharification of Loblolly Pine.Biological and Agricultural Engineering Undergraduate Honors Theses (41).

Hill, C., \& Papadopolus, A. (2001). A review of methods used to determine the size of the cell wall microvoids of wood. Journal of the institute of wood science, 15 (6), 337-345.

Huang, F., \& Ragauskas, A. (2012). Dilute $\mathrm{H}_{2} \mathrm{SO}_{4}$ and $\mathrm{SO}_{2}$ pretreatments of Loblolly pine wood. Industrial Biotechnology, 8 (1), 22-30.

Huergo, H. A. (15 de 10 de 2011). Clarín. Recuperado el 29 de 05 de 2018, de https://www.clarin.com/rural/biodiesel_0_BJhPZk3hPXx.html

Imlauer, C., Felissia, F., Stoffel, R., \& Area, M. (2013). JCT (Jornadas Científico Tecnológicas $\mathrm{UNaM}$ ). Tratamiento alcalino e hidrólisis ácida del aserrín de pino para la biorefinería forestal. Posadas, Argentina.

Imlauer, C., Kruyeniski, J., Area, M., \& Felissia, F. (2014). Congreso Iberoamericano de investigación en celulosa y papel (CIADICYP). Fraccionamiento a la soda-AQ de aserrín de pino para la biorefinería forestal. Medellín, Colombia.

InfoLEG. Información legislativa. (2017a). Recuperado el 29 de 10 de 2017, de http://servicios.infoleg.gob.ar/infolegInternet/anexos/125000-129999/125179/norma.htm

InfoLEG. Información Legislativa. (2017b). Recuperado el 29 de 10 de 2017, de http://servicios.infoleg.gob.ar/infolegInternet/anexos/115000-119999/116299/norma.htm

Informe sobre la situación actual del sector foresto industrial de la provincia de Misiones. Diagnóstico y perspectivas para el año 2016. (2015). Posadas: Instituto Provincial de Estadísticas y Censos.

Inoue, H., Fujimoto, S., \& Sakaki, T. (2016). Two- step hot- compressed water treatment of douglas fir for efficient total sugar recovery by enzymatic hydrolysis. BioResources, 11 (2), 5124-5137.

Janssen, R., \& Rutz, D. (2011). Sustainability of biofuels in Latin America: Risks and opportunities. Energy Policy, 39 (10), 5717-5725.

Kaar, W., Cool, L., Merriman, M., \& Brink, D. (1991).The complete analysis of wood polysaccharides using HPLC.Journal of Wood Chemestry and Tecnology, 11 (4), 447-463.

Kamm, B. K. (2006). Biorefinery Systems - An Overview.En G. P. Kamm M., BiorefineriesIndustrial Processes and Products.Status Quo and Future Directions.Vol. 1 (págs. 3-33). KGaA: Weinheim: WILEY-VCH Verlag GmbH \& Co.

Kang, Q., Appels, L., Tan, T., \& Dewil, R. (2014). Bioethanol from Lignocellulosic Biomass: Current Findings Determine Research Priorities. Sci. World J., 1-13.

Kemp, I. (2007). Pinch Analysis and Process Integration: A User Guide on Process Integration for the Efficient Use of Energy. Butterworth-Heinemann: Elsevier Ltd. 
Kim, K., \& Hong, J. (2001). Supercritical $\mathrm{CO}_{2}$ pretreatment of lignocellulose enhances enzymatic cellulose hydrolysis. Bioresour. Technol., 77 (2), 139-144.

Koo, B., Kim, H., Park, N., Lee, S., Yeo, H., \& Choi, I. (2011).Organosolv pretreatment of Liriodendron tulifera and simultaneous saccharification and fermentation for bioethanol.Biomass and Bioenergy, (35), 1833-1840.

Kruyeniski, J., Felissia, F. \& Area, M. (2015). Enzymatic hydrolysis of pine pretreated with ethanol and sodium hidroxyde. 3er Congreso Iberoamericano sobre Biorrefinerías (CIAB). Concepción, Chile.

Kumar, L., Chandra, R., Chung, P., \& Saddler, J. (2010). Can the same steam pretreatment conditions be used for most softwoods to achieve good, enzymatic hydrolysis and sugar yields? Bioresource Technology, 101, 7827-7833.

Kumar, R., Hu, F., Hubbell, C. A., Ragauskas, A. J., \& Wyman, C. E. (2013).Comparison of laboratory delignification methods, their selectivity, and impacts on physiochemical characteristics of cellulosic biomass.Bioresource Biotechnology, 372-381.

Lai, C., Tu, M., Shi, Z., Zheng, K., Olmos, L., \& Yu, S. (2014). Contrasting effects of hardwood and softwood organosolv lignins on enzymatic hydrolysis of lignocellulose.Bioresource Technology, $163,320-327$.

Lewin, M., \& Goldstein, I. (1991).Wood structure and composition. New York: Marcel Dekker Inc.

Lim, W., \& Lee, J. (2013). Influence of pretreatment condition on the fermentable sugar production and enzymatic hydrolysis of dilute acid-pretreated mixed softwood. Bioresource Technology, 140, 306-311.

Luo, L., van der Voet, E., \& Huppes, G. (2010).Biorefining of lignocellulosic feedstock - Technical, economic and environmental considerations.Bioresource Technology, 101 (13), 5023-5032.

Lynd, L., Zyl, W., McBride, J., \& Laser, M. (2005).Consolidated bioprocessing of cellulosic biomass: an update.Curr.Opin.Biotechnol., 16 (5), 577-583.

Mackie, K., Brownell, H., West, K. L., \& Saddler, J. (1985).Effect of Sulphur Dioxide and Sulphuric Acid on Steam Explosion of Aspenwood.Journal of Wood Chemistry and Technology, 5 (3), 405425 .

Matsuura, M., Sasaki, J., \& Murao, S. (1995). Studies on $\beta$-glucosidases from soybeans that hidrolyze daidzyn and genistin: isolation and characterization of an isozyme. Bioscience, Biotechnology and Biochemistry, 1623-1627.

McDonough T. J..The chemistry of organosolv delignification.TAPPI Solvent Pulping Seminar.November 6-7, 1992, Boston, Massachusetts.

Melin, K., \& Hurme, M. (2011).Lignocellulosic biorefinery economic evaluation.Cellulose Chem. Technol., 45, 443-454. 
Mesa, L., González, E., Cara, C., González, M., Castro, M., \& Mussatto, S. (2011). The effect of organosolv pretratment variables on enzymatic hydrolysis of sugarcane bagasse.Chemical Engineering Journal, (168), 1157-1162.

Miller, G. (1959). Use of Dinitrosalicylic Acid Reagent for Determination of Reducing Sugar.Analytical Chemistry, 31 (3), 426-428.

Ministerio de Energía y Minería. (2017). Recuperado el 04 de 11 de 2017, de https://glp.se.gob.ar/biocombustible/reporte_precios_bioetanol.php

Ministerio de Modernización. (2017). Recuperado el 10 de 10 de 2017, de http://datos.gob.ar/dataset/inventario-nacional-plantaciones-forestales-por-superficie

Mohammad, J., \& Keikhsro, K. (2011). Fermentation inhibitors in ethanol processes and different strategies to reduce their effects. En Biofuels: Alternative feedstocks and conversion Processes (págs. 287-311). Elsevier Inc.

Molina, C. (06 de 02 de 2017). Energía estratégica. Recuperado el 05 de 04 de 2018, de http://www.energiaestrategica.com/bioetanol-desafio-continuar-creciendo/

Morales, M., Pielhop, T., Saliba, P., Hungerbühler, K., Rudolf von Rohr, P., \& Papadokonst, S. (2017).Sustainability assessment of glucose production technologies from highly recalcitrant softwood including scavengers.Biofuels, Bioprod. Biorefining, 11 (3), 441-453.

Muktham, R., Bhargava, S., Bankupalli, S., \& Ball, A. (2016).A Review on 1st and 2nd Generation Bioethanol Production-Recent Progress.J. Sustain. Bioenergy Syst., 6 (3), 72-92.

Naik, S., Goud, V., Rout, P., \& Dalai, A. (2010). Production of first and second generation biofuels: A comprehensive review. Renew. Sustain. Energy Rev., 14 (2), 578-597.

NREL. (2009). Obtenido de http://www.nrel.gov/biomass/biorefinery.html

Pan, X., Arato, C., Gilkes, N., Gregg, D., Mabee, W., Pye, K., y otros. (2005). Biorefining of softwoods using ethanol organosolv pulping: preliminary evaluation of process streams for manufacture of fuel-grade ethanol and co-products. Biotechnol.Bioeng., 90 (4), 473-481.

Pan, X., Zhang, X., Gregg, D., \& Saddler, J. (2004). Enhanced Enzymatic Hydrolysis of SteamExploded Douglas Fir Wood by Alkali-Oxygen Post-treatment. Applied Biochemistry and Biotechnology, 113-116.

Park, N., Kim, H., Koo, B., Yeo, H., \& Choi, I. (2010).Organosolv pretreatment with various catalysts for enhancing enzymatic hydrolysis of pitch pine (Pinus rigida).Bioresource Technology, $101,7046-7053$.

Park, S., Baker, J., Himmel, M., Parilla, P., \& Johnson, D. (2010). Cellulose crystallinity index: measurement techniques and their impact on interpreting cellulase performance. Biotechnology for biofuels, 3 (10), 2-10. 
Park, S., Venditti, R. A., Jameel, H., \& Pawlak, J. J. (2006). Changes in pore size distribution during the drying of cellulose fibers as measured by differential scanning calorimetry. Carbohydrate Polymers, 66 (1), 97-103.

Pielhop, T.; Larrazábal, G. O.; Studer, M. H.; Brehauer, S.; Seidel, C. - M.; Rudolf Von Rohr, P. (2015).Lignin repolimerization in spruce autohydrolysis pretreatment increases cellulose deactivation.Green Chem. 17, 3521-3532.

Przybysz Buzała, K., Kalinowska, H., Małachowska, E., \& Przybysz, P. (2017). The utility of selected kraft hardwood and softwood pulps for fuel ethanol production. Industrial Crops \& Products, 108, 824-830.

Ramos, L., Breuil, C., \& Saddler, J. (1992). Comparison of Steam Pretreatment of Eucalyptus, Aspen, and Spruce Wood Chips and Their Enzymatic Hydrolysis. Applied Biochemistry and Biotechnology, 34 (35), 37-48.

Rosa María Gorzycki, M. R. (2014). Informes de cadenas de valor. Forestal, papel y muebles. Buenos Aires.

Reguant, J., Martínez, J. M., Montané, D., Salvadó, J., \& Farriol, X. (1997). Cellulose from softwood via prehydrolysis and Soda-Anthraquinone pulping, J. Wood Chem Technol, 17 (1-2), 91-110.

Salmén, L., \& Olsson, A. (1998). Interaction Between Hemicelluloses, Lignin and Cellulose: Structure-Property Relationships. Journal of Pulp and Paper Science, 24 (3), 99-102.

Sannigrahi, P., Miller, S., \& Ragauskas, A. (2010). Effects of organosolv pretreatment and enzymatic hydrolysis on cellulose structure and crystallinity in Loblolly pine. Carbohydrate Research, 345, 965-970.

Sarkanen, K. (1971). Lignins: Ocurrence, Formation, Structure and Reactions. John Wiley \& Sons.

Selig, M., Weiss, N., \& Ji, Y. (2008).Enzymatic Saccharification of lignocellulosic biomass.Laboratory Analytical Procedure (LAP). Colorado.

Singha, J., Suhag, M., \& Dhaka, A. (2015). Augmented digestion of lignocellulose by steam explosion, acid and alkaline pretreatment methods: A review. Carbohydrate Polymers, 117, 624-631.

Sjöström, E. (1981). Wood Chemistry: Fundamentals and aplication. New York: Academic Press, INC.

Soccol, C., Faraco, V., Karp, S., Vanderberghe, L., Thomaz-Soccol, V., Woiciechowski, A., y otros. (2011). Lignocelulosic bioethanol: current status and future perspectives. En Biofuels: alternative feedstocks and conversion processes. 101-122: Elsevier Inc.

Sohrab, H., Amir, H., Meisam, T., Gholamreza, S., Gholam, H., Mehdi, G., y otros.(2013). Linocellulosic biomass to bioethanol, a comprehensive review with a focus on pretreatment. Renazable and Sustainable Energy, 27, 77-93. 
Stoffel, R. B. (2016). Tesis de doctorado. Fraccionamiento de aserrín de pino destinado a una biorefinería forestal. La Plata.

Stoffel, R., Felissia, F., Silva Curvelo, A., Gassa, L., \& Area, M. (2014). Optimization of sequential alkaline-acid fractionation of pine.Industrial Crops and Products, 61, 160-168.

Stoffel, R., Vinholi Neves, P., Felissia, F., Ramos, L., Gassa, L., \& Area, M. (2017). Hemicellulose extraction from slash pine sawdust by steam explosion with sulfuric acid.Biomass and Bioenergy, 107, 93-101.

Stone, J. E., Scallan, A. M., Donefer, E., Ahlgren E. (1969). Digestibility as a simple function of a molecule of similar size to a cellulase enzyme. In Cellulases and Their Applications; Hajny, G., et al.; (págs. 219-241), Advances in Chemistry; American Chemical Society: Washington, DC.

Sun, Y., \& Cheng, J. (2002). Hydrolysis of lignocellulosic materials for ethanol production: a review. Bioresource Technology, 83, 1-11.

Tian, X., Rehmann, L., Xu, C., \& Fang, Z. (2016).Pretreatment of eastern white pine (Pinus strobes L.) for enzymatic hydrolysis and ethanol production by organic electrolyte solutions. ACS Sustainable Chem. Eng., 4 (5), 2822-2829.

Uasuf, A., \& Hilbert, J. (2012). El uso de la biomasa de la biomasa de origen forestal con destino a bioenería en la Argentina. Buenos Aires: Ediciones INTA. Publicaciones periódicas.

UserCom 2/2000. (2016). Recuperado el 11 de 5 de 2016, de https://www.mt.com/dam/nonindexed/po/ana/ta-usercom/51710054_UserCom12_TA_e.pdf

Valenzuela, R., Priebe, X., Troncoso, E., Ortega, I., Parra, C., \& Freer, J. (2016).Fiber modifications by organosolv catalyzed with $\mathrm{H} 2 \mathrm{SO} 4$ improves the SSF of Pinus radiata. Industrial Crops and Products, 86, 79-86.

Vallejos, M. E. (2012). Capítulo 2: productos de la biorrefinería. En M. C. Area, \& M. E. Vallejos, Biorrefinería a partir de residuos lignocelulósicos (págs. 21-108). Saarbrucken: Académica Española.

Vallejos, M., Kruyeniski, J., \& Area, M. (2017). Second-generation bioethanol from industrial wood waste of Shouth American species.Biofuel Research Journal (15), 654-677.

Van Eijck, J., Batidzirai, B., \& Faaij, A. (2014). Current and future economic performance of first and second generation biofuels in developing countries. Appl. Energy, 135, 115-141.

Von Schenck, A., Berglin, N., \& Uusitalo, J. (2013). Ethanol from Nordic wood raw material by simplified alkaline soda cooking pre-treatment. Applied Energy, 102, 229-240.

Walker, G. (2011). Fuel Alcohol: Current Production and Future Challenges. J. Inst. Brew. , 3-22.

Walker, J. (1993). Primary wood processing. Principles and practice. Londres: Champman \& Hall.

Wang, K., Chen, J., Sun, S., \& Sun, R. (2015). Chapter 6. Steam Explosion. En Pretreatment of biomass (págs. 75-104).Elsevier. 
Weijers, C., Franssen, M., \& Visser, G. (2008).Glycosyltransferase-catalyzed synthesis of bioactive oligosaccharides.Biotechnology Advances, 26 (5), 436-456.

Wingren, A., Galbe, M., \& Zacchi, G. (2008). Techno-economic evaluation of producing ethanol from softwood: Comparison of SSF and SHF and identification of bottlenecks. Biotechnol.Prog., 119 (4), 1109-1117.

Wingren, A., Galbe, M., \& Zacchi, G. (2008). Techno-Economic Evaluation of Producing Ethanol from Softwood: Comparison of SSF and SHF and Identification of Bottlenecks. Biotechnol.Prog., 19 (4), 1109-1117.

Wong, K., Deverell, K., Mackie, K., Clark, T., \& Donaldson, L. (1988). The Relationship Between FiberPorosity and Cellulose Digestibility in Steam - Exploded Pinus radiata. Biotechnology and Bioengineering, 31, 447-456.

Yang, B., Boussaid, A., Mansfield, S., Gregg, D., \& Saddler, J. (2002).Fast and efficient alkaline peroxide treatment to enhace the enymatic digestibility of steam- exploted softwood substrates.Biotechnology and Bioengineering, 77 (6), 678-684.

Yang, B., Dai, Z., Ding, S., \& Wyman, C. (2011).Enzymatic hydrolysis of cellulosic biomass.Biofuels, 2 (4), 421450.

Yang, H., Xie, Y., Zheng, X., Huang, F., Meng, X., Wu, W., y otros. (2016). Comparative study of lignin characteristics from wheat straw obtained by soda-AQ and kraft pretreatment and effect on the following enzymatic hydrolysis process. Bioresource Technology, 207, 361-369.

Yoshida, M., Liu, Y., Uchida, S., Kawarada, K., Ukagmi, Y., Ichinose, H., y otros. (2008). Effects of Cellulose Crystallinity, Hemicellulose, and Lignin on the Enzymatic Hydrolysis of Miscanthus sinensis to Monosaccharides. Biosci.Biotechnol.Biochem., 72 (3), 805-810.

Yu, Z., Jameel, H., Chang, H., \& Park, S. (2011). The effect of delignification of forest biomass on enzymatic hydrolysis. Bioresource Technology (102), 9083-9089.

Zabed, H., Sahu, J., Suely, A., Boyce, A., \& Faruq, G. (2017). Bioethanol production from renewable sources: Current perspectives and technological progress. Renew. Sustain. Energy Rev., $71,475-501$.

Zhu, J., \& Pan, X. (2010). Woody biomass pretreatment for cellulosic ethanol production: Technology and energy consumption evaluation. Bioresourse Technology, 101 (13), 4992-5002.

Zhu, J., Pan, X., \& Zalesny, R. (2010).Pretreatment of woody biomass for biofuel production: energy efficiency, technologies, and recalcitrance. Appl. Microbiol. Biotechnol., 101 (13), 847-857.

Zhu, J., Pan, X., Wang, G., \& Gleiser, R. (2009).Sulfite pretreatment (SPORL) for robust enzymatic saccharification of spruce and red pine. Bioresourse Biotechnology, 100 (8), 2411-2018. 


\section{PROYECTOS QUE FINANCIARON LA TESIS}

\section{PROYECTOS INCENTIVADOS UNaM}

- Bio-productos y bio-materiales a partir de la biorrefinería de residuos agro y forestoindustriales. 2015-2017. Código: 16Q582. Res CD 336-15. 21/10/2015. Directora: Dra. María Cristina Area.

- Tecnologías de fraccionamiento y separación - purificación de subproductos en biorrefinerías de residuos agro y forestoindustriales. 2015-2017. Código: 16Q577. Res 0273-15. 02/09/2015. Director: Dr. Fernando E. Felissia. Co-Directora: Dra. María Cristina Area.

- Biorrefinería a partir de residuos de industrialización primaria de la madera. Código: 16Q488. Res CD 107-12 FCEQYN. Prórroga hasta diciembre 2014 Res CD 078-14. Proyecto financiado Convocatoria Especial UNaM Res. Consejo Superior 001/12 (16/02/12). FCEQYN-FCF. Directora: Dra. María Cristina Area.

\section{PROYECTOS FINANCIADOS}

- Proyectos de Investigación Plurianuales PIP 2015-2017 CONICET: Tecnologías de fraccionamiento y separación - purificación de subproductos en biorrefinerías de residuos agro y forestoindustriales ( $\left.\mathrm{n}^{\circ} 11220150100592 \mathrm{CO}\right)$. Res.111. 20/01/2016. Monto: \$150.000.Directora: Dra. María Cristina Area.

- PICTO-UNaM 2011-0083. "Biorrefinería a partir de residuos de industrialización primaria de la madera". Agencia Nacional de Promoción Científica y Tecnológica. Ministerio de Ciencia, Tecnología e Innovación Productiva. Res.317-12. Monto: \$180.000.- Directora: Dra. María Cristina Area. 
- Proyectos de Investigación Plurianuales PIP 2012 - 2014 CONICET (n¹12 20110100107 ). "Biorrefinería a partir de residuos de industrialización primaria de la madera". Res.1675. 6 de Junio 2012. Monto: \$90.000.- Directora: Dra. María Cristina Area.

- Proyectos especiales de la UNaM 2011: "Biorrefinería a partir de residuos de industrialización primaria de la madera" Febrero 2012. Otorgado por la UNaM. Res. CS 001/12 (16/02/12). Monto: \$ 40.000.- Directora: Dra. María Cristina Area. 


\section{PUBLICACIONES DERIVADAS DE ESTE TRABAJO DE TESIS}

1. Vallejos, M.E., Kruyeniski, J., Area, M.C., 2017. Second-generation bioethanol from industrial wood waste of South American species. Biofuel Research Journal, 4, (3), 654-667. E-ISSN: 2292-8782. DOI: $10.18331 / \mathrm{BRJ} 2017.4 .3 .4$

2. Kruyeniski, J., Felissia, F.E.; Area; M.C., 2017, Pretreatment soda-ethanol of pine and its influence on enzymatic hydrolysis. Revista de Ciencia y Tecnología, año 19, N²8, 37-41.

3. Kruyeniski, J., Ferreira, P., Carvalho, M.G.V.S., Vallejos, M.E., Felissia, F.E., Area, M.C., Influence of the physical and chemical characteristics of pretreated pine sawdust on its enzymatic hydrolysis. Enviado a Biomass and Bioenergy, abril 2018. En evaluación.

\section{Trabajos en congresos y jornadas}

1. Julia Kruyeniski, Paulo Ferreira, M. Graça V.S. Carvalho, Fernando E. Felissia, María C. Area "Physical and chemical characteristics of pretreated pine sawdust and its enzymatic hydrolysis" IX Iberoamerican Conference on Pulp and Paper Research, Espoo-Helsinki, Finlandia, 5-8 de septiembre de 2016. (presentación oral).

2. Julia Kruyeniski, Fernando E. Felissia, Camila M. Imlauer, María C. Area "Enzymatic hydrolysis of pine pretreated with ethanol and sodium hydroxide" 3er Congreso Iberoamericano sobre Biorrefinerías (CIAB), 4to Congreso Latinoamericano sobre Biorrefinerías y 2do Simposio Internacional sobre Materiales Lignocelulósicos, Concepción, Chile, 23-25 noviembre 2015 (resumen impreso, presentación en poster).

3. Julia Kruyeniski, Fernando E. Felissia, Romina B. Stoffel, Camila M. Imlauer, María C. Area “Influencia del pretratamiento sobre la hidrólisis enzimática de aserrín de pino" Congreso Iberomericano de Investigación en Celulosa y Papel (CIADICYP), Medellín, Colombia, 2628 noviembre 2014 (trabajo completo en CD, presentación en poster). Editorial Universidad Pontificia Bolivariana. ISBN: 9789587642117. 
4. Camila M. Imlauer, Julia Kruyeniski, Maria C. Area and Fernando E. Felissia, "Fraccionamiento a la soda-AQ de aserrín de pino para la biorrefinería forestal". VIII Congreso Iberoamericano de Investigación en Celulosa y Papel, CIADICYP 2014. Medellín, Colombia, 26 al 28 de noviembre de 2014 (trabajo completo en CD, presentación en poster). Editorial Universidad Pontificia Bolivariana. ISBN: 9789587642117.

5. Romina B. Stoffel, Julia Kruyeniski, Fernando E. Felissia, Luiz Pereira Ramos, Liliana M. Gassa, María C. Area. "Estrategia de fraccionamiento de aserrín de pino mediante explosión de vapor". Congreso Iberomericano de Investigación en Celulosa y Papel (CIADICYP), Medellín, Colombia, 26-28 noviembre 2014 (trabajo completo en CD, presentación oral). Editorial Universidad Pontificia Bolivariana. ISBN: 9789587642117.

6. Kruyeniski J., Felissia F. E., Stoffel R. B., Area M.C., "Influencia del pretratamiento de aserrín de pino sobre la producción de bioetanol" Jornadas Científico Tecnológicas 40 aniversario UNaM. ISBN: 978-950-579-270-2. Facultad de Ciencias Exactas Químicas y Naturales, Universidad Nacional de Misiones, Posadas, 15-17 mayo 2013 (resumen extendido, presentación en poster). 